\title{
The influence of aspect ratios and wall heating conditions on flow and passive pollutant exposure in 2D typical street canyons
}

Article

Accepted Version

Creative Commons: Attribution-Noncommercial-No Derivative Works 4.0

Hang, J., Chen, X., Chen, G., Chen, T., Lin, Y., Luo, Z., Zhang, $X$. and Wang, $Q$. (2020) The influence of aspect ratios and wall heating conditions on flow and passive pollutant exposure in 2D typical street canyons. Building and Environment, 168. 106536. ISSN 0360-1323 doi:

https://doi.org/10.1016/j.buildenv.2019.106536 Available at https://centaur.reading.ac.uk/87289/

It is advisable to refer to the publisher's version if you intend to cite from the work. See Guidance on citing.

To link to this article DOI: http://dx.doi.org/10.1016/j.buildenv.2019.106536

Publisher: Elsevier

All outputs in CentAUR are protected by Intellectual Property Rights law, including copyright law. Copyright and IPR is retained by the creators or other copyright holders. Terms and conditions for use of this material are defined in the End User Agreement. 


\section{www.reading.ac.uk/centaur}

\section{CentAUR}

Central Archive at the University of Reading

Reading's research outputs online 


\section{Journal Pre-proof}

The influence of aspect ratios and wall heating conditions on flow and passive pollutant exposure in 2D typical street canyons

Jian Hang, Xieyuan Chen, Guanwen Chen, Taihan Chen, Yuanyuan Lin, Zhiwen Luo, Xuelin Zhang, Qun Wang

PII:

S0360-1323(19)30748-6

DOI: https://doi.org/10.1016/j.buildenv.2019.106536

Reference: BAE 106536

To appear in: Building and Environment

Received Date: 9 August 2019

Revised Date: 2 November 2019

Accepted Date: 5 November 2019

Please cite this article as: Hang J, Chen X, Chen G, Chen T, Lin Y, Luo Z, Zhang X, Wang Q, The influence of aspect ratios and wall heating conditions on flow and passive pollutant exposure in 2D typical street canyons, Building and Environment, https://doi.org/10.1016/j.buildenv.2019.106536.

This is a PDF file of an article that has undergone enhancements after acceptance, such as the addition of a cover page and metadata, and formatting for readability, but it is not yet the definitive version of record. This version will undergo additional copyediting, typesetting and review before it is published in its final form, but we are providing this version to give early visibility of the article. Please note that, during the production process, errors may be discovered which could affect the content, and all legal disclaimers that apply to the journal pertain.

(c) 2019 Elsevier Ltd. All rights reserved. 
1 To be resubmitted to Building and Environment 2019

2 The influence of aspect ratios and wall heating conditions on flow

3 and passive pollutant exposure in 2D typical street canyons

4

5 Jian Hang ${ }^{\mathrm{a}}$, Xieyuan Chen ${ }^{\mathrm{a}}$, Guanwen Chen ${ }^{\mathrm{a}}$, Taihan Chen ${ }^{\mathrm{a}}$, Yuanyuan Lin ${ }^{\mathrm{a}}$, Zhiwen Luo ${ }^{\mathrm{b}}$,

6 Xuelin Zhang ${ }^{\mathrm{c}^{*}}$, Qun Wang ${ }^{\mathrm{d}^{*}}$

7

$8{ }^{a}$ School of Atmospheric Sciences and Guangdong Province Key Laboratory for Climate

9 Change and Natural Disaster Studies, Sun Yat-sen University, Guangzhou, P.R. China.

$10{ }^{\mathrm{b}}$ School of the Built Environment, University of Reading, UK.

$11{ }^{c}$ Department of Civil and Environmental Engineering, The Hong Kong University of Science

12 and Technology, Clear Water Bay, Kowloon, Hong Kong.

$13{ }^{\mathrm{d}}$ Department of Mechanical Engineering, the University of Hong Kong, Pok Fu lam Road,

14 Hong Kong

15

16

17

18 Corresponding author: Xuelin Zhang, Qun Wang

19 Email: xuelin.zhang@connect.ust.hk; wangqun_sysu@163.com 
Abstract

Deep street canyons and unfavourable meteorological conditions usually induce high pollutant exposure. Validated by experimental data, this paper employs computational fluid dynamic simulations with $\mathrm{RNG} k-\varepsilon$ model to investigate the flow, and passive pollutant dispersion within scale-model two-dimensional street canyons $(H=3 \mathrm{~m})$. As a novelty, this paper quantifies the impacts of various wall heating scenarios(bottom, leeward/windward wall and all-wall heating), ambient velocity $\left(U_{r e f}=0.5-2 \mathrm{~m} / \mathrm{s}\right.$, Froude numbers $F r=0.25-4.08$, Reynolds numbers $R e=95602-382409$ ) and aspect ratios(building height/street width, $A R=0.5$, $0.67,1,2,3)$ on personal intake fraction for entire streets $\left(\left\langle P_{-} I F\right\rangle\right)$. The governing equations are implicitly discretized by a finite volume method (FVM) and the second-order upwind scheme with Boussinesq model for quantifying buoyancy effects. The SIMPLE scheme is adopted for the pressure and velocity coupling.

In most isothermal cases, one-main-vortex structure exists as $A R=0.5-3\left(\left\langle P \_I F\right\rangle=0.43\right.$ $3.96 \mathrm{ppm}$ and $1.66-27.51 \mathrm{ppm}$ with $U_{r e f}=2$ and $0.5 \mathrm{~m} / \mathrm{s}$ ). For non-isothermal cases with $F r=4.08\left(U_{r e f}=2 \mathrm{~m} / \mathrm{s}\right)$, wind-driven force dominates urban airflow as $A R=0.5-1$ and four heating conditions attain similar $\left\langle P \_I F\right\rangle(0.39-0.43 \mathrm{ppm}, 0.57-0.60 \mathrm{ppm}, 0.91-0.98 \mathrm{ppm})$. As $A R=2$, windward and all-wall heating get two-vortex structures with greater $\left\langle P \_I F\right\rangle(3.18$ $3.33 \mathrm{ppm})$ than others $\left(\left\langle P \_I F\right\rangle=2.13-2.21 \mathrm{ppm}\right)$. As $A R=3$, leeward-wall heating slightly reduces $\left\langle P \_I F\right\rangle(\sim 3.72-3.96 \mathrm{ppm})$, but the other three produce two-vortex structures with greater $\left\langle P \_I F>(6.13-10.32 \mathrm{ppm})\right.$. As $F r=0.25\left(U_{\text {ref }}=0.5 \mathrm{~m} / \mathrm{s}\right)$, leeward-wall heating always attains smaller $\left\langle P \_I F>(1.20-7.10 \mathrm{ppm})\right.$ than isothermal cases(1.66-27.51ppm) as $A R=0.5-3$, however the influence of the other three is complicated which sometimes raises or reduces $\left\langle P \_I F\right\rangle$. Overall, smaller background wind speed $(F r=0.25)$ with two-vortex structures attains much larger $\left\langle P_{-} I F\right\rangle$. Special attention is required at night(all-wall heating), 
noon(bottom-heating) and cloudy period(no-wall heating) as $A R=2-3$, while it is during windward-wall heating and cloudy period for $A R=0.5-1$.

Keywords: Street canyon, Aspect ratio $(A R)$, Wall heating, Street intake fraction $\left\langle P \_I F\right\rangle$, Froude number, Computational fluid dynamic (CFD) simulations

\section{Introduction}

With the increase in number of vehicles on the road due to global urbanization, traffic emissions have become one of the major pollutant sources in cities [1, 2]. Critical pollutants emitted from these sources include oxides of nitrogen (NOx), carbon monoxide (CO), ultrafine particles and fine particulate matter $\left(\mathrm{PM}_{2.5}\right)$ with an aerodynamic diameter of less than $2.5 \mu \mathrm{m}$ and volatile organic compounds (VOCs). Heavy traffic flow, deep street canyons and unfavourable meteorological conditions are the main factors that result in poor ventilation capacity, a high pollutant exposure for urban residents and the related adverse impacts on human health $[3,4]$. Traffic-related pollutant exposure is determined by three factors: the emission rate of pollutants, as determined by traffic density and types; the pollutant dilution capacity, which is correlated with street layouts and meteorological conditions, and the distance between people and pollutant sources. Vehicular pollutant exposure for residents living in near-road buildings merits special attention because their proximity to emission sources puts them at higher health risk than those living inother urban micro-environments. In addition to reducing vehicular pollutant emissions, improving urban ventilation capacity through sustainable street design is another effective technique to reduce

67 such traffic-related pollutant exposure in cities [5-9]. 
In the past three decades, the relation of street layout and atmospheric conditions to turbulent flow and pollutant dispersion has been widely investigated and modeled using field and wind tunnel experiments and computational fluid dynamic (CFD) simulations [10-20].

Street aspect ratios (building height/street width, $A R$ or $H / W$ ) [8, 10-12, 21-23], building packing densities and urban porosity (e.g., [24-27]) are the most significant factors influencing urban airflow and traffic-related pollutant dispersion. Other reportedly key parameters are ambient wind directions [33-34], uneven street layouts and building height variability [30-32], street vegetation [33] and lift-up building designs [e.g., 34-35]. The thermal dynamics of street canyons related to solar shading and the thermal storage of buildings also affect the flow of pollutants through the urban environment. Field measurement have shown that air-wall temperature differences can reach $12-14^{\circ} \mathrm{C}$ or more [50-53]. Models of three-dimensional (3D) urban-like environments [37-40] and twodimensional (2D) street canyons [40-47] have shown that if the Richardson number $(R i)$ is large or the Froude number $(F r)$ is small, thermal stratification and buoyancy force, or thermal forcing, can influence or dominate the flow regime and pollutant dispersion . In the 2D street canyon models in most of the aforementioned studies, various uniformly heated walls are considered with arbitrary air-wall temperature differences corresponding to solar angle or building heat release within a day [40-47], i.e., no-wall heating (periods of strong wind or cloudy days with small temperature differences), leeward-wall heating, windwardwall heating, ground or bottom heating (at noon on a sunny day), and all-wall heating (i.e., at nighttime with the urban heat island heating all wall surfaces).

In 2D street canyon models, four isothermal flow regimes have been reported [8-12, 2023, 41-54], those being the isolated roughness flow regime (IRF, $A R$ or $H / W<0.3$ ), the wake interference flow regime (WIF, $0.3<A R<0.67$ ), the skimming flow regime with single main 
93 literature is generally consistent with regard to the first three flow regimes but differs on the

94 fourth multi-vortex flow in deep street canyons, in which the flow and vehicular pollutant dispersion capacity are usually weak. For instance, Xie et al. [52] and Li et al. [23] reported two contra-rotative vortexes where $A R=2$, and three to five vertically aligned vortexes where $A R=3-5$ for wind-tunnel-scale $2 \mathrm{D}$ street canyons with a building height of $H=0.6 \mathrm{~m}$ and the reference Reynolds number $(R e)$ of 12000 . Other research has contradicted these findings. Zhang et al. [53] found a single-main-vortex structure in a full-scale street canyon where $A R=2.7$ and $R e=5 \times 10^{6}$. Later validated by wind tunnel and scale-model outdoor experimental data, He et al. [54] numerically confirmed a single-main-vortex structure as $A R=1-4$ and two main vortexes as $A R=5-6$ for full-scale $2 \mathrm{D}$ street canyons $(W=24 \mathrm{~m}$, $\operatorname{Re} 10^{6}-10^{7}$ ). That study [54] reported that the reason for this difference was that $R e$ must be much greater than 11000 to ensure Reynolds number independence in urban airflow [55], and that full-scale models usually satisfy this requirement [53-54] but wind-tunnel-scale models sometimes cannot (e.g. [22-23, 49-52]. Recently, Chew et al. [56] further confirmed this issue by conducting water channel experiments with $R e \sim 10^{4}-10^{5}$ at three aspect ratios $(A R=1,1.5$ and 2) and pointed out that the widely adopted $R e=11,000$ is not applicable for the $\mathrm{Re}$ independence of street canyons with an aspect ratio greater than 1.5.

110 In recent years, experimental and numerical studies of wind-tunnel-scale models $111\left(H \sim 0.1 \mathrm{~m}, R e \sim 10^{4}\right)$ [48-52], scaled models $\left(H \sim 1 \mathrm{~m}, R e \sim 10^{5}\right)$ [44-47] and full-scale models $112\left(H \sim 10 \mathrm{~m}-100 \mathrm{~m}, \operatorname{Re} \sim 10^{6} \sim 10^{7}\right)[41-43]$ have been performed to investigate the relative flow and

113 temperature distribution and pollutant dispersion in 2D street canyons by coupling dynamic 114 and thermal effects. Chew et al. [57] reported differing findings between wind-tunnel-scale 115 experiments and full-scale field measurements with heated windward walls, even with similar $116 F r$ or $R i$ numbers. Such contradictory buoyancy effects are present mainly because wind117 tunnel-scale experiments with heated windward walls do not satisfy the the requirement of 
118 Reynolds number independence [56]. Wind-tunnel-scale results for canyon flows with

119 thermally induced buoyancy should not be assumed to represent full-scale street canyons,

120 unless the flow is verified to be independent of both Reynolds number and a similar Grashof

121 number (or $R i$ and $F r$ ). In particular, for wind-tunnel-scale models, it is relatively difficult to

122 measure or simulate non-isothermal urban airflow with significant thermal effects because it

123 is a challenge to simultaneously attain a sufficiently large Reynolds number and relatively

124 small $\mathrm{Fr}$ (or large $\mathrm{Ri}$ ) because this usually requires a large temperature difference $\left(\sim 100^{\circ} \mathrm{C}\right)$

125 [48-50]. Thus, full-scale models $\left(H \sim 10 \mathrm{~m}-100 \mathrm{~m}, \operatorname{Re} \sim 10^{6} \sim 10^{7}\right)$ [38-43] and scaled models

$126\left(H \sim 1 \mathrm{~m}, \operatorname{Re} 10^{5}\right)[44-47]$ are proposed to study urban airflow coupling dynamic and thermal

127 effects. A scale-model CFD simulation $\left(H \sim 1 \mathrm{~m}, R e \sim 10^{5}\right)$ was selected in this study,

128 considering that scaled models [44-47] make it easier to satisfy the $R e$ independence

129 requirement and get similar $F r$ (or $R i$ ) as full-scale models [38-43], and CFD simulations of

130 full-scale 2D or 3D streets with heated walls usually require enormous computational

131 resources because fine grids are required to solve the viscous sub-layer and heat transfer near

132 wall surfaces [38-40].

133 Considering the differing findings in the literature, further investigations are still 134 necessary to verify the non-isothermal flow mechanisms in high-rise deep street canyons 135 (AR>1.5) with a sufficiently large Reynolds number and various Froude (or Richardson) 136 numbers. In addition, most previous studies only investigated the flow and spatial distribution 137 of temperature and pollutant concentration. Few researchers have estimated the impact of 138 street layouts and wall heating conditions on personal exposure to air pollutants within micro139 scale street canyons. For instance, Memon et al. [44] studied the impact of street aspect ratios $140(A R=0.5-8)$, four wall-heating conditions and ambient wind speeds $\left(0.5-4 \mathrm{~m} \mathrm{~s}^{-1}\right)$ on air

141 temperature in 2D scale-model street canyons $(H \sim 0.5 \mathrm{~m}-8 \mathrm{~m})$ with $R e \sim 16000-270000$ and a 142 bulk Richardson number (Ri 0.01-17.1). Tong and Leung [43] later modeled the reactive 
143 pollutant dispersion within full-scale urban street canyons $(A R=0.5-8, H=20-80 \mathrm{~m})$ with

144 various wall heating and ambient wind conditions. Yet few studies have considered the

145 impacts of these factors on the detailed flow structure and the related pollutant exposure on

146 street level.

147 Finally, vehicular intake fraction $(I F)$ in urban areas was used to represent the fraction of

148 total pollutant emissions by vehicles that is inhaled by a population [58-60]. An IF of 1 ppm

149 (one per million or $10^{-6}$ ) indicates $1 \mathrm{~g}$ of air pollutants is inhaled by an exposed population for every one ton of pollutants emitted by the vehicles in that city and its street canyons. Personal intake fraction $\left(P_{-} I F\right)$, which is independent of population size and density, has also been adopted by the literature [8-9, 61-63] to compare the fraction of pollutants inhaled by each person in a population on average to the total emitted vehicular pollutants in nearby streets or neighborhoods. So far these investigations on pollutant exposure emphasize $2 \mathrm{D}$ or $3 \mathrm{D}$ idealized urban models under neutral atmospheric conditions [8-9, 58-60, 61-63].

This paper couples the personal intake fraction $\left(P_{-} I F\right)$ with CFD simulations to quantify the impacts of street aspect ratios $(A R=H / W=0.5-0.67$ (avenue canyon), 1 (regular canyon), 2-3 (deep canyon) [10]) and four kinds of wall heating conditions (at leeward, windward, ground and all walls) on the detailed flow structure, $\mathrm{CO}$ dispersion and personal exposure in 2D scale-model street canyons. As a novelty, the interaction of wind-driven airflow and buoyancy force with a sufficiently large Reynolds number and various Froude numbers and the detailed flow structure and related street-scale $\mathrm{CO}$ exposure are emphasized, as this interaction is still unclear and requires further investigation.

The structure of the remainder of this paper is as follows: Section 2 describes the concept of the personal intake fraction. Section 3 depicts the cases investigated and the 
167 Section 5. The Appendix presents CFD model validation using wind tunnel data [22, 49] as

168 well as the scale-model outdoor field measurement in Zhang et al. [9].

\section{Population intake fraction $(I F)$ and Personal intake fraction $\left(P \_I F\right)$}

Intake fraction $(I F)$ has been extensively applied to evaluate the population exposure to

vehicular emissions in streets or cities, some examples being the $\sim 270 \mathrm{ppm}$ value derived for

173 the high-rise compact city of Hong Kong [58], the street-scale vehicular IF of $371 \mathrm{ppm}$ in a street $(A R=H / W=1.5)$ in central Athens in Greece [59] and the overall $I F$ of $3000 \mathrm{ppm}$ for a typical street canyon in midtown Manhattan, New York [60]. For idealized 2D street canyon models, Hang et al. [8] reported vehicular CO IFs of 230-913 ppm where $A R=1-0.5$. Later, He et al. [54] further clarified that $I F$ could reach $\sim 10^{5} \mathrm{ppm}$ in extremely deep $2 \mathrm{D}$ street canyons with two main vortexes $(H / W=5-6)$. It is therefore apparent that vehicular intake fraction for a population $(I F)$ is independent of the pollutant emission rate and depends on several factors, such as the street layout, meteorological conditions, distance to pollutant sources and local population size and density. the average pollutant exposure for each person in a population, which is independent of population size and density and can emphasize the influence of urban morphology and atmospheric conditions. Similarly, the spatial mean values of a building or entire street were named as building intake fraction or street intake fraction, respectively $\left(\left\langle P \_I F\right\rangle\right)[61-63]$.

187 One study numerically estimated the $\left\langle P \_I F\right\rangle$ in $2 \mathrm{D}$ street canyons as $\sim 1-5$ ppm when $A R=0.5-1$ [8] and $\sim 100-1000 \mathrm{ppm}$ when $A R=5-6[9,54]$. Other studies [61-63] further evaluated $\left\langle P \_I F\right\rangle$ in 3D urban district models $(A R=0.5-1, \sim 0.1 \mathrm{ppm})$ to be one-order smaller than that in 2D street canyons with similar aspect ratios $(\sim 1 \mathrm{ppm})$. 
The intake fraction $(I F)$ for the emission of a specific pollutant is defined as:

193 where $N$ is the number of population groups and $M$ is the number of different

194 microenvironments considered, $P_{i}$ is the total number of people exposed in the $i^{\text {th }}$ population 195 group; $\Delta t_{i j}$ (s) is the time spent in the microenvironment $j$ for population group of $i$; $B r_{i, j}$ is 196 the average volumetric breathing rate for individuals in the $i^{\text {th }}$ population group $\left(\mathrm{m}^{3} / \mathrm{s}\right)$ in the 197 microenvironment $j$; $C e_{j}$ is the pollutant concentration attributed to urban traffic emissions in microenvironment $j\left(\mathrm{~kg} / \mathrm{m}^{3}\right)$; and $q$ is the total vehicular emission rate over the period $(\mathrm{kg})$. elderly, which means that $N=3$ in this study. As depicted in Fig. 1 [64-65], the time-activity patterns were divided into four micro-environmental types $(M=4)$ for the three age groups, including indoors at home $(j=1)$, other indoor locations $(j=2)$, in or near vehicles $(j=3)$, and other outdoor locations away from vehicles $(j=4)$. It was assumed that the near-road buildings were naturally ventilated residential buildings, and two microenvironments $j=1$ (indoor at home) and $j=3$ (in or near a vehicle, i.e., pedestrian level) were considered. The values for the breathing rates from previous studies [64-65] were adopted for the current study. Furthermore, As the indoor/outdoor $(\mathrm{I} / \mathrm{O})$ ratio in naturally ventilated buildings is close to one [3-4, 66-67], it is reasonable to use the pollutant concentration, originating from vehicle emissions, at building wall surfaces as the indoor concentration in naturally ventilated buildings. 
$213 \quad P_{-} I F=I F / \sum_{j}^{M} P_{i}$

214 where $I F$ is the total population intake fraction, and $P_{i}$ is the total number of people exposed

215 in the $i^{\text {th }}$ population group.

The spatial mean $P_{-} I F$ for an entire street is defined as the street intake fraction $\left\langle P \_I F\right\rangle$

217 to evaluate the average $P_{-} I F$ for a population on the entire street.

218

219

\section{Methodology}

Ansys Fluent [68] with the Renormalization Group (RNG) $k-\varepsilon$ model [69] was adopted to perform CFD simulations and numerically investigate the effects of typical aspect $\operatorname{ratios}(A R=0.5-3)$ and thermal buoyancy force induced by various types of wall heating on turbulent structures, passive pollutant dispersion and its exposure in two-dimensional (2D) street canyons.

\subsection{Consideration of 2D street geometry and selection of turbulence model}

This study first considers idealized 2D street canyons with a simplified urban geometry where the street is infinitely long (e.g., street length $L>8 H$ ) and surrounded by buildings, with a wind approaching perpendicular to the street axis [10-12, 20-22]. Modelling urban street canyons in 2D may simplify the 3D recirculation flows that lead to the removal of pollutants and mass-momentum exchange through the lateral boundaries of 3D streets (Madalozzo et al., [70]). 2D streets usually experience worse ventilation and higher pollutant concentrations than 3D cases with similar aspect ratios and atmospheric conditions. For instance, studies

234 have reported a street intake fraction of $1-5 \mathrm{ppm}$ in $2 \mathrm{D}$ street canyons where $A R=1$ whereas the intake in 3D cubic building arrays was in the in order of $0.1 \mathrm{ppm}$. Despite corresponding 
with the worst urban ventilation performance, 2D street canyon models are still commonly employed to study and clarify the basic governing mechanisms in urban areas (e.g., [7-11,20existing literature and investigate the influence of various wall heating types and typical aspect ratios on the fine details of flow pattern and pollutant exposure.

Large-eddy simulations (LES) [23, 30, 38-39, 42, 70] are known to outperform

Reynolds-Averaged Navier-Stokes (RANS) models [16, 57, 70-72] in predicting turbulence

of LES include a longer computational time, difficulty in specifying appropriate boundary conditions at wall surfaces and a time-dependent inlet. Despite their limitations, RANS approaches are still widely used [7-9, 14-20, 24-29, 31-35, 43-46, 50-52]. Among the RANS models, the RNG $k-\varepsilon$ model has been one of the most widely adopted and has been successfully validated in predicting flow and dispersion of gaseous pollutants [43-46, 50-52, 57, 73]. Chew et al. [57] reported that, RANS approaches perform well at reduced scales but over-predict the thermal effects of heated windward walls at full scale, while LES predictions agree closely with measurements at both scales. Considering both numerical accuracy and computational time, the RNG $k-\varepsilon$ model was selected to solve the steady-state flow field and pollutant dispersion in scale-model street canyons [43-46, 50-52,57].

\subsection{Model descriptions in the CFD test cases}

Fig. 2a shows the few 2D street canyon models that were built for numerical simulations.

257 The scale ratio of the simulated model to the full-scale model is 1:10. The building height $(H)$

258 of the CFD models is a constant of $3 \mathrm{~m}$ corresponding to the $30 \mathrm{~m}$ height of full-scale buildings (10 floors). The width $(W)$ of the target street canyon is set as $1 \mathrm{~m}, 1.5 \mathrm{~m}, 3 \mathrm{~m}, 4.5$ 
$\mathrm{m}$ or $6 \mathrm{~m}$, which produces various aspect ratios: $A R=3$ and 2 (deep canyon); 1 (regular canyon); 0.67 and 0.5 (avenue canyon), according to Vardoulakis et al. [10]. This selection of the street width is to cover the aspect ratios from 0.5 to 3 , which refer to regular and deep street canyons, respectively. In the upstream and downstream of the target street canyon, there are five identical street canyons to explicitly reproduce roughness elements at both sides [e.g., 51, 54] (Fig. 2a).

In addition to the different aspect ratios, this study also investigated five different wall heating scenarios of the target street canyon: an isothermal case as a controlled base case, bottom heating, leeward wall heating, windward wall heating, and all wall heating. All of these cases have the same temperature difference $(\Delta T=10 \mathrm{~K})$ between air and wall and denote various thermal effects induced by solar radiation and wall heating. The model descriptions of all of the test cases are listed in Table 2. Two mean wind speeds of $0.5 \mathrm{~m} \mathrm{~s}^{-1}$ and $2 \mathrm{~m} \mathrm{~s}^{-1}$ were selected as the reference velocity $\left(U_{r e f}\right)$ at $H$ of the domain inlet boundary condition. The two $U_{\text {ref }}$ values represent wind conditions with different Reynolds numbers, and the case name follows the coding system: Case Heating type $\left[A R, U_{r e f}\right]$. The heating types of $\mathrm{N}, \mathrm{B}, \mathrm{L}, \mathrm{W}$ and $\mathrm{A}$ represent no wall heating, bottom heating, leeward heating, windward heating, and all wall heating. For example, $\mathrm{N}[0.5,0.5]$ refers to the isothermal target street canyon with an aspect ratio of 0.5 under a $0.5 \mathrm{~m} \mathrm{~s}^{-1}$ mean wind speed condition.

The reference Reynolds numbers $\left(R e=\rho U_{r e f} H / \mu, H=3 \mathrm{~m}\right)$ are 95602 at $U_{r e f}=0.5 \mathrm{~m} \mathrm{~s}^{-1}$ and 382409 at $U_{\text {ref }}=2 \mathrm{~m} \mathrm{~s}^{-1}$ (Table 3) which are in the order of $10^{5}$ to ensure Reynolds number independence [55-56]. 
$283 \quad F_{r}=\frac{U_{r e f}^{2}}{\beta g H\left(T_{w}-T_{r e f}\right)}=\frac{U_{r e f}^{2}}{g H \Delta T / T_{r e f}}$

284 where $T_{w}$ is the surface temperature of the heated wall, $T_{r e f}=300 \mathrm{~K}$ is the reference air 285 temperature in the free stream and at the domain inlet and $\Delta T=10 \mathrm{~K}$ is a constant for all cases

286 with wall heating. $\beta=1 / T_{\text {ref }}$ is the thermal expansion coefficient and $g$ is the gravitational 287 acceleration. The Froude number ranges from 0.25 to 4.08 (Table 3).

\subsection{CFD setups for flow modelling}

As shown in Fig. 2a, the 2D computational domain was built to be $23 H$ in length and $6 H$ in height. A total number of approximately 0.4 million cells were used. To capture the viscous sub-layer and heat transfer near the wall surfaces, the grid was refined toward the wall surfaces with a minimum grid size of $0.6 \mathrm{~mm}$ (i.e., $2 \times 10^{-4} \mathrm{H}$, see Fig. $2 \mathrm{~b}$ ). This grid arrangement is confirmed to be sufficiently refined by our CFD validation study with grid independence tests in subsection 4.1.

Table 4 summarizes boundary conditions and solver settings for the CFD simulations.

297 At the domain inlet, a power-law velocity profile $\left(U(y)=U_{r e f} \times\left(\frac{y-y_{r e f}}{y_{r e f}}\right)^{\alpha}, U_{r e f}=0.5\right.$ or $\left.2.0 \mathrm{~m} \mathrm{~s}^{-1}, a=0.22\right)$ and the profiles of turbulent kinetic energy and its dissipation rate were used as displayed in Table 3 [45-46]. No-slip wall boundary conditions with enhanced wall functions (EWF) were applied for near-wall treatment. The present grid is sufficiently refined close to the wall surfaces with a minimum grid size equal to $1 \mathrm{~mm}$ (see Fig. $2 \mathrm{~b}$ ) to ensure that the dimensionless wall distance $y^{+}$near walls is in order of 1 and satisfy the requirement of enhanced wall functions [38-40, 42-46]. This solves the viscous sub-layer near wall surfaces and heat transfer within it. Zero normal gradient conditions were used at the domain top (symmetry boundary) and domain outlet (fully developed outflow boundary). 
The Boussinesq model was employed to assess the buoyancy effect [38-46, 49-51], in

which the air density is treated as a constant except in the momentum equation of vertical

velocity. The governing equations for the flow and turbulent quantities were implicitly

discretized by a finite volume method (FVM) with the second-order upwind scheme to

310 guarantee the numerical accuracy. The SIMPLE scheme was used for the pressure and

311 velocity coupling.

The under-relaxation factors for the pressure term, momentum term, turbulent kinetic

simulations do not stop until all of the residuals become constant. Typical residuals at convergence are $1 \times 10^{-6}$ and $1 \times 10^{-7}$ for $U x$ and $U y$, respectively, $1 \times 10^{-7}$ for continuity, $1 \times$ $10^{-6}$ for turbulent kinetic energy $k, 1 \times 10^{-6}$ for dissipation rate $\varepsilon$ and $1 \times 10^{-13}$ for the energy.

\subsection{CFD setups for pollutant dispersion modelling} which is positioned in the middle of the target street canyon at a height of $0.04 \mathrm{~m}$ (Fig. 2a).

Carbon monoxide (CO) was released with a small pollutant emission rate $\left(S_{c}=10^{-7} \mathrm{~kg} / \mathrm{m}^{3} \mathrm{~s}\right)$ to ensure that the source release produced little disturbance to the flow field [25-27,61-63]. The geometry size and the pollutant emission rate were the same in all test cases. The sidewalks on both windward and leeward side represent the pedestrian regions with a height of $0.2 \mathrm{~m}$, corresponding to $2 \mathrm{~m}$ height in full-scale.

$$
\bar{u}_{j} \frac{\partial \bar{c}}{\partial x_{j}}-\frac{\partial}{\partial x_{j}}\left(K_{c} \frac{\partial \bar{c}}{\partial x_{j}}\right)=S_{c}
$$


where, $\bar{c}$ is the pollutant concentration $\left(\mathrm{kg} / \mathrm{m}^{3}\right), K_{c}$ is the turbulent eddy diffusivity of

330 pollutants, the $S_{c}$ is the item of the pollutant source. According to $K_{c}=v_{t} / S c_{t}, v_{t}$ is the

331 kinematic eddy viscosity and $S c_{t}$ is the turbulent Schmidt number, which is treated as a constant of 0.7 [25-27, 31, 61-63] .

In Eq. (4), the zero normal flux condition was used at the wall surfaces, and a zero normal gradient condition was applied at the domain outlet and domain roof. At the domain inlet, the concentration was null.

where $U_{\text {ref }}$ is taken as a constant of $0.5 \mathrm{~m} \mathrm{~s}^{-1}$ or $2.0 \mathrm{~m} \mathrm{~s}^{-1}$ for all test cases, $L$ and $W_{s}$ are the source length and source width and $Q$ is the total mass release rate $(\mathrm{kg} / \mathrm{s})$.

In summary, the personal intake fraction $\left(P_{-} I F\right)$ was analyzed based on the results for pollutant concentration. As described and assumed in Section 2, only one microenvironment (i.e. indoor at home) was considered, and the concentrations along the windward-side wall and leeward-side wall of near-road buildings were emphasized for quantifying the concentration of the microenvironment ("indoor at home") originating from outdoor vehicular pollutant emissions (see Fig. 2a and Table 1).

\section{Results and Discussions}

\subsection{Validation of flow and pollutant dispersion modelling}

For flow modelling in regular street canyons $(A R=H / W=1)$ with wall heating conditions,

350 CFD simulations were validated by the wind tunnel data reported by Allegrini et al. [49]. The details of the validation procedure can be found in our previous research (Lin et al. [45]) and 
352 Appendix A1. To validate the finding of passive pollutant dispersion in the regular and deep

353

354 street canyons ( $A R=1$ and 2), we compared the CFD simulation results with the concentration distribution in the wind tunnel data from Meroney et al. [22]. Further detailed description can be found in $\mathrm{He}$ et al. [54] and Appendix A2. Moreover, scale-model outdoor field experiments $(H=1.2 \mathrm{~m})$ were carried out to confirm that only one main vortex existed in the deep street canyon where $A R=2$ and 3 as the background wind speed was sufficiently high; in other words, where the wind-driven dynamic force is dominant and buoyancy force is relatively weak. Descriptions of the scale-model experiments have been introduced in detail in Zhang et al. [9] and Appendix A2. Finally, in Appendix A4, CFD validation and grid independence study of flow modelling in scaled deep street canyon $(A R=2.4, H=1.2 \mathrm{~m}$, $\left.U_{\text {ref }}=13 \mathrm{~m} \mathrm{~s}^{-1}, W=B=0.5 \mathrm{~m}, R e \sim 10^{6}\right)$ are conducted under the estimation by wind tunnel data $\left(A R=2.4, H=12 \mathrm{~cm}, U_{\text {ref }}=13 \mathrm{~m} \mathrm{~s}^{-1}, W=B=5 \mathrm{~cm}, R e \sim 10^{5}\right)$. The results of the above validation tests indicated that the CFD simulations presented in this study have a satisfactory performance and agree well with the experimental data.

In the following sections, firstly, we discuss the effects of street aspect ratios $(A R=0.5-3)$, wall heating and Froude numbers $\left(U_{r e f}=2\right.$ and $0.5 \mathrm{~m} \mathrm{~s}^{-1}, \triangle T=10 \mathrm{~K}, F r=0.25$ and 4.08) on urban airflow, pollutant distribution and personal exposure (i.e. street intake fraction) within street canyons.

\subsection{Re-number independence evaluation}

The airflow characteristics within the reduced-scale street canyons are different from that within full-scale models if Re-number-independence cannot be satisfied. To verify this issue, we performed additional scaled CFD simulations with various background wind speeds $\left(U_{\text {ref }}=0.5,2\right.$ and $\left.4 \mathrm{~m} \mathrm{~s}^{-1}, H=3 \mathrm{~m}\right)$ and reference Reynolds number $(\operatorname{Re}=95602,382409$, 764818) to verify whether the Reynolds numbers independence is satisfied or not in the isothermal cases where $A R=0.5-3$. Fig. 3a shows that, background wind speed of $0.5 \mathrm{~m} \mathrm{~s}^{-1}$ 
and $2 \mathrm{~m} \mathrm{~s}^{-1}(\operatorname{Re}=95602$ and 382409) are sufficient to ensure Reynolds numbers independence as $A R=0.5,0.67,1$, and 2, however as $A R=3$ (Fig. 3b-c), the flow with $R e=382409\left(U_{\text {ref }}=2 \mathrm{~m}\right.$ $\left.\mathrm{s}^{-1}\right)$ and $764818\left(U_{\text {ref }}=4 \mathrm{~m} \mathrm{~s}^{-1}\right)$ are $R e$-number independent but that with $R e=95602\left(U_{\text {ref }}=0.5\right.$ $\mathrm{m} \mathrm{s}^{-1}$ ) is not. Therefore, in the following sections, the analyses mainly focus on the cases as $U_{\text {ref }}=0.5$ and $2 \mathrm{~m} \mathrm{~s}^{-1}$.

\subsection{Flow and pollutant dispersion as $U_{r e f}=2 \mathrm{~m} \mathrm{~s}^{-1}$ and $F r=4.08$}

All of the CFD simulations reported in this subsection were conducted under the condition of a high wind speed condition $\left(U_{r e f}=2.0 \mathrm{~m} \mathrm{~s}^{-1}\right.$ and $\left.F r=4.08\right)$ with a relatively weak buoyancy force $(F r=4.08)$, which satisfied the Re-number independence.

\subsubsection{In deep street canyons with aspect ratio of $A R=3$ ( $R e$-number independence)}

Fig. 4a shows the distribution of the mean wind speed and normalized pollutant concentration $(K)$ of the deepest street canyon $(A R=3)$ under five different heating scenarios. A single clockwise vortex formed in Cases $\mathrm{N}[3,2]$ (No heating) and $\mathrm{L}[3,2]$ (Leeward wall heating). The flow patterns of the remaining cases formed a multi-vortex structure with a worse pollutant dilution capacity and higher concentrations near the ground (three vortexes for Case W[3, 2], and Case A[3, 2] and two vortexes for Case B[3, 2]). Due to the high $A R$ of the street canyon, the approaching wind has difficulty entering the space inside the canyon, especially at the street level. Therefore, the mean wind speeds at the pedestrian level of the street canyons are relatively small $\left(<0.2 \mathrm{~m} \mathrm{~s}^{-1}\right)$. Fig.4b-4d summarize the wind speed distribution $\left(u_{x}\right.$ and $\left.u_{y}\right)$ at the windward line, leeward line and the line near the bottom. Fig.4e shows the normalized $\mathrm{CO}$ concentration $(K)$ along the windward and leeward wall. vary under different heating scenarios. As shown in Fig. 4a and 4e, the single clockwise vortex in Case $\mathrm{N}[3,2]$ and $\mathrm{L}[3,2]$ results in a higher $K$ at the leeward wall than the windward 
wall. The mean wind speeds $u_{y}$ below $y / H=0.6$ of these two cases are relatively higher, which

402

403

404

405

406

407

408

409

410

411

412

413

414

415

416

417

418

419

420

421

422

423

424

tends to reduce $K$ within the street canyons more effectively (Fig. 4e). Unlike with the single vortex pattern, the formation of multiple vortexes significantly aggravated the air pollutant dispersion near the ground, as presented in Case W[3, 2], B[3, 2] and A[3, 2] (Fig. 4a and 4e). In other words, the vertical buoyancy force even worsens the air pollution near the ground under high wind speed conditions $(F r=4.08)$. For example, the concentration $K$ near the leeward-side ground $(y / H<0.2)$ rapidly increases to 1500 in Case $\mathrm{B}[3,2]$ and 1750 in Case $\mathrm{A}[3,2]$ (Fig. 4e).

\subsubsection{In deep street canyons with aspect ratio of $A R=2$ (Re-number independence)}

Fig. 5 shows the distributions of wind speed and $K$ in the street canyon where $A R=2$. In contrast to the street canyon where $A R=3$, the wind-driven force becomes a more dominant factor in flow pattern formation and pollutant dispersion in the wider canyons where $A R=2$. As shown in Fig. 5a, only one clockwise vortex can be observed in Case N[2, 2], B[2, 2] and $\mathrm{L}[2,2]$ and two vortexes with opposite directions were formed in Case $\mathrm{W}[2,2]$ and $\mathrm{A}[2,2]$. In cases with one main vortex, the leeward-side $K$ is much higher than that near windwardside. Both $u_{x}$ and $u_{y}$ of Case $\mathrm{N}[2,2]$ are slightly smaller than those of Case B[2, 2] and L [2, 2] (Fig.5b-5d). This phenomenon indicates that bottom heating and leeward wall heating can slightly strengthen the turbulent flow and pollutant dilution capacity. In Case $A[2,2]$ and $\mathrm{W}[2,2]$, there is a stronger main vortex at the upper levels and a much weaker one at low levels (Fig. 5a), which produces a higher $K$ value near the windward side (below $y / H=0.5$ ), but a smaller $\mathrm{K}$ value at the upper level. The peak of the $K$ values in the two-vortex cases is much higher (maximum 400) than those of one-vortex cases (maximum 230) (Fig. 5e). Overall, the $K$ values where $A R=2$, varied between 80 to 400 are much lower than that in the deeper street canyons where $A R=3$ (Fig. 4e). 


\subsubsection{In regular street canyons with an aspect ratio of $A R=1$ ( $R e$-number independence)}

427

428

430

431

432

433

434

435

436

437

438

439

440

441

442

443

444

445

446

447

448

449

When the street aspect ratio was further reduced to $A R=1$ with $F r=4.08\left(U_{\text {ref }}=2 \mathrm{~m} \mathrm{~s}^{-1}\right)$, as shown in Fig. 6, only one clockwise vortex was formed in all five cases and the leeward-side $K$ was much higher than for the windward side. The velocity and $K$ profiles were close in all cases with different heating scenarios (Fig. 6c-6e), confirming that the buoyancy force hardly changed the flow and dispersion pattern. The $K$ values were around 35 on the windward side and 90 on the leeward side (Fig. 6f), which are much lower than those with $A R=2$ (Fig. 5f) and 3 (Fig. 4f).

Overall, when $F r=4.08$, and $A R$ was reduced from 3 and 2 to 1 , the wind-driven force became more dominant than the buoyancy force. Therefore, the flow pattern and pollutant dispersion in street canyons where $A R=0.67$ and 0.5 is not shown here. However, the personal intake fraction is analyzed in sub-section 3.4

\subsection{Pollutant dispersion under low wind speed condition $\left(U_{r e f}=0.5 \mathrm{~m} \mathrm{~s}^{-1}\right.$ and $\left.F r=0.25\right)$}

\subsubsection{In deep street canyons with an aspect ratio of $A R=3$}

As we discussed in the section 4.2, the cases with the $A R$ of 3 , are not satisfied the $R e$ number independence under the condition of a relatively weak background wind $\left(U_{r e f}=0.5 \mathrm{~m}\right.$ $\mathrm{s}^{-1}$ ). The flow patterns and pollutant distributions are more complicated in street canyons under the low wind speed conditions than under high wind speed conditions $\left(U_{r e f}=2 \mathrm{~m} \mathrm{~s}^{-1}\right.$ and $F r=4.08)$. Due to the relatively low Reynolds number $(R e=95602)$, two vortexes moving in the opposite directions were formed in the isothermal Case $\mathrm{N}[3,0.5]$, and the pollutants near the ground were transported to the windward side. In Case B [3, 0.5]), a stronger, narrower vortex was formed at the leeward bottom side and the upper vortex was smaller compared with that in Case $\mathrm{N}[3,0.5]$. There was a similar phenomenon in Case $\mathrm{W}[3,0.5]$ but with an 
even stronger vortex at the bottom side, which resulted in pollutant transportation to the

451

452

453

454

455

456

457

458

459

460

461

462

463

464

465

466

467

468

469

470

471

472

473

474

windward side. Heating of the leeward wall $(\mathrm{L}[3,0.5])$ modified the flow pattern within the street canyon significantly, where the flow pattern was dominated by a single clockwise vortex, as shown in Fig. 7a. When the walls and ground were all heated $(\mathrm{A}[3,0.5])$, three main vortexes were formed, with two clockwise vortexes located at the left side and one counter-clockwise vortex located at the right side. However, the core of the vortex was mostly located at the upper level of street canyons, so although the formations of multiple vortexes may assist the dilution of pollutants in the entire street canyons, the pollutants would accumulate in the middle and lower levels because of the lower wind speeds there.

Fig. 7b-7c show that the vertical wind speed $u_{y}$ in Case $\mathrm{L}$ and $\mathrm{W}[3,0.5]$ is higher than that in other cases. Wind circulation with higher wind speed results in the lower concentration of pollutants, as shown in Fig. 7a. Compared to Case $\mathrm{N}[3,2]$, the insufficient wind speed $u_{y}$ in Case $\mathrm{N}[3,0.5]$ leads to the accumulation of air pollutants. The $K$ value at the bottom level of Case $\mathrm{N}[3,0.5]$ reached 1500, as shown in Fig. 7e. The buoyancy effect is the dominant force driving wind flow and the pollutant dispersion within the street canyon under a low wind speed. This resulted in pollutant accumulation at street level in Case $\mathrm{N}[3$, 0.5]. This can also be observed in Case $\mathrm{N}$ [2, 0.5], in which the wind force became more important with the decrease of $A R$ and the pollutants had the potential to be be spread along the leeward wall. Case $\mathrm{N}[2,0.5]$ is further discussed in the following sections.

\subsubsection{In deep street canyons with an aspect ratio of $A R=2$ ( $R e$-number independence)}

The effects of wind flow became more distinct when the $A R$ value decreased to 2 and the case tends to satisfy the $R e$-number independence with the decrease of $A R$ (Fig. 3) in the presence of background wind of $0.5 \mathrm{~m} \mathrm{~s}^{-1}$. As shown in Fig. 8a, the wind speed contour maps of Case $\mathrm{N}[2,0.5]$ showed the single clockwise vortex pattern within the canyons. This pattern significantly improved pollution levels at street level. Compared to Case $\mathrm{N}$ [3, 0.5], 
the maximum $K$ value of Case $\mathrm{N}[2,0.5]$ decreased from 1500 to 900, as shown in Fig. 8e.

476

477

478

479

480

481

482

483

484

485

486

487

488

489

490

491

492

493

494

495

496

497

498

499

The flow patterns of Case B [2, 0.5], W [2, 0.5], L [2, 0.5] and A [2, 0.5] were similar to the patterns of the corresponding cases with $A R=3$. Specifically, the heated wall at the leeward side enhanced the wind circulation of the single clockwise vortex shown in Fig. 8a, and the heating windward wall is the main reason for the formation of the large counter-clockwise vortex observed in Case W $[2,0.5]$.

The modified flow patterns affect the CO dispersion within the canyon. The pollutant level at the leeward side was higher than that at windward side in Case $\mathrm{N}[2,0.5]$ and $\mathrm{L}[2$, 0.5]. However, the large vortex moving in the opposite direction from the one in Case W [2, 0.5] drove the pollutant accumulation at the windward side. The two large vortexes of Case B [2, 0.5] caused the $K$ value to decrease sharply at the height of $y / H=0.5$, shown in Fig. 8e. This is due to the variation in the $u_{y}$ value at the windward and leeward sides shown in Fig. 8b-8c. Comparing Case B [3, 0.5] and N [2, 0.5], Case B[2, 0.5] shows the strengthened upper level vortex partly compresses the development of the bottom vortex as the aspect ratios decrease, resulting in a higher concentration $K$ below $y / H=0.5$.

\subsubsection{In regular street canyons with an aspect ratio of $A R=1$ ( $R e$-number independence)}

For the street canyon with an $A R$ of 1 , the forces with the highest impact are the wind force and buoyancy effect, as shown in Fig. 9a. As in Case N [2, 0.5], a single vortex formed in the canyon of Case $\mathrm{N}[1,0.5]$, which was affected by wind force only. The pollutants assembled at the leeward side in Case $\mathrm{N}[1,0.5]$ as occurred in Case $\mathrm{L}[1,0.5]$. The concentration differences between the two cases were due to the buoyancy force near the leeward wall in Case L $[1,0.5]$, which enhanced the circulation in the street canyons and removed the pollutants from the street level (Fig. 9b and 9f). For Case B [1, 0.5], the bottom heating generated the buoyancy force, which formed another vortex to the right of the center. The two opposite vortexes brought about the dramatically change of $K$ values at $y / H=0.7$, as 
500 shown in Fig. 9f. The vertical buoyancy force is another reason for the right vortex formation

501 observed in Case W [1, 0.5].

502

503

504

505

506

507

508

509

510

511

512

513

514

515

516

517

518

519

520

\subsubsection{In avenue street canyons with an aspect ratio of $A R=0.67$ ( $R e$-number} independence)

As the aspect ratio of the street canyons decreased further, the impacts of wind force increased. As shown in Fig. 10a, Case B [0.67, 0.5], $\mathrm{N}[0.67,0.5]$, and L [0.67, 0.5] all have the single vortex flow pattern. The wind circulation of Case B $[0.67,0.5]$ is even stronger than that of Case L $[0.67,0.5]$, and the $u_{x}$ and $u_{y}$ values of the two cases are higher than the mean wind speeds in Case $\mathrm{N}[0.67,0.5]$, as shown in Fig. 10c-10e. A right vortex appeared in both Case W [0.67, 0.5] and Case A [0.67, 0.5] but differed in sizes. The smaller vortex of Case $\mathrm{A}[0.67,0.5]$ indicated that the buoyancy forces near the ground compressed this vortex into a smaller one, as the buoyancy near the windward side and ground drove the vortex in the opposite direction.

From Fig. 10f, we can see that the vertical distribution pattern of the $K$ values for the five cases. Case A $[0.67,0.5]$ and B $[0.67,0.5]$ had the lower pollutant concentration near the buildings, and Case $\mathrm{N}[0.67,0.5]$ had the worst air quality within the canyon. Compared to Case $\mathrm{N}[0.67,0.5]$, Case $\mathrm{W}[0.67,0.5]$ had a weaker wind circulation but a lower pollutant concentration at the leeward side. This is because the pollutants were not be dispersed throughout the entire canyon, especially at the windward side, under the low wind speed conditions $\left(<0.5 \mathrm{~m} \mathrm{~s}^{-1}\right)$ with $F r=0.25$. This caused a lower pollutant concentration at the leeward side in Case W [0.67, 0.5], shown in Fig. 10b and 10f. 


\subsubsection{In avenue street canyons with an aspect ratio of $A R=0.5(R e$-number}

522

524

526

\section{independence)}

For the wider street canyon with $A R=0.5$, the flow patterns and the pollutant concentration distributions for the five cases are shown in Fig. 11a-11b. The detailed vertical and horizontal mean wind speed in various locations and the vertical $K$ values near the buildings are shown in Fig. 11f. The flow patterns and the $K$ distributions are quite similar to those in the previous cases with an aspect ratio of 0.67 . In the previous studies $[21,70]$ the flow patterns within the wide street canyons were clarified, with $A R<0.66$ as reference, as the wake interference flow, which was not observed in this study. This is because the Re number of this study is different from the previous number. With a higher $R e$ number, an even smaller $A R$ value is required to transform the flow pattern from a skimming flow to a wake interference flow.

As discussed above, the buoyancy effect can be very effective in removing the air pollutants within the street canyons under the low wind speed conditions. Greater street width, corresponding with a smaller $A R$ value, allows wind into the street level. That wind flow can further modify the pollutant dispersion inside the canyon by, for example, decreasing the pollutant concentration. The aspect ratio, background wind speed, and the heating scenario are the three important factors that should be carefully considered by the urban planners and engineers when designing urban environments.

\subsection{Effects of different heating conditions on the personal intake fraction of $\mathrm{CO}$}

The patterns of pollutant dispersion within the street canyons are mainly determined by the street aspect ratio, heating scenario, and background wind speed conditions. Under high wind speed conditions $(F r>1, R e=382409)$, the wind force almost acts as the dominant factor 
545 forming the flow patterns within the canyon with lower $A R(A R=1-0.5)$. As the wind speed 546 decreases $(F r<1, \operatorname{Re}=95602)$, the dominant force is switched to a buoyancy force within the 547 canyons with a higher $A R(A R=3-1)$. These characteristics lead to the non-uniform 548 distribution of pollutants within the street canyons, as shown in the previous analysis. 549 Considering that factors such as different human activities, various durations of stay and 550 breathing rates in different microenvironments would affect the amount of pollutants inhaled by urban residents, one average value of pollutant concentration cannot represent the real pollutant exposure in local streets or districts. This is the reason why $P_{-} I F$ (personal intake fraction) was applied in this study to evaluate the effect of the heating conditions and the $A R$ on personal exposure. A higher $P \_I F$ value refers to a higher amount of pollutants inhaled by pedestrians. Fig. 12 gives the detailed variation in $P_{-} I F$ value under high wind speed conditions (Fig. 12a-12b) and low wind speed conditions (Fig. 12c-12d). The $P \_I F$ value is higher in the street canyons with a higher aspect ratio under both high and low wind speed conditions. The following will discuss separately discuss the $P \_I F$ values calculated under the high and low background wind conditions respectively.

Within the narrow street canyon $(A R=3)$, the approaching wind had difficulty penetrating the street, even under high wind speed conditions. This means that the buoyancy effect is one of the key factors impacting the pollutant dispersion. For an isothermal case where $A R=3$, the $P_{-} I F$ is $3.96 \mathrm{ppm}$, as shown in Fig. 12a. The $P_{-} I F$ value was the lowest in

564 Case $L[3,2]$ at $P_{-} I F=3.72 \mathrm{ppm}$. This result that the heating leeward side would enhance the 565 single vortex, which carries the pollutant to the upper level of the street, is consistent with the 566 results shown in Fig. 4a. The wind and buoyance forces both present in the flow patterns of 567 Case B [3, 2], W [3, 2] and A [3, 2] competed, resulting in the multiple vortexes within the canyon. The variation in the $P_{-} I F$ value follows the flow features discussed in Fig. 4a, where the $P_{-} I F \mathrm{~s}$ are $6.13 \mathrm{ppm}, 8.63 \mathrm{ppm}$ and $10.32 \mathrm{ppm}$ for Case $\mathrm{W}[3,2], \mathrm{B}[3,2]$ and A $[3,2]$, 
respectively. For the cases with an $A R$ value of 2, where more wind can blow at street level,

571

572

573

574

575

576

577

578

579

580

581

582

583

584

585

586

587

588 the overall $P_{-} I F$ value decreases by $40 \%$ compared to the cases with an $A R$ of 3 . The flow patterns of Case $\mathrm{W}[2,2]$ and Case A $[2,2]$ contained two vortexes, which brought about the higher $P_{-} I F$ values $\left(P \_I F=3.33\right.$ and 3.18 ppm, respectively) compared to the close range for $P \_I F$ in Case $\mathrm{N}[2,2], \mathrm{B}[2,2]$ and $\mathrm{L}[2,2]\left(P \_I F\right.$ ranges from $\left.2.13-2.21 \mathrm{ppm}\right)$. For the wider street canyons with $A R s$ of $1,0.67$ and 0.5 , the influence of wind was more dominant, so the $P \_I F$ values were lower and relatively constant under different heating scenarios $\left(P \_I F s\right.$ were around $0.91-0.98 \mathrm{ppm}, 0.57-0.60 \mathrm{ppm}$ and $0.39-0.43 \mathrm{ppm}$ where $A R=1,0.67$ and 0.5 ), as shown in Fig. 12b.

Under low wind speed conditions $\left(U_{r e f}=0.5 \mathrm{~m} \mathrm{~s}^{-1}\right.$ and $\left.F r=0.25\right)$, the overall $P \_I F$ values of all cases increased by $30 \%$ to $50 \%$, compared to the case under the same heating conditions but a higher wind speed (Fig. 12). For cases with an $A R$ value of 3, the $P_{-} I F$ values were mainly affected by the buoyancy effects, but the $P_{-} I F$ values of the rest of the cases were determined by both wind and buoyancy force, as shown in Fig. 12c-12d. The maximum $P \_I F$ value was $27.51 \mathrm{ppm}$, appearing in the Case $\mathrm{N}[3,0.5]$. For the narrow streets, the low approaching wind and lack of heating conditions made the air movement very weak inside the street canyon. The almost static airflow stopped the pollutant dilution and resulted in the highest $P_{-} I F$ value. The buoyancy effect from heating increased the strength of the bottom vortex in Case $\mathrm{L}[3,0.5]$ and Case $\mathrm{W}[3,0.5]$ (Fig. 10), and therefore the $P \_I F$ values decreased to 7.10 and $9.56 \mathrm{ppm}$, respectively. The vortex structures of Case A [3, 0.5] and $\mathrm{B}[3,0.5]$ were multi-vortex patterns due to the heating walls and the vortexes at the pedestrian level were relatively weak. This means that a multiple-vortex situation deteriorates the air quality, resulting in a higher $P_{-} I F$ values of 15.39 and 14.77 ppm, respectively. For all the cases with an $A R$ value of 2, the $P_{-} I F$ values decreased due to more wind entering the canyon. When the $A R$ value further decreased to $1,0.67$ and 0.5 , the wind became the main 
595 force to modify the flow features within the canyons, and the $P_{-} I F$ values were further

596

597

598

599

600

601

602

603

604

605

606

607

608

609

610

611

612

613

614

615

616

617

618

619 decreased to approximately $0.71-1.66 \mathrm{ppm}$.

Above all, the variation in the overall $P_{-} I F$ value was determined by the flow patterns within the street canyons. The single-vortex pattern was more efficient in removing pollutants at street level than the multi-vortex flow. Whether the buoyancy effect enhances or worsens the pollutant dilution capacity depends on the aspect ratio and wall-heating types of the street canyons. A lower background wind speed usually results in higher pollutant exposure. As $U_{r e f}=0.5 \mathrm{~m} \mathrm{~s}^{-1}(R e=95602, F r=0.25)$, deep street canyons $(A R=2$ and 3$)$ with no wall heating (cloudy day), all wall heating (nighttime with urban heat island effects) and bottom heating (at noon) experienced a larger street intake fraction than leeward or windward heating. Regular and avenue street canyons $(A R=1$ and $0.5-0.67)$, windward wall heating and no wall heating produced greater pollutant exposure. Leeward wall heating always improved pollutant dilution and reduced the street intake fraction. Overall, if the background wind speed is relatively lower and the buoyancy force has significant effects, attention should be paid to deep street canyons (e.g. $A R=2-3$ ) at nighttime (all-wall heating), noon (bottom heating) and cloudy weather (no wall heating). Similarly, regular and avenue street canyons with $A R=0.5-1$ are of particular concern during windward-wall heating and periods of cloudy weather.

\subsection{Limitations and future researches}

As pointed out by Chew et al. [56-57], the reduced-scale street canyons may experience different findings from full-scale models if Re-number-independence cannot be satisfied. Therefore, in the near future, we will conduct CFD simulations from the wind-tunnel scale $\left(H \sim 0.1 \mathrm{~m}, R e \sim 10^{4}-10^{5}\right)$ to scaled model $\left(H \sim 1 \mathrm{~m}, \operatorname{Re} \sim 10^{5}-10^{6}\right)$ and full-scale models $(H \sim 10$ $\mathrm{m}-100 \mathrm{~m}, \operatorname{Re} \sim 10^{6} \sim 10^{7}$ ) under the validation using experimental data.The critical $R e$ number 
$620\left(R e_{c}\right)$ required for $R e$ number independence will be quantified and compared in cases with various aspect ratios (e.g. $A R=0.5-6)$ with the coupling effect of dynamic force and thermal buoyancy force on the flow and pollutant exposure in street canyons. wind speed above the building roof is considerable and the buoyancy force induced by roof heating is not significant when the background wind speed is relatively large, such impacts cannot be disregarded in calm weather condition. In addition, more realistic urban heating scenarios have been used in several CFD studies by the literature [42, 73-77] in which the integrated impacts of urban turbulence and radiation processes with partially-heated walls determined by solar angles are considered. Furthermore, the scaled outdoor experiments in

630 Appendix 3 verify that the realistic background wind speed and direction may vary with time, thus the influence of such unsteady boundary conditions and indoor-outdoor interactions coupling with radiation processes and/or wall heating scenarios on urban turbulence, pollutant dispersion and pollutant exposure should be further investigated under the highquality scaled outdoor experimental data (e.g., Fig. A3e, measured data from Appendix A3).

\section{Conclusion}

Deep street canyons and unfavourable meteorological conditions (e.g., a weak background wind) are the main factors producing poor ventilation capacity, a high pollutant exposure of urban residents and the related adverse impacts on human health. This study

640 focuses on the impact of aspect ratios $(A R=3,2,1,0.67,0.5 ; H=3 \mathrm{~m})$, background wind speeds $\left(U_{\text {ref }}=2 \mathrm{~m} \mathrm{~s}^{-1}\right.$ and $\left.0.5 \mathrm{~m} \mathrm{~s}^{-1}\right)$ and various wall-heating scenarios $\left(T_{\text {wall }}-T_{\text {air }}=10 \mathrm{~K}\right)$ on air

642 flow, pollutant dispersion and the related human exposure in scale-model street canyon 643 models, which has not received significant research attention. Various Froude numbers

$644(F r=0.25$ and 4.08) and reference Reynolds numbers ( $R e=95602$ and 382409) were 
645 considered. The use of CFD methodologies combined with a RNG $k-\varepsilon$ model has been

646 validated by wind tunnel data and scale-model outdoor field experiments. The personal intake

647 fraction $\left(P \_I F\right)$ and its spatial mean value for an entire street, or street intake fraction $\left\langle P \_I F\right\rangle$,

648 are used to quantify personal exposure in near-road buildings.

649 In most isothermal cases, only one-main-vortex structure exists when $A R=0.5-3$, but two

650 vortexes appear for $A R=3$ and $R e=95602$, confirming that $R e=95602$ cannot satisfy the $R e$ 651 independence requirement when $A R=3$.

652 In non-isothermal cases with $F r=4.08$ and $U_{r e f}=2 \mathrm{~m} \mathrm{~s}^{-1}(R e=382409)$, the most salient

653 features is that the formation of a single vortex removes the pollutant efficiently; however,

654 the formation of a multi-vortex structure due to different heating scenarios increases $\left\langle P \_I F\right\rangle$

655 to a certain extent, where $A R=2-3$. As $A R=0.5-1$, the wind dynamic force dominates the flow 656 patterns in street canyons and the buoyancy effect is less important. The four heating 657 conditions attain similar $\left\langle P \_I F\right\rangle$ in isothermal cases $(0.91-0.98 \mathrm{ppm}, 0.57-0.60 \mathrm{ppm}, 0.39$ $6580.43 \mathrm{ppm}$ for $A R=1,0.67,0.5$ respectively).

659 In contrast to the isothermal case as $A R=3$, leeward-wall-heating slightly enhances the 660 single-main-vortex structure and slightly reduces $\left\langle P \_I F\right\rangle(3.96 \mathrm{ppm}$ to $3.72 \mathrm{ppm})$, but other 661 heating scenarios induce a multi-vortex structure that significantly increases pollutant 662 exposure $\left(\left\langle P \_I F\right\rangle=3.96 \mathrm{ppm}\right.$ to $\left.6.13-10.32 \mathrm{ppm}\right)$. When $A R=2$, bottom or leeward wall 663 heating only slightly affects the single vortex, resulting in a similar $\left\langle P \_I F\right\rangle(2.13-2.21 \mathrm{ppm})$ 664 but windward and all-wall heating creates multi-vortex structures, resulting in an increased 665 $<P \_I F>(3.18-3.33 \mathrm{ppm})$.

When $F r=0.25$ and $U_{r e f}=0.5 \mathrm{~m} \mathrm{~s}^{-1}$, the isothermal case where $A R=3$ experiences the 667 highest $\left\langle P \_I F\right\rangle(27.51 \mathrm{ppm})$, and $\left\langle P \_I F\right\rangle$ decreases with the decrease of $A R(7.85 \mathrm{ppm}, 3.47$ $668 \mathrm{ppm}, 2.30 \mathrm{ppm}$ and $1.66 \mathrm{ppm}$ where $A R=2,1,0.67,0.5)$. The four heating condition all 669 significantly influence vortex structure. Leeward wall heating always enhances pollutant 
670 dilution and results in a lower $\left\langle P \_I F\right\rangle$ than in the isothermal case (i.e. $7.10 \mathrm{ppm}, 4.41 \mathrm{ppm}$,

$6712.29 \mathrm{ppm}, 1.57 \mathrm{ppm}, 1.20 \mathrm{ppm}$ where $A R=3,2,1,0.67,0.5)$, but the influence of the other

672 three heating conditions is complicated. Where $A R=0.67$ and 0.5 , the other three heating

673 conditions will improve the air quality (Fig. 12). However, where $A R=2$, the bottom wall

674 heating results in a higher $\left\langle P \_I F\right\rangle(10.07 \mathrm{ppm})$ compared to the isothermal case where $A R=2$.

675 Where $A R=1$, both the bottom and windward heating will increase the $\left\langle P \_I F\right\rangle$ to 3.51 and

$4.52 \mathrm{ppm}$, respectively. The flow patterns and pollutant dispersion under weak conditions also depend on the competition between the wind-driven dynamic force and buoyant force.

In general, a single vortex pattern is more efficient in removing the pollutants at the street level for both high and low wind speeds. Leeward wall heating always enhances the 680 circulation in street canyons where $A R=0.5-3$. The buoyancy effect induced by other wall heating scenarios can sometimes raise or reduce pollutant exposure, depending on the aspect ratios, ambient wind speed and wall-heating types. Lower background wind speeds merit more attention, since they usually result in a higher pollutant exposure. Certain other conditions require particular attention: $U_{r e}=0.5 \mathrm{~m} \mathrm{~s}^{-1}(\operatorname{Re}=95602, F r=0.25)$, and deep street canyons (e.g., $A R=2-3$ ) at nighttime (all-wall heating), at noon (bottom heating) and in cloudy weather periods (no wall heating); while regular and avenue street canyons with $A R=0.5-1$ need more attention during windward-wall heating and cloudy weather periods. but this study serves as one of the first attempts to evaluate the influence of various wall heating and aspect ratios on pollutant exposure in urban street. The methods adopted in this study can be used to assess the street intake fraction in more complicated urban streets or neighborhoods under a variety of atmospheric conditions. 
This study was financially supported by the National Key R\&D Program of China

696

697

698

699

700

701

702

703

704

705

706

707

708

709

710

711

712

713

714

715

716

717 [2016YFC0202206, 2016YFC0202205 and 2016YFC0202204], the National Science Fund for Distinguished Young Scholars (No. 41425020), the National Natural Science Foundation-Outstanding Youth Foundation (No. 41622502), STINT (dnr CH2017-7271) and the National Natural Science Foundation of China (No. 51811530017 and 41875015) as well as the Key Projects of the Guangdong Natural Science Foundation (No. 2018B030311068). The help from Miss Lan Chen, Miss Xia Yang, Miss Hongyu Yang in Sun Yat-sen University and the support by National Supercomputer center in Guangzhou, P.R. China are also gratefully acknowledged.

\section{References}

[1] Fenger, J. 1999. Urban air quality, Atmos. Environ. 33:4877-4900.

[2] Kumar P., Morawska L., Birmili W., Paasonen P., Hu M., Kulmala M., Harrison R.M., Norford L., Britter R., 2014. Ultrafine particles in cities, Environ. Int. 66:1-10.

[3] Chen C., Zhao B., Zhou W.T., Jiang X.Y., Tan Z.C., 2012. A methodology for predicting particle penetration factor through cracks of windows and doors for actual engineering application, Build. Environ. 47:339-348.

[4] Ji W.J., Zhao B., 2015. Estimating mortality derived from indoor exposure to particles of outdoor origin, PloS. One. 10: e0124238.

[5] Zhang Y., Gu Z., 2013. Air quality by urban design, Nat. Geosci. 7:506.

[6] Yuan C., Ng E., Norford L.K., 2014. Improving air quality in high-density cities by understanding the relationship between air pollutant dispersion and urban morphologies, Build. Environ. 71:245-258. 
718

719

720

721

722

723

724

725

726

727

728

729

730

731

732

733

734

735

736

737

738

739

740

741

[7] Ng, W., Chau, C., 2014. A modeling investigation of the impact of street and building configurations on personal air pollutant exposure in isolated deep urban canyon, Sci. Total Environ. 468:429-448.

[8] Hang J., Luo Z.W., Wang X.M., He L.J., Wang B.M., Zhu W., 2017. The influence of street layouts and viaduct settings on daily $\mathrm{CO}$ exposure and intake fraction in idealized urban canyons, Environ. Pollut. 220:72-86.

[9] Zhang K., Chen G., Wang X., Liu S., Ming C., Fan Y., Hang J., 2019. Science of the Total Environment Numerical evaluations of urban design technique to reduce vehicular personal intake fraction in deep street canyons, Sci. Total Environ. 653:968-994.

[10] Vardoulakis S., Fisher B.E.A., Pericleous K., Gonzalez-Flesca N., 2003. Modeling air quality in street canyons: a review, Atmos. Environ. 37:155-182.

[11] Li X.X., Liu C.H., Leung D.Y.C., Lam K.M., 2006. Recent progress in CFD modelling of wind field and pollutant transport in street canyons, Atmos. Environ. 40:5640-5658.

[12] Fernando H.J.S, Zajic D., Di Sabatino S., Dimitrova R., Hedquist B., Dallman A.,2010. Flow, turbulence, and pollutant dispersion in urban atmospheres, Phys. Fluids. 22:051301.

[13] Kumar P., Ketzel M., Vardoulakis S., Pirjola L., Britter R., 2011. Dynamics and dispersion modelling of nanoparticles from road traffic in the urban atmospheric environment-A review, J. Aerosol Sci. 42:580-603.

[14] Di Sabatino, S., Buccolieri, R., Salizzoni, P., 2013. Recent advancements in numerical modelling of flow and dispersion in urban areas: a short review, Int. J. Environ. Pollut. $52: 172-191$

[15] Blocken B., 2015. Computational fluid dynamics for urban physics: importance, scales, possibilities, limitations and ten tips and tricks towards accurate and reliable simulations, Build. Environ. 91:219-245. 
[16] Blocken B., 2018. LES over RANS in building simulation for outdoor and indoor applications : A foregone conclusion ?, Build. Simul. 11: 821-870.

744 [17] Lateb M., Meroney R. N., Yataghene M., Fellouah H., Saleh F., Boufadel M.C., 2016. 745 On the use of numerical modelling for near-field pollutant dispersion in urban 746 environments-A review, Environ. Pollut. 208:271-283.

747 [18] Meroney R.N., 2016. Ten questions concerning hybrid computational/physical model 748 simulation of wind flow in the built environment, Build. Environ. 96:12-21.

749 [19] Toparlar Y., Blocken B., Maiheu B., van Heijst G.J.F., 2017. A review on the CFD 750 analysis of urban microclimate, Renew. Sustain. Energy Rev. 80:1613-1640.

751 [20] Zhang Y., Gu Z., Chuck W. Y., 2018. Review on numerical simulation of airflow and 752 pollutant dispersion in urban street canyons under natural background wind conditions, Aerosol. Air. Qual. Res. 18:780-789.

[21] Oke T.R., 1988. Street design and urban canopy layer climate, Sci. Total Environ. 11:103-113.

[22] Meroney R.N., Pavegeau M., Rafailidis S. and Schatzmann M., 1996. Study of line source characteristics for 2-D physical modelling of pollutant dispersion in street canyons, J. Wind. Eng. Ind. Aerodyn. 62:37-56.

[23] Li X.X., Liu C.H., Leung D.Y.C., 2009. Numerical investigation of pollutant transport characteristics inside deep urban street canyons, Atmos. Environ. 43:2410-2418.

[24] Hanna S.R., Tehranian S., Carissimo B., Macdonald R.W., Lohner R., 2002. Comparisons of model simulations with observations of mean flow and turbulence within simple obstacle arrays, Atmos. Environ. 36:5067-5079. 
764

765

766

767

768

769

770

771

772

773

774

775

776

777

778

779

780

781

782

783

784

785

[25] Buccolieri R, Sandberg M, Di Sabatino S., 2010. City breathability and its link to pollutant concentration distribution within urban-like geometries, Atmos. Environ. 44:1894-1903.

[26] Hang J., Li Y.G., 2011. Age of air and air exchange efficiency in high-rise urban areas, Atmos. Environ. 45:5572-5585.

[27] Ramponi R., Blocken B., de Coo L.B., Janssen W.D., 2015. CFD simulation of outdoor ventilation of generic urban configurations with different urban densities and equal and unequal street widths, Build. Environ. 92:152-166.

[28] Yassin M. F., 2013. Numerical modeling on air quality in an urban environment with changes of the aspect ratio and wind direction, Environ. Sci. Pollut. R. 20: 3975-3988.

[29] Lin M., Hang J., Li Y.G., Luo Z.W., Sandberg M., 2014. Quantitative ventilation assessments of idealized urban canopy layers with various urban layouts and the same building packing density, Build. Environ. 79:152-167.

[30] Gu Z.L., Zhang Y.W., Cheng Y., Lee S.C., 2011. Effect of uneven building layout on air flow and pollutant dispersion in non-uniform street canyons, Build. Environ. 46:26572665.

[31] Hang J., Li Y.G., Sandberg M., Buccolieri R., Di Sabatino S., 2012. The influence of building height variability on pollutant dispersion and pedestrian ventilation in idealized high-rise urban areas, Build. Environ. 56:346-360.

[32] Chen L., Hang J., Sandberg M., Claesson L., Di Sabatino S., Wigo H., 2017. The impacts of building height variations and building packing densities on flow adjustment and city breathability in idealized urban models, Build. Environ. 118: 344-361. 
786

787

788

789

790

791

792

793

794

795

796

797

798

799

800

801

802

803

804

805

806

807

808

[33] Gromke C, Blocken B., 2015. Influence of avenue-trees on air quality at the urban neighborhood scale. Part I: Quality assurance studies and turbulent Schmidt number analysis for RANS CFD simulations, Environ Pollut. 196: 214-223.

[34]Du Y.X., Mak C.M., Liu J.L., Xia Q., Niu J.L., Kwok K.C.S., 2017. Effects of lift-up design on pedestrian level wind comfort in different building configurations under three wind directions, Build. Environ. 117:84-99.

[35]Zhang X., Tse K. T., Weerasuriya A. U., Li S. W., Kwok K. C. S., Mak C. M., Niu J.L., Lin, Z., 2017. Evaluation of pedestrian wind comfort near 'lift-up' buildings with different aspect ratios and central core modifications, Build. Environ. 124:245-257.

[36] Nakamura Y., Oke T.R., 1988. Wind temperature and stability conditions in an east-west oriented urban canyon, Atmos. Environ. 22:2691-2700.

[37] Yang L., Li Y., 2009. City ventilation of Hong Kong at no-wind conditions, Atmos. Environ. 43:3111-3121.

[38]Nazarian N., Kleissl J., 2016. Realistic solar heating in urban areas: Air exchange and street-canyon ventilation. Build. Environ. 95:75-93.

[39]Li Q., Bou-Zeid E., Anderson, W., Grimmond S., Hultmark M., 2016. Quality and reliability of LES of convective scalar transfer at high Reynolds numbers. Int. J. Heat. Mass. Tran.102:959-970.

[40]Liu J., Srebric J. and Yu N., 2013. Numerical simulation of convective heat transfer coefficients at the external surfaces of building arrays immersed in a turbulent boundary layer. Int. J. Heat. Mass. Tran. 61:209-225.

[41] Kim J.J., Baik J.J., 2001. Urban street-canyon flows with bottom heating, Atmos. Environ. 35:3395-3404. 
809 [42]Cai X.M., 2012. Effects of differential wall heating in street canyons on dispersion and

$810 \quad$ ventilation characteristics of a passive scalar, Atmos. Environ. 51: 268-277.

811 [43] Tong N.Y.O., Leung D.Y.C.,2012. Effects of building aspect ratio, diurnal heating 812 scenario, and wind speed on reactive pollutant dispersion in urban street canyons, J.

$813 \quad$ Environ. Sci. 24:2091-2103.

814 [44]Memon R. A., Leung D.Y.C., Liu C.H., 2010.Effects of building aspect ratio and wind 815 speed on air temperatures in urban-like street canyons. Build. Environ., 45(1): 176-188.

816 [45]Lin L., Hang J., Wang X., Wang X., Fan S., Fan Q., Liu Y., 2016. Integrated effects of

817 street layouts and wall heating on vehicular pollutant dispersion and their reentry into

818 downstream canyons. Aerosol. Air. Qual. Res., 16: 3142-3163.

819 [46]Hang J., Lin M., Wong D. C., Wang X., Wang B., Buccolieri R., 2016. On the influence 820 of viaduct and ground heating on pollutant dispersion in 2D street canyons and toward $821 \quad$ single-sided ventilated buildings Atmos. Pollut. Res. 7:817-832.

[47]Dallman A., Magnusson S., Britter R., Norford L., Entekhabi D., Fernando H.J.S., 2014. Conditions for thermal circulation in urban street canyons, Build. Environ. 80:184-191.

[48] Cui P.Y., Li Z. , Tao W.Q., 2016. Wind-tunnel measurements for thermal effects on the air flow and pollutant dispersion through different scale urban areas, Build. Environ. 97:137-151.

[49] Allegrini J., Dorer V., Carmeliet J., 2013. Wind tunnel measurements of buoyant flows in street canyons, Build. Environ. 59:315-326

[50] Allegrini J., Dorer V., Carmeliet J., 2014. Buoyant flows in street canyons: Validation of CFD simulations with wind tunnel measurements, Build. Environ. 72:63-74. 
831 [51] Xie X., Liu C.H., Leung D.Y.C., 2007. Impact of building facades and ground heating

832 on wind flow and pollutant transport in street canyons, Atmos. Environ. 41:9030-9049.

833 [52] Xie X., Huang Z., Wang J., 2006. The impact of urban street layout on local atmospheric 834 environment, Build. Environ. 41:1352-1363.

835 [53] Zhang Y., Gu Z., Lee S.C., Fu T.M., Ho, K.F., 2011. Numerical simulation and in situ 836 investigation of fine particle dispersion in an actual deep street canyon in Hong Kong, 837 Indoor Built Environ. 20:206-216.

838 [54] He L.J., Hang J., Wang X.M., Lin B.R., Li X.H., Lan G.D., 2017. Numerical

839 investigations of flow and passive pollutant exposure in high-rise deep street canyons

840 with various street aspect ratios and viaduct settings, Sci. Total Environ. 584:189-206.

841 [55] Snyder W. H., 1972. Similarity criteria for the application of fluid models to the study of 842 air pollution meteorology, Bound.-Layer Meteorol. 3:113-134.

843 [56] Chew L.W. , Aliabadi A.A., Norford L.K., 2018. Flows across high aspect ratio street 844 canyons: Reynolds number independence revisited. Environ. Fluid. Mech. 18(5):1275-

[57] Chew L.W., Glicksman L.R.,Norford L.K., 2018. Buoyant flows in street canyons: Comparison of RANS and LES at reduced and full scales. Build. Environ. 146:77-87.

848 [58] Luo Z.W., Li Y.G., Nazaroff W.W., 2010. Intake fraction of nonreactive motor vehicle exhaust in Hong Kong, Atmos. Environ. 44:1913-1918.

850 [59] Habilomatis G., Chaloulakou A., 2015. A CFD modeling study in an urban street canyon 851 for ultrafine particles and population exposure: The intake fraction approach, Sci. Total. $852 \quad$ Environ. 530: 227-232. 
[60] Zhou Y., Levy J.I., 2008. The impact of urban street canyons on population exposure to traffic-related primary pollutants, Atmos. Environ. 42:3087-3098.

[61] Lin, Y., Chen, G.W., Chen, T.H., Luo, Z.W., Yuan, C., Gao, P., Hang, J., 2019. The influence of advertisement boards, street and source layouts on $\mathrm{CO}$ dispersion and building intake fraction in three-dimensional urban-like models. Build. Environ. 150: 297-321.

[62]Sha C.Y., Wang X.M., Lin Y.Y., Fan Y.F., Chen X., Hang J., 2018. The impact of urban open space and 'lift-up' building design on building intake fraction and daily pollutant exposure in idealized urban models, Sci. Total. Environ. 633:1314-1328.

[63]Hang, J., Xian, Z., Wang, D., Mak, C. M., Wang, B., Fan, Y., 2018. The impacts of viaduct settings and street aspect ratios on personal intake fraction in three-dimensional urban-like geometries. Build. Environ. 143: 138-162.

[64] Chau C.K., Tu E.Y., Chan D.W.T., Burnett C.J., 2002. Estimating the total exposure to air pollutants for different population age groups in Hong Kong, Environ. Inter. 27:617-630.

[65] Allan M., Richardson G.M., Jones-Otazo H., 2008. Probability density functions describing 24-hour inhalation rates for use in human health risk assessments: an update and comparison, Hum. Ecol. Risk. Assess. 14:372-391.

[66]Kalaiarasan M., Balasubramanian R., Cheong K.W.D., Tham K.W., 2009. Trafficgenerated airborne particles in naturally ventilated multi-story residential buildings of Singapore: Vertical distribution and potential health risks, Build. Environ. 44:1493-1500.

[67] Quang T.N., He C., Morawska L., Knibbs L.D., Falk M., 2012. Vertical particle concentration profiles around urban office buildings, Atmos. Chem. and Phys. 12:50175030. 
[68] ANSYS Inc, 2013. ANSYS FLUENT User's Guide.

878

879

880

881

882

883

884

885

886

887

888

889

890

891

892

893

894

895

896

897

898

899

900

[69]Yakhot, V., Orszag. S.A., 1986. Renormalization group analysis of turbulence. I. Basic theory. J. Sci. Comput. 1, 3-51.

[70] Madalozzo M.S., Braun A.L., Awruch A.M., Morsch I.B. 2014. Numerical simulation of pollutant dispersion in street canyons: Geometric and thermal effects. Applied Mathematical Modelling, 38:5883-5909.

[71] Kikumoto H., Ooka R. 2018. Large-eddy simulation of pollutant dispersion in a cavity at fine grid resolutions. Build. Environ. 127: 127-137.

[72] Tominaga, Y., Stathopoulos, T., 2012. CFD modeling of pollution dispersion in a street canyon: comparison between LES and RANS. J. Wind Eng. Ind. Aerodyn. 99: 340-348.

[ 73] Inagaki, A., Castillo, M.C.L., Yamashita, Y., Kanda, M., Takimoto, H., 2012. Largeeddy simulation of coherent flow structures within a cubical canopy. Boundary-Layer. Meteorol. 142(2):207-222.

[74] Nazarian, N., Martilli, A., Kleissl, J., 2018. Impacts of realistic urban heating, Part I: Spatial variability of mean flow, turbulent exchange and pollutant dispersion. BoundaryLayer. Meteorol. 166:367-393.

[75] Qu, Y., Milliez, M., Musson-Genon, L., Carissimo, B., 2012. Numerical study of the thermal effects of buildings on low-speed airflow taking into account 3D atmospheric radiation in urban canopy. J. Wind. Eng. Ind. Aerodyn. 104:474-483.

[76] Santiago, J., Krayenhoff, E., Martilli, A., 2014. Flow simulations for simplified urban configurations with microscale distributions of surface thermal forcing. Urban. Clim. 9:115-133.

[77] Yaghoobian, N., Kleissl, J., 2012. An indoor-outdoor building energy simulator to study urban modification effects on building energy use-model description and validation. 
Energy. Build. 54:407-417.

902

903 
905

906

907

908

909

910

911

912

913

914

915

916

917

918

919

920

921

922

923

924

925

926

Fig. 1. Breathing rate and time patterns for various age groups and microenvironments [64$65]$.

Fig. 2. (a) Dimensions of the simulated street canyon model in CFD. (b) The grid arrangement of 2D CFD simulations.

Fig. 3. Normalized stream-wise velocity along the street centerline in isothermal cases with (a) background wind speed of $U_{r e f}=0.5 \mathrm{~m} \mathrm{~s}^{-1}$ and $2 \mathrm{~m} \mathrm{~s}^{-1}(\mathrm{Re}=95602$ and 382409) where $A R=0.5,0.67,1$, and 2, (b) $U_{r e f}=0.5 \mathrm{~m} \mathrm{~s}^{-1}, 2 \mathrm{~m} \mathrm{~s}^{-1}, 4 \mathrm{~m} \mathrm{~s}^{-1}$ where $A R=3(\operatorname{Re}=95602$, 382409, 764818). (c) Normalized stream-wise velocity and streamline in deep street $(A R=3)$ in isothermal case.

Fig. 4. In cases where $A R=3, U_{\text {ref }}=2.0 \mathrm{~m} \mathrm{~s}^{-1}$ : (a) Contour of the mean wind speed $\left(\mathrm{m} \mathrm{s}^{-1}\right)$ and normalized concentration $K$, Vertical velocity $\boldsymbol{u}_{\boldsymbol{y}}$ along (b) the windward line and (c) the leeward line, (d) streamwise velocity $\boldsymbol{u}_{\boldsymbol{x}}$ along the bottom line. (e) Spatial average $\langle K\rangle$ along the windward wall and leeward wall.

Fig. 5. In cases where $A R=2, U_{\text {ref }}=2.0 \mathrm{~m} \mathrm{~s}^{-1}$ : (a) Contour of the mean wind speed $\left(\mathrm{m} \mathrm{s}^{-1}\right)$ and $K$; $u_{y}$ along (b) the windward line and (c) the leeward line; (d) $u_{x}$ along the bottom line; (e) $<K>$ at the windward and leeward walls.

Fig. 6. In cases where $A R=1$ and $U_{\text {ref }}=2 \mathrm{~m} \mathrm{~s}^{-1}$ : Contour of (a) the mean wind speed ( $\mathrm{m} \mathrm{s}^{-1}$ ) and $K . u_{y}$ along (c) the windward line and (d) the leeward line; (e) $u_{x}$ along the bottom line; (f) $\langle K\rangle$ at the windward and leeward walls.

Fig. 7. In cases where $A R=3$ and $U_{r e f}=0.5 \mathrm{~m} \mathrm{~s}^{-1}$ : (a) Contour of the mean wind speed $\left(\mathrm{m} \mathrm{s}^{-1}\right)$ and $K . u_{y}$ along (b) the windward line and (c) the leeward line; (d) $u_{x}$ along the bottom line; (e) $\langle K\rangle$ at the windward and leeward walls. 
927 Fig. 8. In cases where $A R=2$ and $U_{r e f}=0.5 \mathrm{~m} \mathrm{~s}^{-1}$ : (a) Contour maps of the mean wind speed (m $\mathrm{s}^{-1}$ ) and $K . u_{y}$ along (b) the windward line and (c) the leeward line; (d) $u_{x}$ along the bottom line; (e) $\langle K\rangle$ at the windward and leeward walls.

930 Fig. 9. In cases where $A R=1$ an $U_{r e f}=0.5 \mathrm{~m} \mathrm{~s}^{-1}$ : Contour of (a) the mean wind speed ( $\mathrm{m} \mathrm{s}^{-1}$ ) and (b) $K . u_{y}$ along (c) the windward line and (d) the leeward line; (e) $u_{x}$ along the bottom line; (f) $\langle K\rangle$ at the windward and leeward walls.

Fig. 10. In cases where $A R=0.67$ and $U_{r e f}=0.5 \mathrm{~m} \mathrm{~s}^{-1}$ : Contour of (a) the mean wind speed ( $\mathrm{m} \mathrm{s}^{-}$ ${ }^{1}$ ) and (b) $K . u_{y}$ along (c) the windward line and (d) the leeward line; (e) $u_{x}$ along the bottom line; (f) $\langle K\rangle$ at the windward and leeward walls.

936 Fig. 11. In cases where $A R=0.5$ and $U_{r e f}=0.5 \mathrm{~m} \mathrm{~s}^{-1}$. Contour maps of (a) the mean wind speed $\left(\mathrm{m} \mathrm{s}^{-1}\right.$ ) and (b) $K . u_{y}$ along (c) the windward line and (d) the leeward line; (e) $u_{x}$ along the bottom line; (f) $\langle K\rangle$ at the windward wall and leeward wall.

Fig. 12. Spatial mean value of the personal intake fraction of a local street with different

940 heating conditions as $A R=0.5-3$ with (a) $U_{r e f}=2.0 \mathrm{~m} \mathrm{~s}^{-1}$, and (b) $U_{r e f}=0.5 \mathrm{~m} \mathrm{~s}^{-1}$.

943 Table list

944 Table 1 Breathing rate and time patterns for indoor at home for each age group [58, 64-65].

945 Table 2. Model descriptions of the simulated test cases.

946 Table 3. Boundary conditions and solver settings for the CFD simulations

947 Table 4. Reynolds and Froude numbers investigated in all test cases with wall heating $\left(T_{\text {wall }}{ }^{-}\right.$

$$
\left.T_{\text {air }}=10 \mathrm{~K}\right)
$$




\section{Appendix A1. Flow validation for 2D street canyon with wall heating by}

\section{wind tunnel experiment $(A R=1)$}

954

955

956

957

958

959

960

961

962

963

964

965

966

967

968

969

970

The CFD simulations were first evaluated using wind tunnel data from the work of Allegrini et al. [49], which studied the flow and turbulence characteristics within a street canyon ( $W=H=0.2 \mathrm{~m}$ ) under isothermal and non-isothermal conditions (Fig. A1). Four situations, including leeward wall heating, windward wall heating, ground heating and all wall heating, were investigated. The Froude number $\left(F_{r}=\frac{U_{r e f}{ }^{2}}{\beta g H\left(T_{w}-T_{r e f}\right)}\right)$ ranges from 0.65 to 17.29, where $U_{\text {ref }}$ and $T_{\text {ref }}$ are the reference velocity and air temperature in the upstream free stream, respectively $\left(T_{\text {ref }}=23^{\circ} \mathrm{C}, U_{\text {ref }}\right.$ ranges from 2.32 to $\left.0.68 \mathrm{~m} \mathrm{~s}^{-1}\right) ; T_{\mathrm{w}}$ is the surface temperature of the heated building wall or ground, ranging from $70{ }^{\circ} \mathrm{C}$ to $130{ }^{\circ} \mathrm{C}$.

In this CFD validation case, the computational domain has the same dimension as the wind tunnel (Fig. A1a) and the CFD setup is similar to that described in subsection 2.2. A fine grid with enhanced wall function (EWF) near wall surfaces is used to resolve the viscous sub-layer, in which the order of magnitude of $y^{+}$is 1 and the grid number is 58085 with a minimum cell size of $1 \mathrm{~mm}$. To verify the grid independence, we also compared the results with results from a finer grid arrangement with 190.016 cells and a minimum cell size of $0.5 \mathrm{~mm}$. Fig. A1b shows the vertical profiles of stream-wise velocity $U(z)$ and turbulent kinetic energy (TKE) $k(z)$ measured in the free flow $\left(U_{r e f}=1.45 \mathrm{~m} \mathrm{~s}^{-1}\right)$ of the wind tunnel. They are used as the domain inlet boundary conditions in the CFD simulations.

The RNG $k-\varepsilon$ model is used with a predefined $x$-Component "wall shear stress" at upstream and downstream points on the ground to minimize the stream-wise TKE decay and 
973 to reproduce a horizontally approaching atmospheric boundary layer (Allegrini et al. [50]).

974 Finally, considering the work of Allegrini et al. [50] which stated that a large difference

975 between the air and wall temperature has a significant effect on the buoyant flow, we used a

976 user-defined function (UDF) to model the effect of temperature variation on the air density

977 (i.e. air density is not a constant). As an example of validation tests, Fig. A1c and A1d show

978 profiles of the normalized mean vertical velocity $\left(V / U_{r e f}\right)$, mean stream-wise velocity $\left(U / U_{r e f}\right)$

979 and turbulent kinetic energy TKE $\left(k / U_{r e f}^{2}\right)$ in isothermal $\left(\Delta T=0 \mathrm{~K}, U_{r e f}=1.45 \mathrm{~m} \mathrm{~s}^{-1}, R e=19200\right)$

980 and non-isothermal (uniform all wall heating, $F r=6.75, U_{r e f}=1.45 \mathrm{~m} \mathrm{~s}^{-1}, R e=19200$ ) cases.

981 The simulation results agreed well with the wind tunnel data in terms of mean flows, while

982 the turbulent kinetic energy was slightly under-predicted. The results using the fine and the

983 finer grids do not show significant differences.

984

985

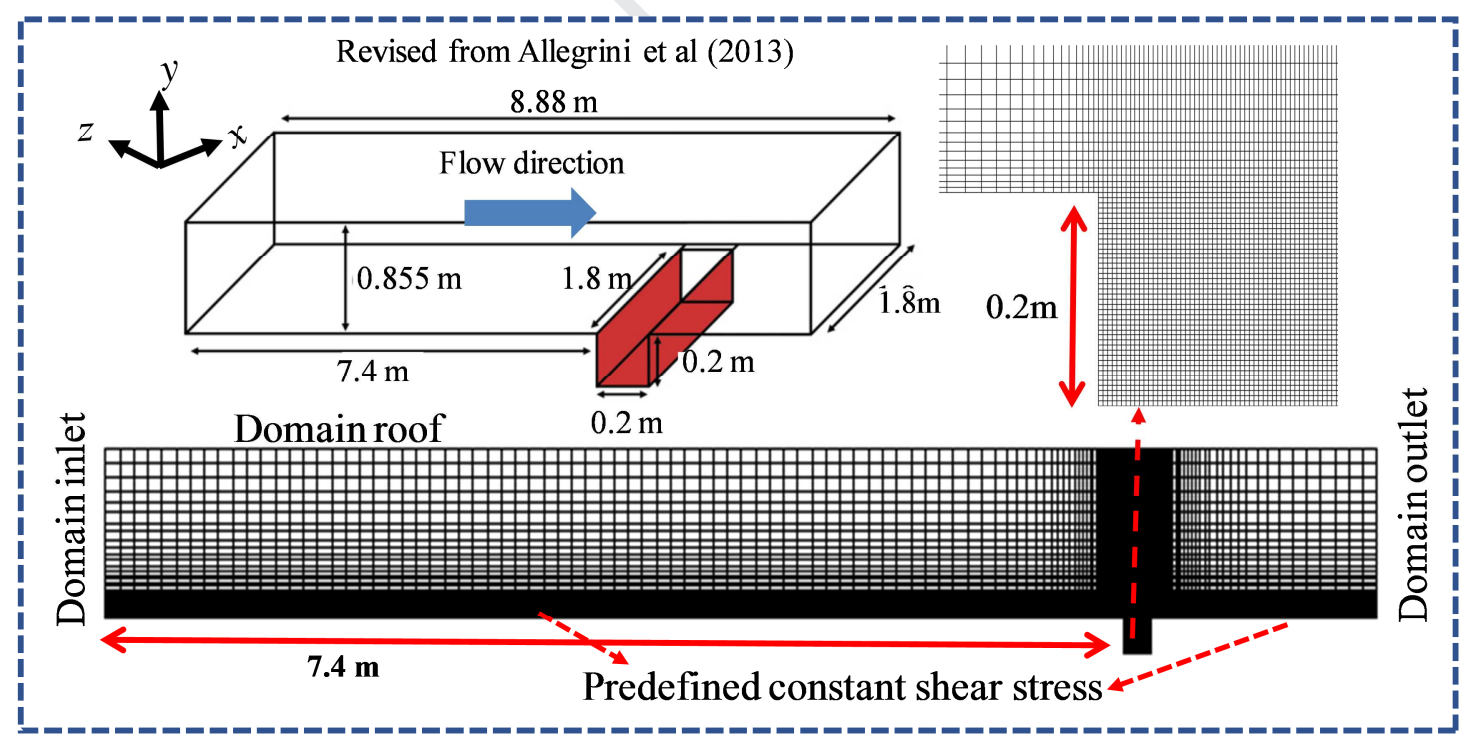




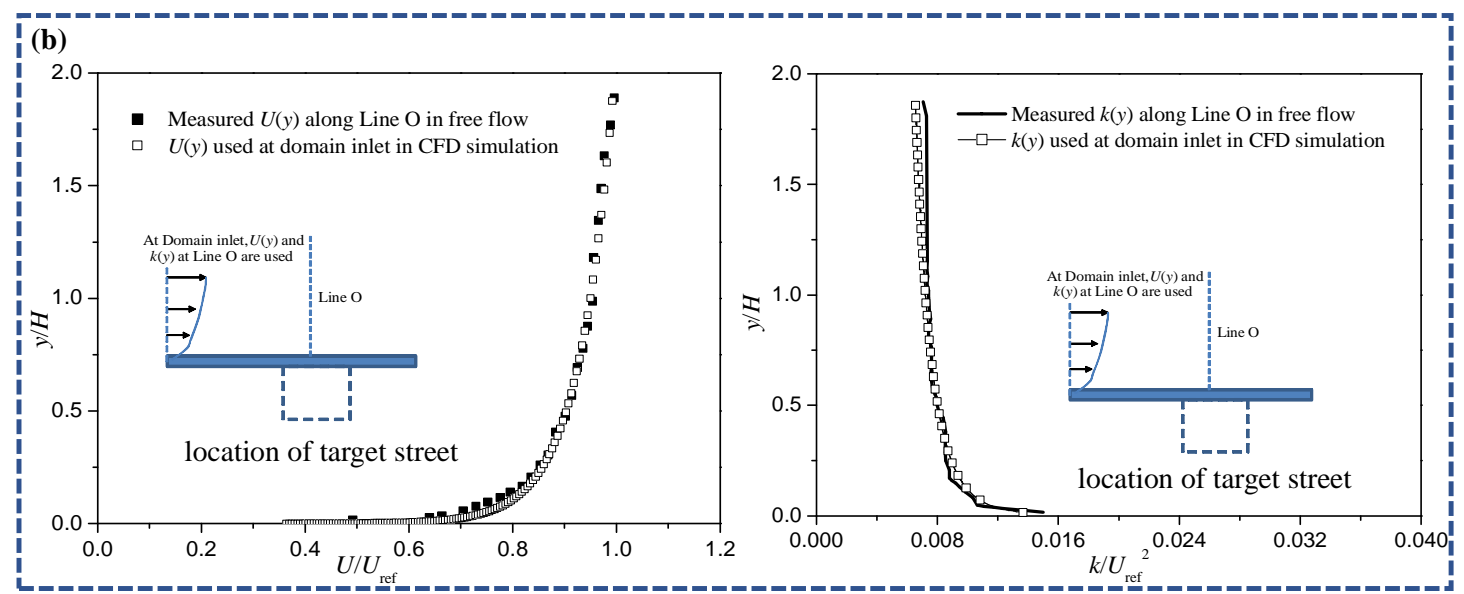

987
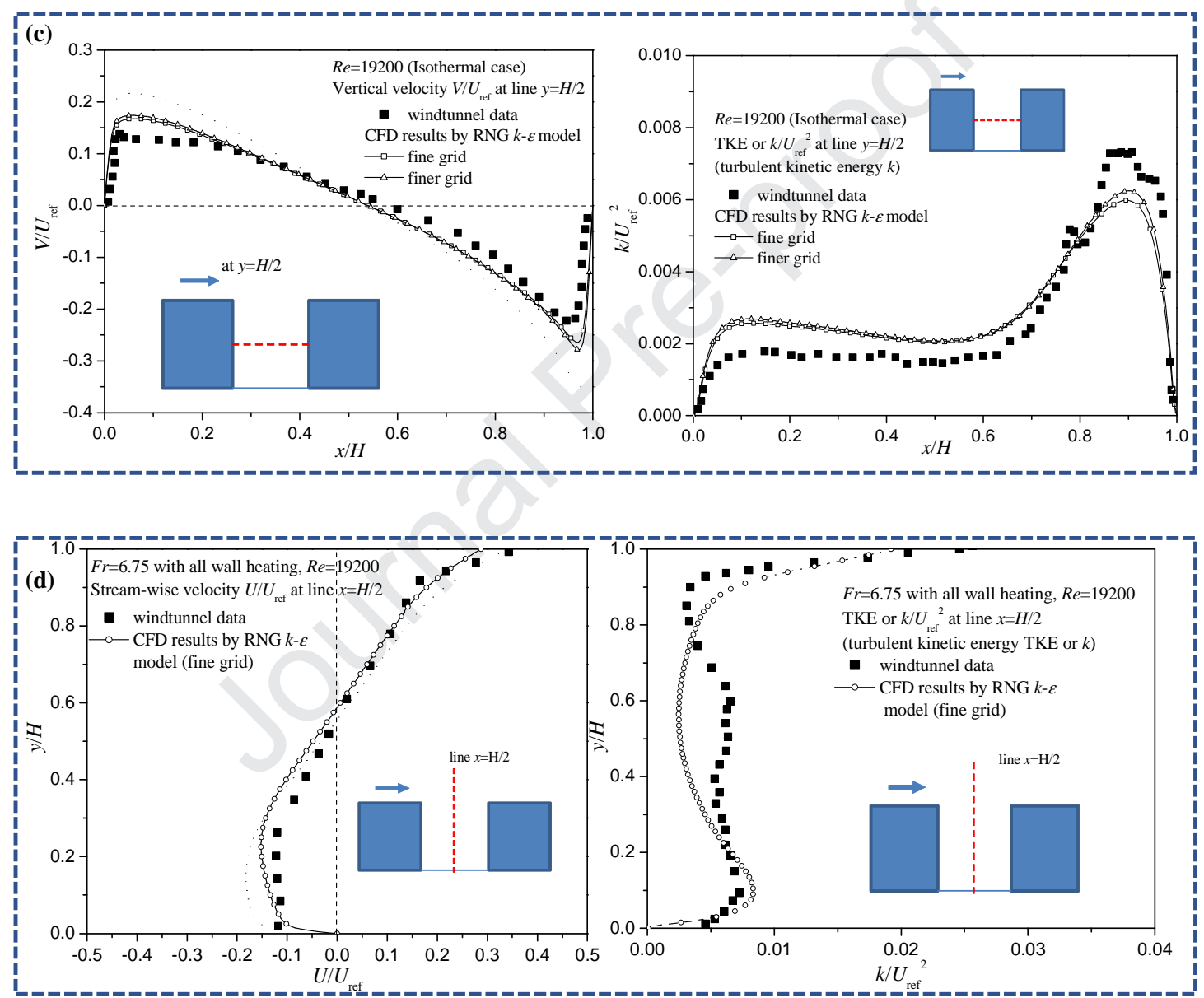

989 Fig. A1. CFD validation study with reference to the literature [45-46]: (a) Wind tunnel model

990 from Allegrini et al. [49] and CFD set-up. (b) Measured inlet profiles for the domain inlet

991 boundary conditions in the CFD simulations. Validation profiles obtained from CFD

992 simulations and wind tunnel data in (c) the isothermal case and (d) case with all wall heating.

993 Here $U_{\text {ref }}=1.45 \mathrm{~m} \mathrm{~s}^{-1}$ and $R e=19200$. 


\section{Appendix A2. Validation of pollutant dispersion in a 2D street canyon $(A R=1)$}

996

997

998

999

1000

1001

1002

1003

1004

1005

1006

1007

1008

1009

1010

1011

1012

1013

1014

1015

1016

Fig. A2 shows a sketch of the geometry and grid used for the validation of the pollutant dispersion in street canyons. The CFD results are compared with the wind tunnel data from Meroney et al. [22] which were performed in isothermal conditions. The experiments are conducted with 28 parallel 2D street canyons of a uniform building height $H$ $(H=W=B=60 \mathrm{~mm})$, considering the street canyons that completely spanning the width of the tunnel and are perpendicular to the wind direction. There are 20 street canyons upstream of the target street canyon and 8 downstream. A steady line source (also lying entirely across the width of the wind tunnel) is located in the target street canyon. Measurements are taken of the vertical profiles of tracer gas (ethane) concentration along the windward and leeward wall surfaces. Here the concentration is presented in dimensionless form as $K=C U H L / Q$, where $C$ is the measured ethane concentration, $U$ is wind velocity measured in the free stream at $0.50 \mathrm{~m}$ above the tunnel floor, and $L$ is line source length and $Q$ is the source emission rate.

In this CFD validation case, the $2 \mathrm{D}$ computational domain, the size of the street canyon and the boundary conditions are the same as in wind tunnel experiments. The total number of cells is 372.889 with a minimum grid size of $0.025 \mathrm{~mm}$ at the wall surfaces (Fig. A2). To validate the numerical simulations, Fig. A2 shows vertical profiles of $K$ at the leeward-side and windward-side walls of the target street canyon with $V_{\text {in }}=3 \mathrm{~m} \mathrm{~s}^{-1}$ (at domain inlet). As expected $K$ at the leeward wall is much higher than that at the windward wall; and $K$ along the windward wall is almost constant, while that along the leeward wall decreases with increasing height. Overall, the results show that calculated $K$ is in good agreement with the wind tunnel data, even though slightly over-estimated. 


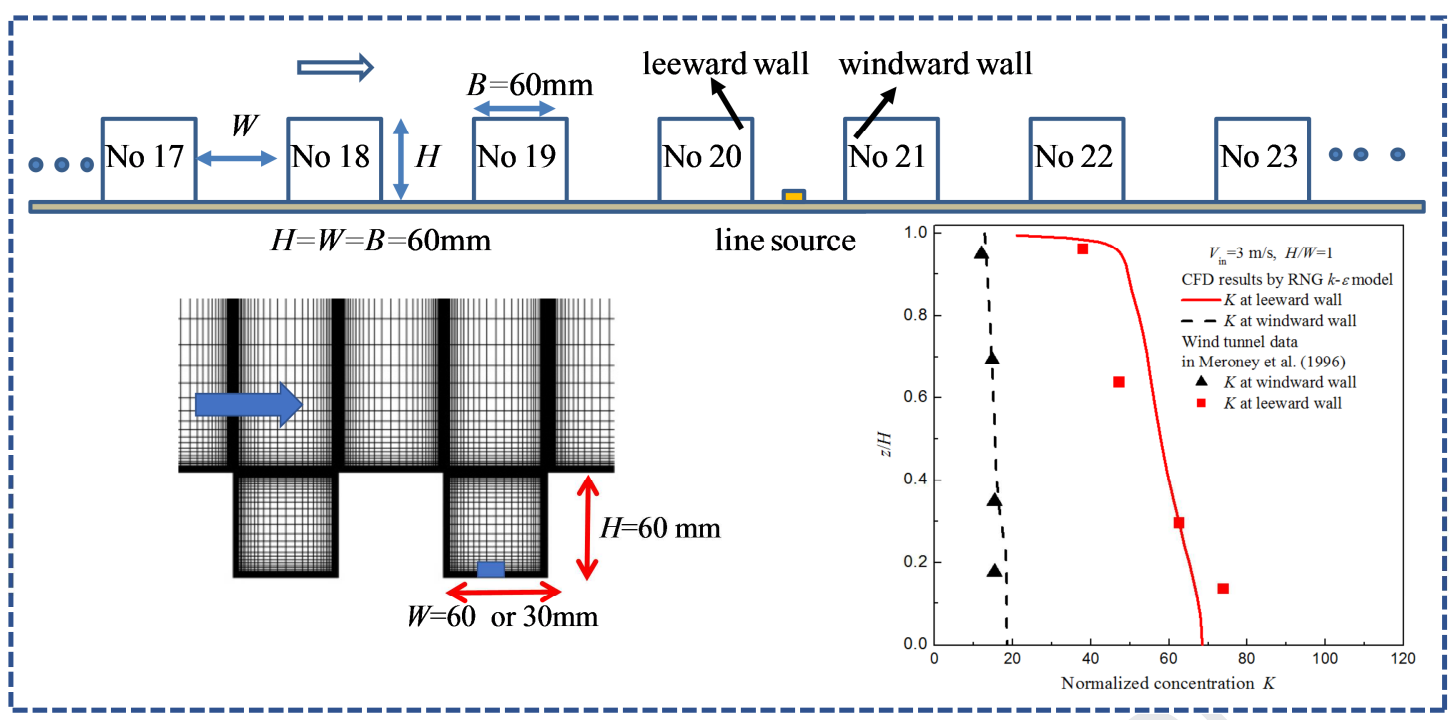

1019 Fig. A2. CFD set-up, grid arrangement and validation profiles of the normalized

1020 concentration $K$ along the windward wall and leeward wall evaluated using wind tunnel data

1021 from Meroney et al. [22].

1022

1023 Appendix A3. Flow pattern validation for a 2D deep street canyon by scaled outdoor experiments $(A R=2$ and $3, H=1.2 \mathrm{~m})$

As displayed in Fig. A3a, ,Zhang et al. [9] carried out the scale-model outdoor field experiments to study the flow patterns in a 2D street canyon with various street aspect ratios

1027 (building height $H=1.2 \mathrm{~m} ; A R=1,2,3$; street length $L=12.5 \mathrm{~m}>10 H$ ). The velocity and turbulence distribution, radiation fluxes, and the wall and air temperature in and above the idealized street canyons were measured by 3D ultrasonic anemometers (Gill windmaster, $\mathrm{UK}$ ), four component radiometers (CRN4), thermal couples (K type) and temperature sensors

1031 (iButton thermochron data logger).

For each type of streets canyon $(A R=1,2,3)$, five 3D ultrasonic anemometers were used 1033 to measure the temporal profiles of velocity components ( $U x, U y$ and $U z)$ and turbulence at 1034 five heights $(z=0.3,0.6,0.9,1.44,2.4 \mathrm{~m})$ (Fig. A3b). The sampling rate of the ultrasonic 
anemometer was $20 \mathrm{~Hz}$. Here, Fig. A3c and A3d only presents some examples of the

experimental profiles of stream-wise velocity ( $U x$, i.e. perpendicular to the street axis) in

1037

street canyon with $A R=3$ when the Reynolds number is large $\left(R e \sim 1.5 \times 10^{5} \gg 11000\right.$ as $U_{r e f} \sim 2.0$

$1038 \mathrm{~m} \mathrm{~s}^{-1}$ ) and the buoyancy force is relatively weak (i.e. Froude number $F_{r}=\frac{U_{r e f}^{2}}{g H\left(\Delta T / T_{r e f}\right)}$

$1039 \sim 10.2$ as $\Delta T=10 \mathrm{~K}$ and $U_{r e f}=2.0 \mathrm{~m} \mathrm{~s}^{-1}$ ). Thus, the wind-driven dynamic force dominates

1040 urban airflows and the Reynolds number independence requirement is fully satisfied.

1041 Obviously, Fig. A3c and A3d show that, regardless of the aspect ratio being 3 or 2, the

1042 stream-wise velocities at $z=0.25 \mathrm{H}$ in the field measurements are positive while those at

$1043 z=0.75 H$ and $z=2 \mathrm{H}$ are negative, confirming that there is only one main vortex in such $2 \mathrm{D}$

1044 deep street canyons ( $A R=2$ and 3). This is consistent with the flow patterns of the CFD results

1045 in subsection 3.1. The more detailed experimental setups can be found in Zhang et al. [9].

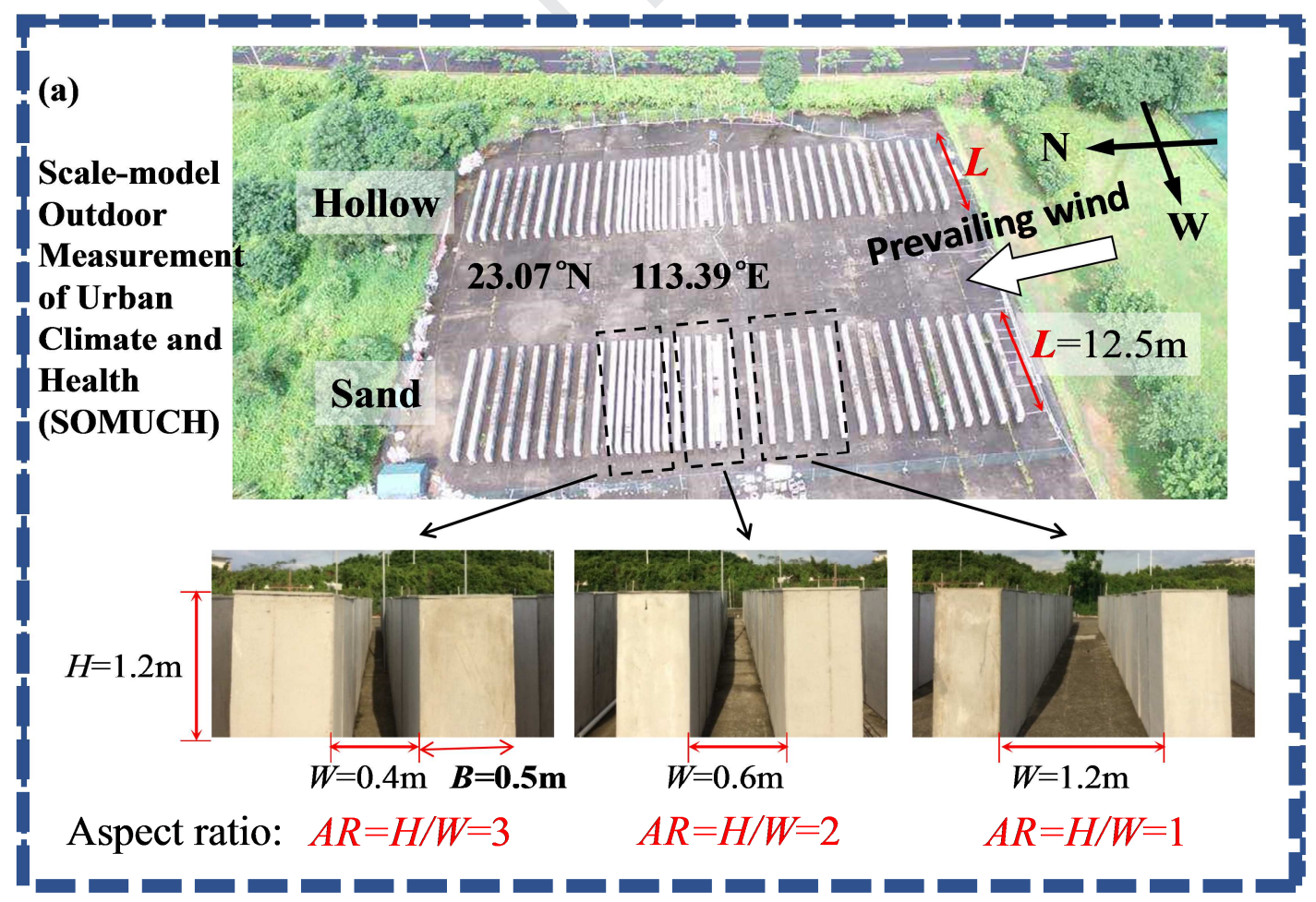


(b)

Location of

$z=240 \mathrm{~cm}$

3D supersonic anemometer

$z=144 \mathrm{~cm}$
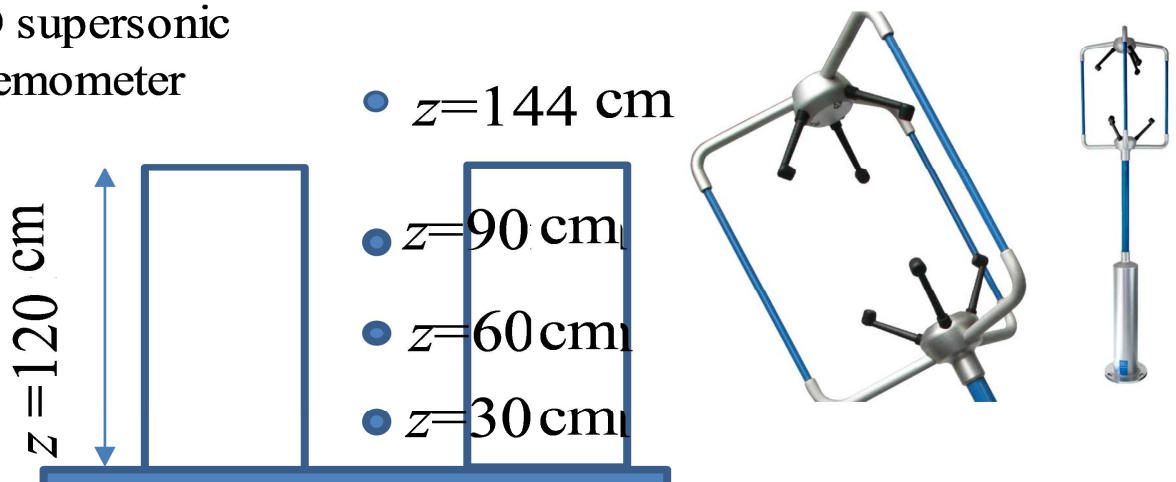

1047

1048

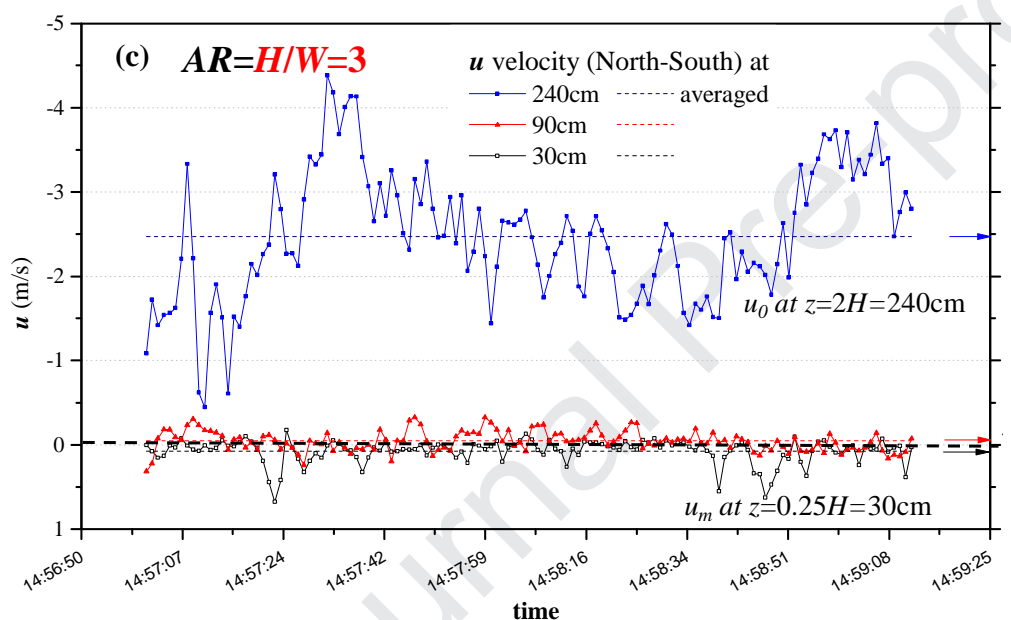

$-\boldsymbol{u}=$ south wind
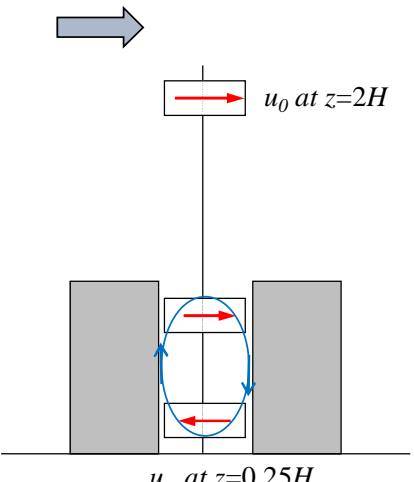

time

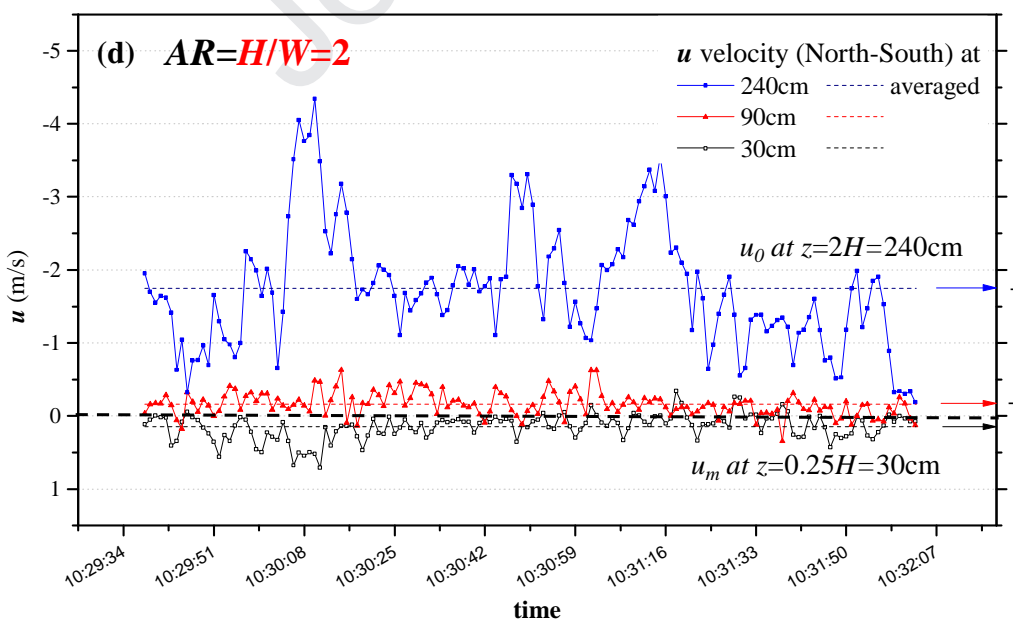

$-\boldsymbol{u}=$ south wind
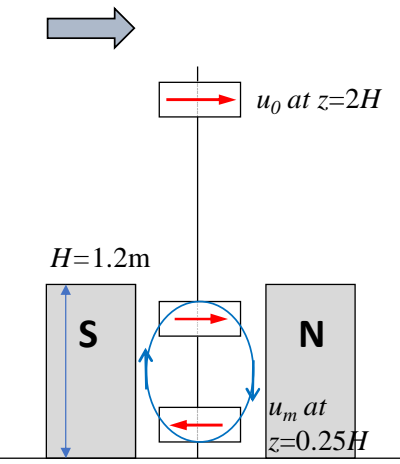

1049 
(e) Ventilation and turbulence, solar shading and trapping

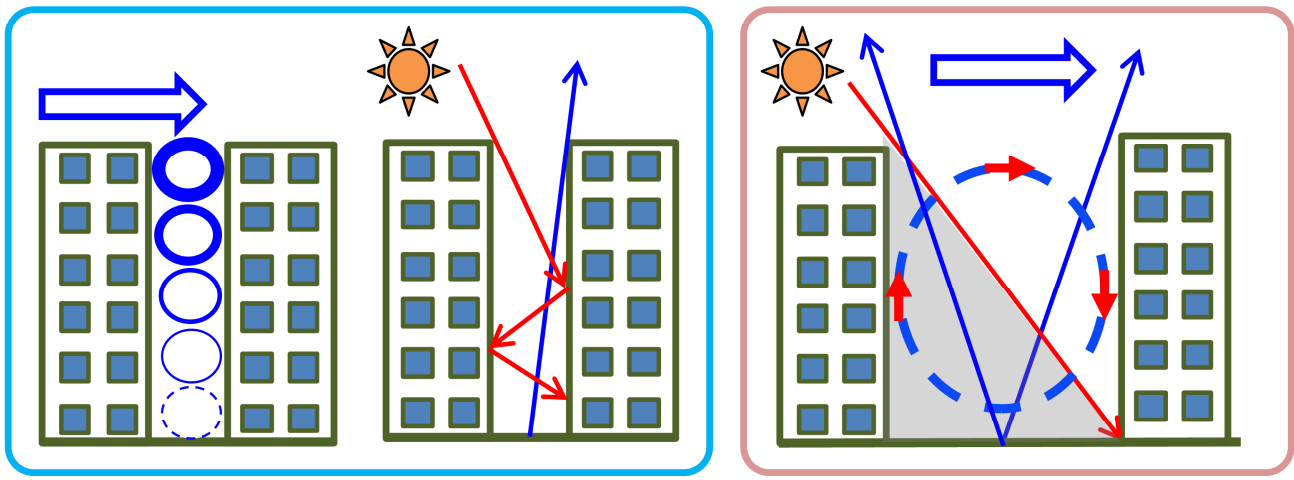

Scaled outdoor experiments by coupling turbulence and radiation, or integrating indoor and outdoor environment
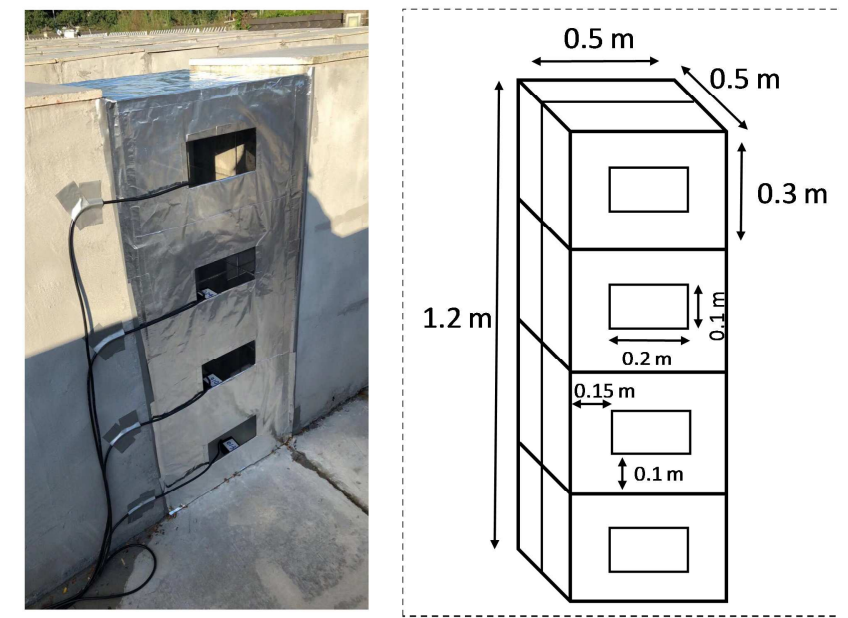

1051 Fig. A3. (a) View of the scale-model outdoor experiment on street canyon models with $A R=1$,

2 and 3. (b) Schematic of the 3D ultrasonic anemometer locations. Example profiles of the stream-wise velocity $\left(U_{x}, \mathrm{~m} \mathrm{~s}^{-1}\right)$ in a street canyon with (c) $A R=3$ and (d) $A R=2$. (e) Future studies of coupling urban turbulence and radiation processes, or integrating indoor and outdoor.

Appendix 4 Scaled CFD flow validation estimated by the wind tunnel data $(A R=2.4$, 
1061 A4a) with the working section of $11 \mathrm{~m}$ long, $3 \mathrm{~m}$ wide, $1.5 \mathrm{~m}$ tall. There are 25 rows of

1062 building models and 24 street canyons from upstream toward downstream with a

1063 perpendicular approaching wind to street axis. The key parameters of wind-tunnel-scale

1064 street canyon models (Fig. A4a) include building height $(H=12 \mathrm{~cm})$, building width $(B=5 \mathrm{~cm})$,

1065 street width $(W=5 \mathrm{~cm})$, i.e. street aspect ratio is $A R=2.4$. The span-wise length is

$1066 L=1.25 \mathrm{~m}>10 \mathrm{H}$ which ensure the $2 \mathrm{D}$ flow characteristics in street canyons. The measured

1067 vertical profiles along street centreline in the $12^{\text {th }}$ and $13^{\text {th }}$ street canyon are almost the same

1068 (not shown here), verifying that the flow in the $12^{\text {th }}$ street canyon is fully-developed. The

1069 background wind speed at the boundary-layer height in far upstream free flow is $U_{\text {ref }}=13 \mathrm{~m}$

$1070 \mathrm{~s}^{-1}$, attaining the reference $R e$ numbers of $10^{5}\left(\operatorname{Re}=U_{r e f} H / v\right)$. Stream-wise $(U x)$ and vertical

$1071(U z)$ velocity components along the street centreline of Line $\mathrm{F}$ in the $12^{\text {th }}$ street canyon are

1072 measured by Laser Doppler Anemometry (LDA) System (Fig. A4a). The measured vertical

1073 profiles of stream-wise velocity $(U x)$ and turbulent kinetic energy $(k)$ along the centreline

1074 above building roof center (Line E) are displayed in Fig. A4b which will be adopted to

1075 provide boundary condition at the domain inlet of CFD simulations.

1076 In the CFD validation case, the scaled street canyon models $(H=1.2 \mathrm{~m}, W=B=0.5 \mathrm{~m})$ are 1077 investigated with the scale ratio of 10:1 to the wind-tunnel-scale models $(H=12 \mathrm{~cm})$. Ansys

1078 Fluent with the RNG $k-\varepsilon$ model is used to perform CFD simulations. The domain inlet

1079 boundary condition is provided by the vertical profiles of stream-wise velocity and turbulent

1080 quantities measured at Line E (Fig. A4b) with a spatial scale ratio of 10:1. To perform a grid

1081 independence study, two kinds of grid arrangements are tested with the minimum grid sizes

1082 of $0.5 \mathrm{~mm}$ (fine grid) and $1 \mathrm{~mm}$ (medium grid) in which grid numbers are 1383668 and

1083807024 respectively (Fig. A4c).

1084 Then Fig. A4d compares CFD results and wind tunnel data by the stream-wise velocity

$1085(U x)$ profiles at Line F. Obviously, the predicted wind profiles with the fine and medium 
1086 grids are nearly the same and both agree well with wind tunnel data. As a result, the RNG $k-\varepsilon$

1087 model is reliable in simulating flow in 2D idealized street canyons with $A R=2.4(\operatorname{Re} \gg 11000)$

1088 and the medium grid arrangement is recommended in the case studies. The CFD validation

1089 study also confirms that there is only one main vortex as $A R=2.4$ (Fig. A4d) if the Re-

1090 number-independence requirement is satisfied.

(a)

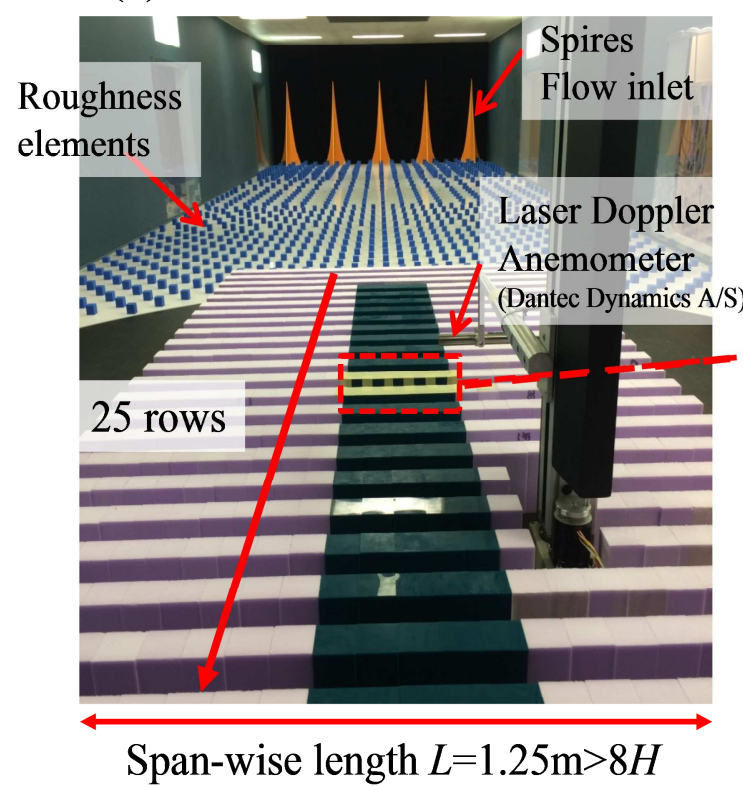

1091

1092

1093
Scaled model in CFD: $H=1.2 \mathrm{~m}, W=B=0.5 \mathrm{~m}$

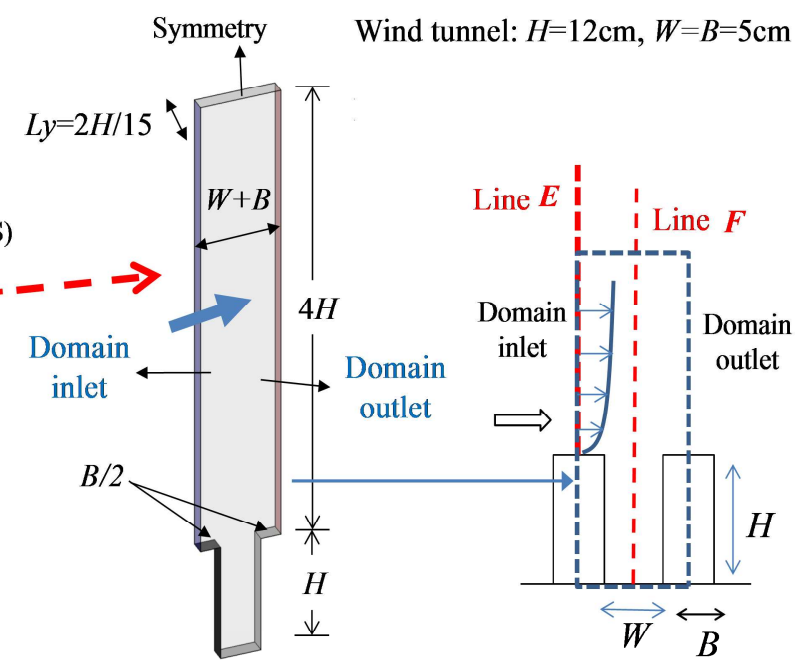

(a)

(b) $\quad U x$ and $k$ along Line $\mathrm{E}$ above building roof $(y>H=0.12 \mathrm{~m})$ in wind tunnel experiment
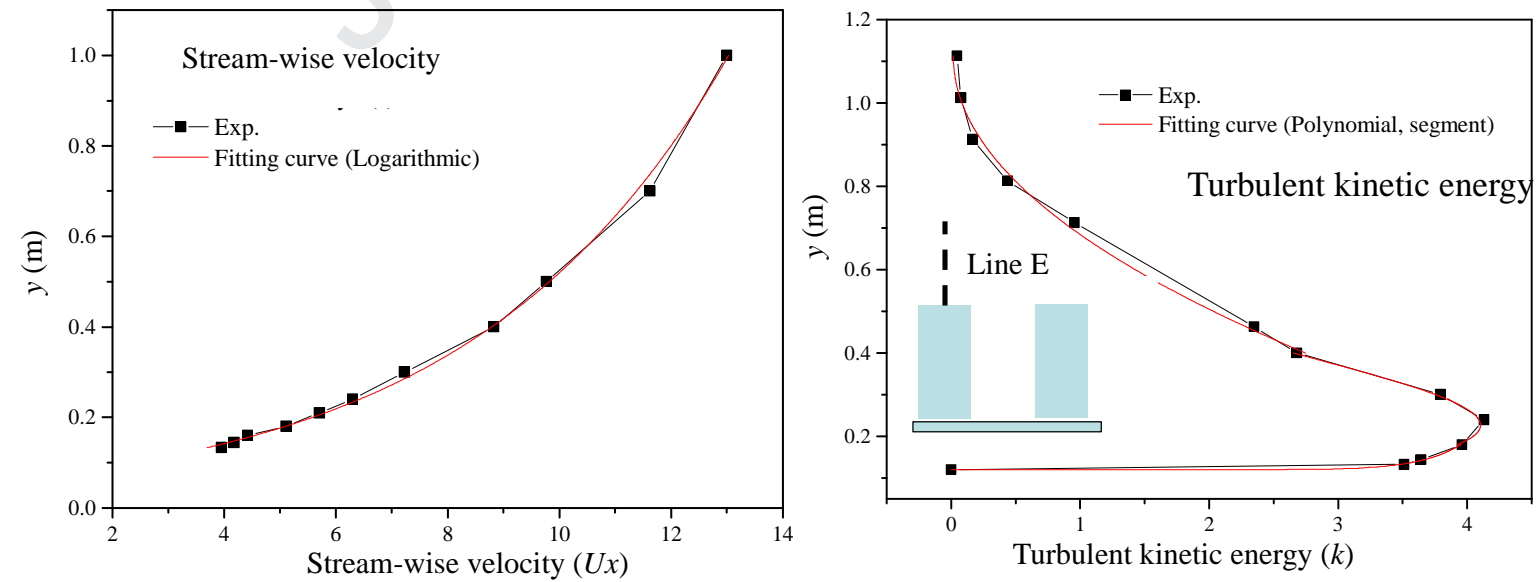

(b) 
(c) Medium grid arrangement with
minimum grid size of $1 \mathrm{~mm}$

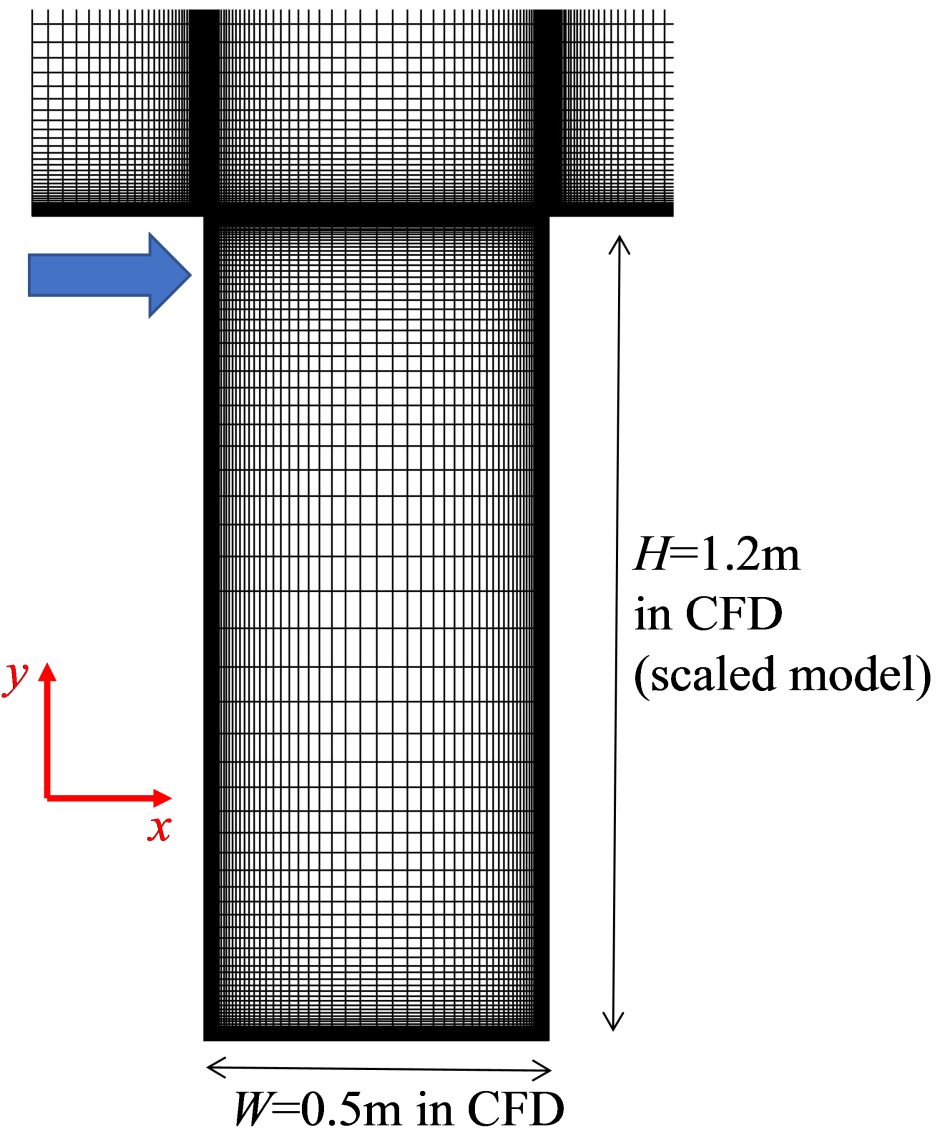

1096

(c)

1097 

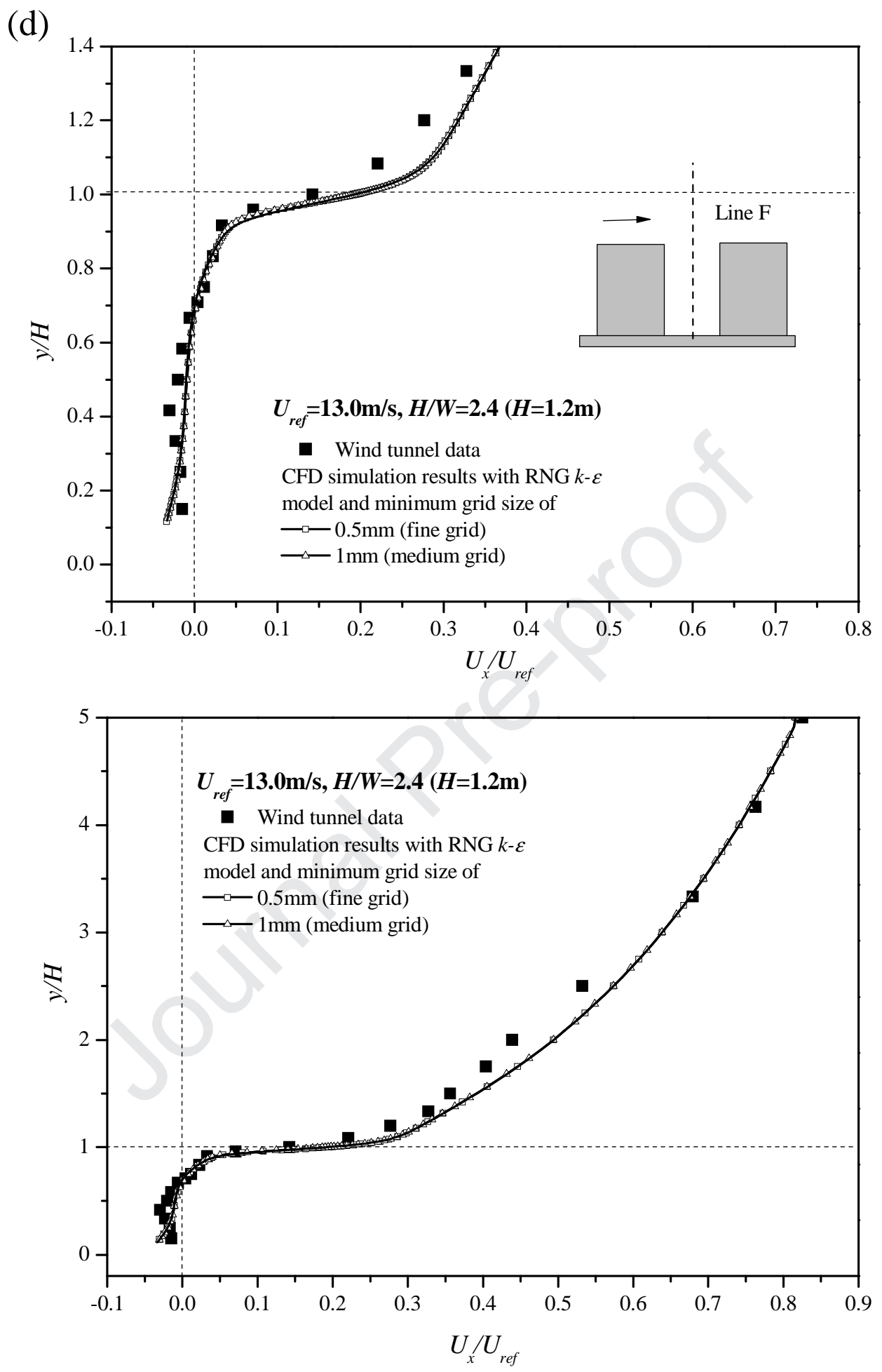

1099 Fig. A4. (a) Wind tunnel experiments in 2D street canyon with $\left(A R=2.4, H=12 \mathrm{~cm}, U_{\text {ref }}=13 \mathrm{~m}\right.$

$\left.1100 \mathrm{~s}^{-1}, W=B=5 \mathrm{~cm}, R e \sim 10^{5}\right)$ and the CFD setups in scaled model $\left(A R=2.4, H=1.2 \mathrm{~m}, U_{\text {ref }}=13 \mathrm{~m} \mathrm{~s}^{-1}\right.$,

$1101 W=B=0.5 \mathrm{~m}, \operatorname{Re} 10^{6}$ ); (b) The measured vertical profiles of the stream-wise velocity $(U x)$ and

1102 the turbulent kinetic energy $(k)$ along the centreline above building roof center (Line E). 
1103 (c)The medium grid arrangements in the scaled CFD simulations. (d) The CFD validation and

1104 grid-independence study in the scaled CFD simulation with the stream-wise velocity profiles

1105 along the Line $\mathrm{F}\left(H=1.2 \mathrm{~m}, R e \sim 10^{6}\right)$. 

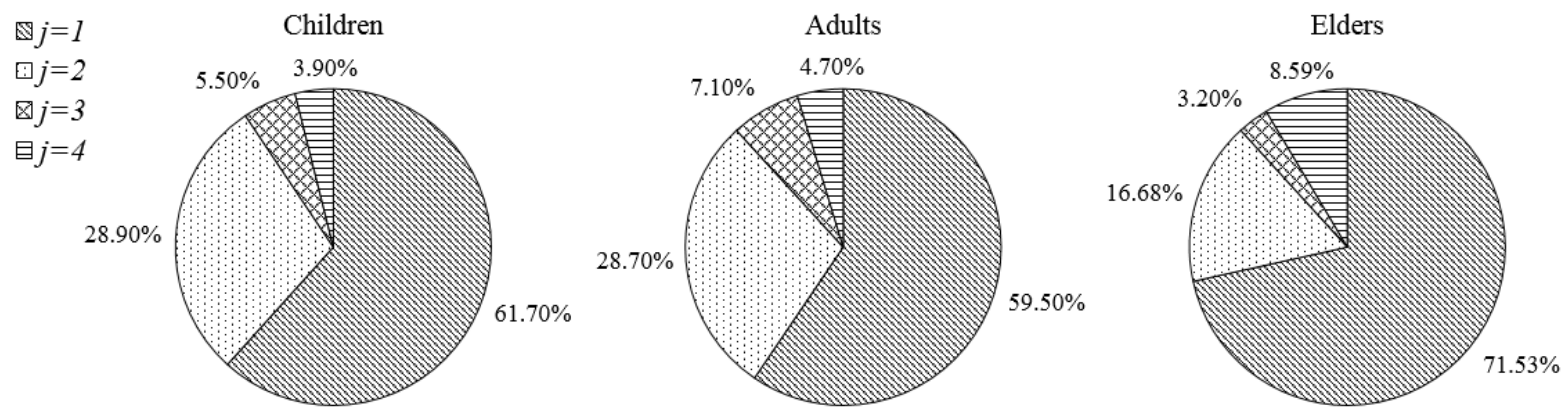

Figure 1. Breathing rate and time patterns for various age groups and microenvironments [64-65]. 


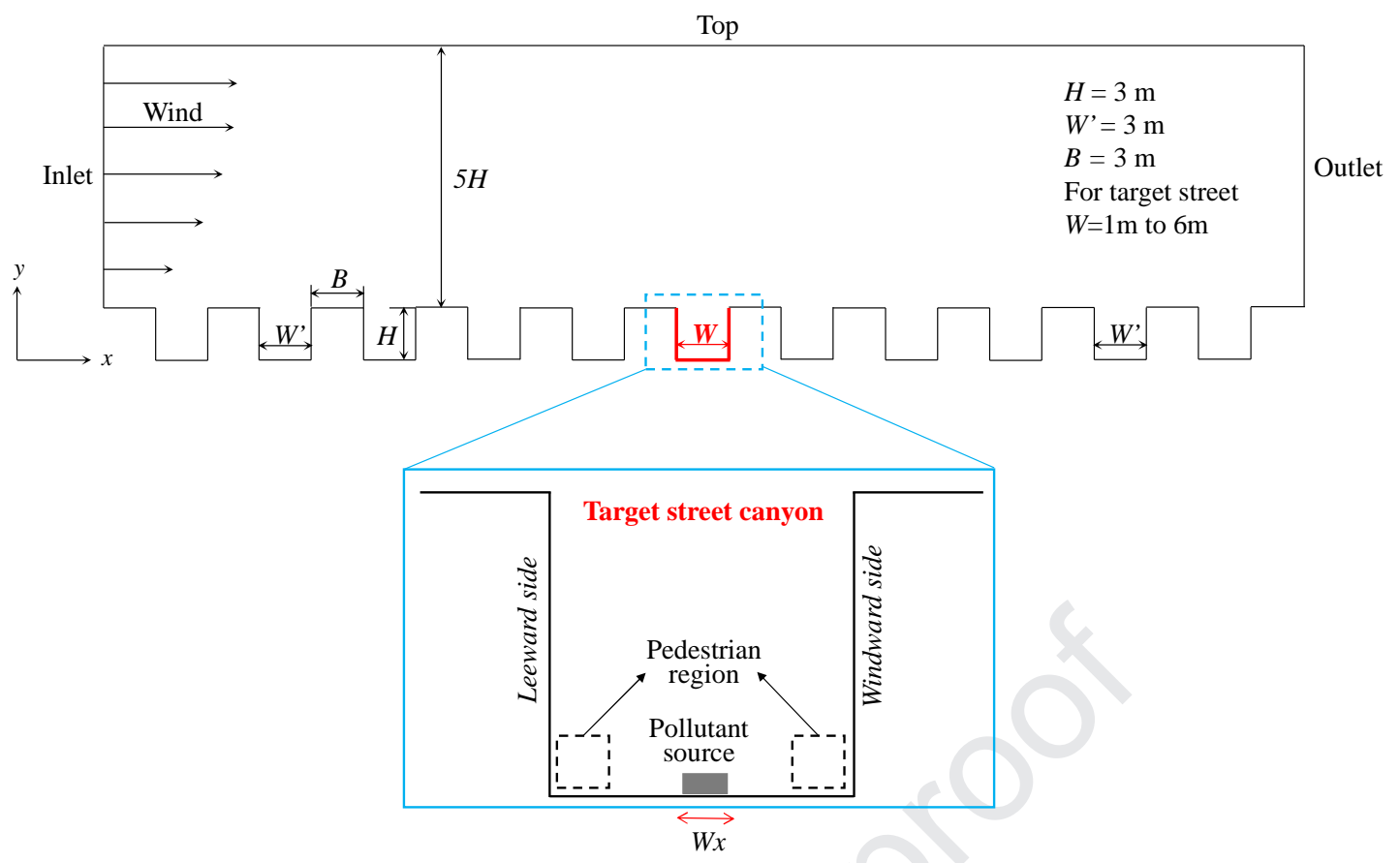

(a)

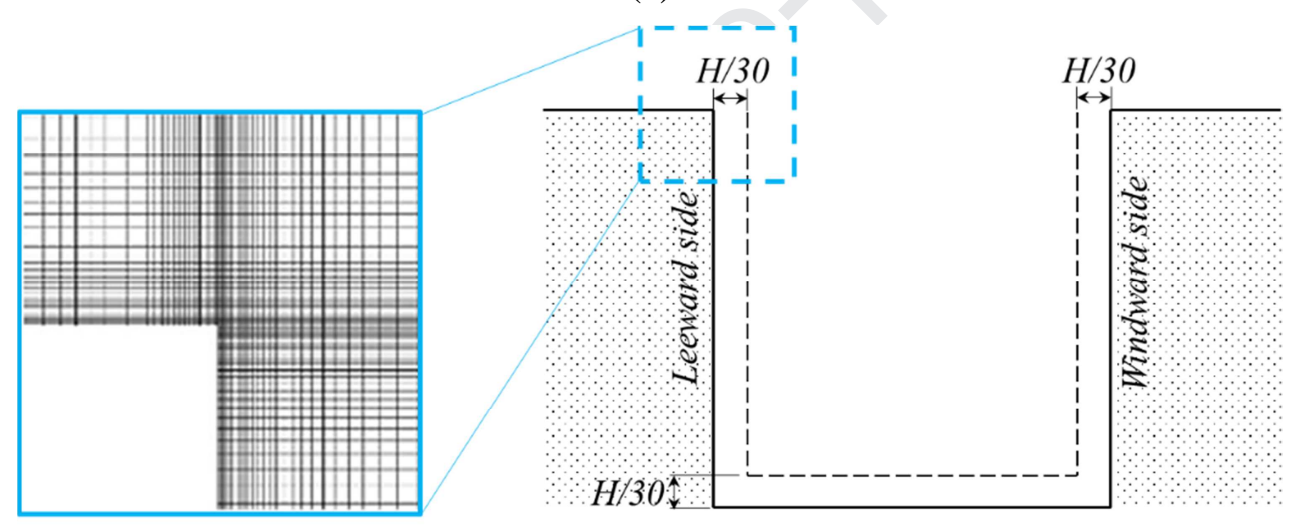

(b)

Figure 2. (a) Dimensions of the simulated street canyon model in CFD. (b) The grid arrangement of 2D CFD simulations. 


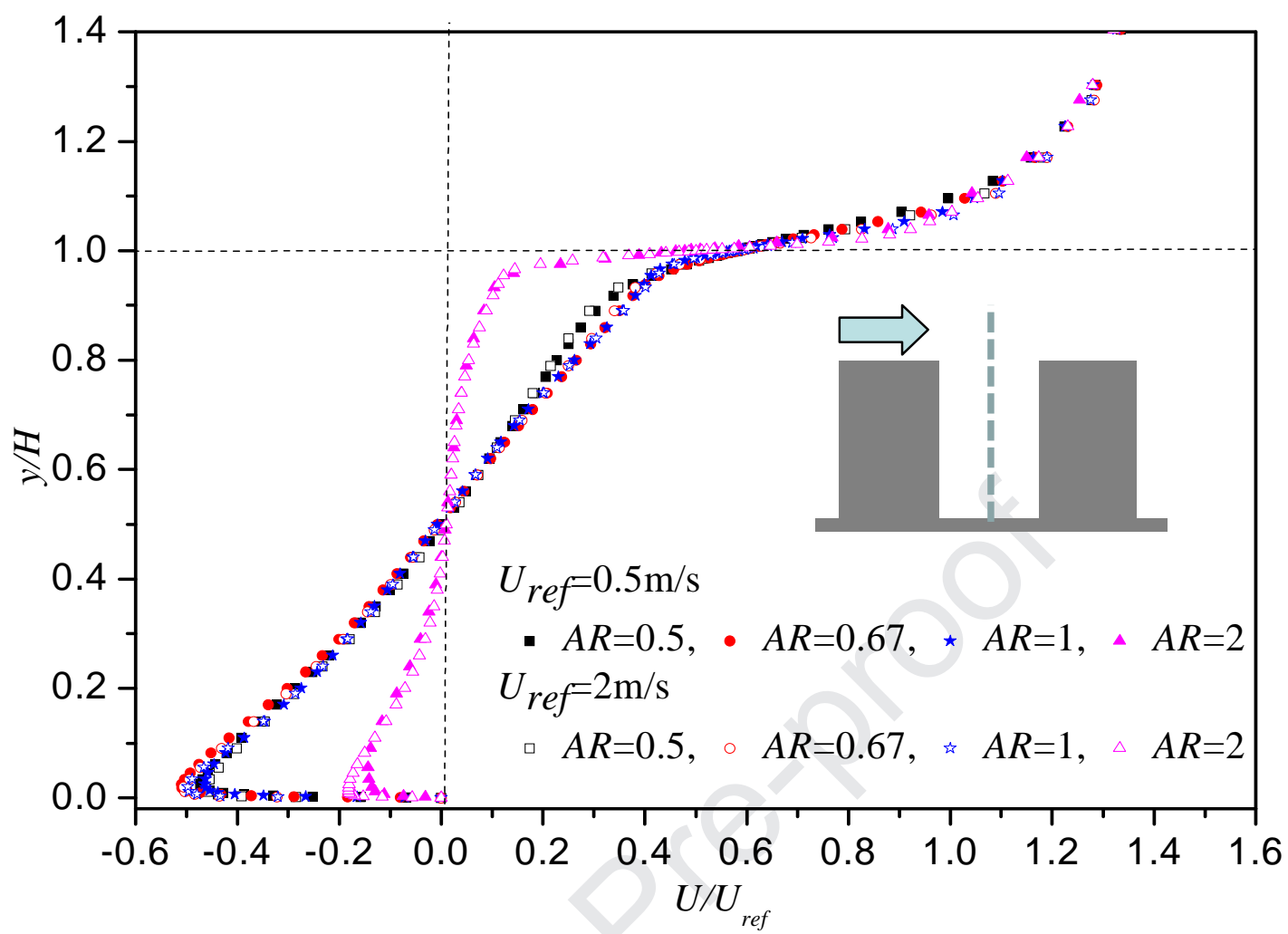

(a)

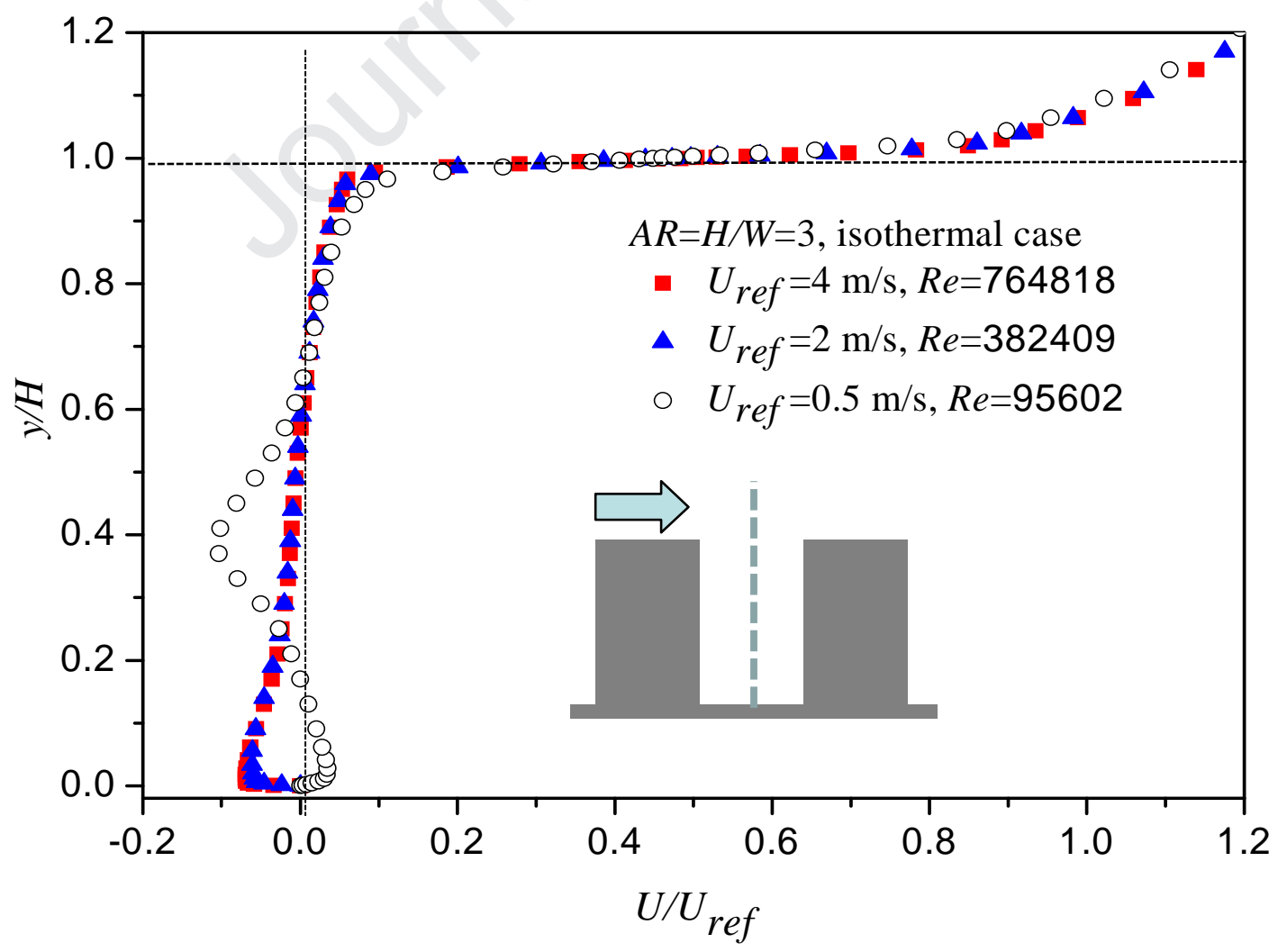


(b)
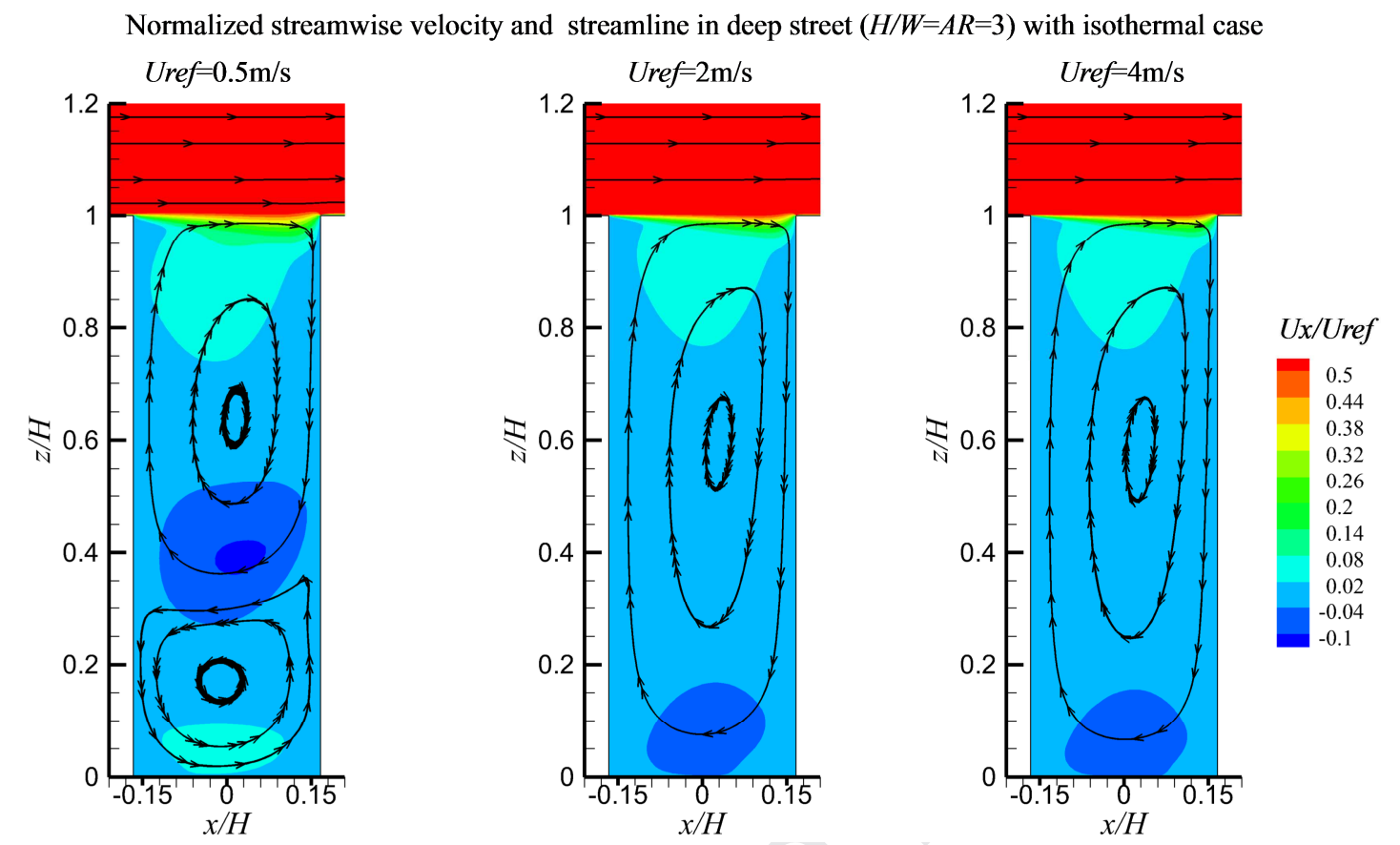

(c)

Figure 3 Normalized stream-wise velocity along the street centerline in isothermal cases with (a) background wind speed of $U_{\text {ref }}=0.5 \mathrm{~m} \mathrm{~s}^{-1}$ and $2 \mathrm{~m} \mathrm{~s}^{-1}(R e=95602$ and 382409) as $A R=H / W=0.5,0.67,1$, and 2, (b) $U_{\text {ref }}=0.5 \mathrm{~m} \mathrm{~s}^{-1}, 2 \mathrm{~m} \mathrm{~s}^{-1}, 4 \mathrm{~m} \mathrm{~s}^{-1}$ where $A R=3$ ( $R e=95602,382409,764818)$. (c) Normalized streamwise velocity and streamline in deep street $(H / W=A R=3)$ in isothermal case. 
(a) $\quad \mathrm{N}[3,2]$
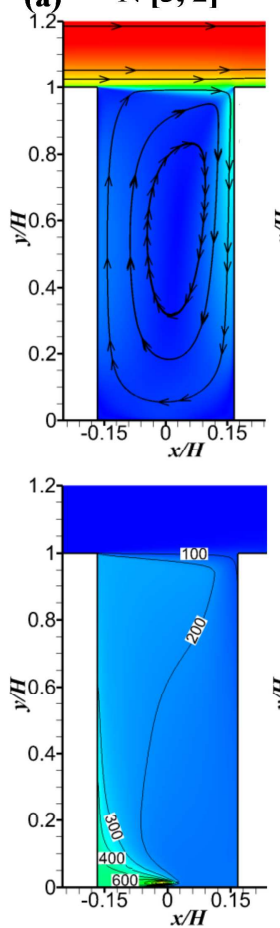

(b)

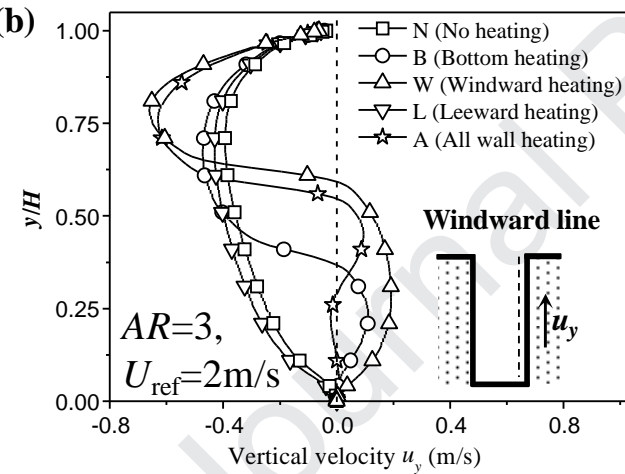

(d)

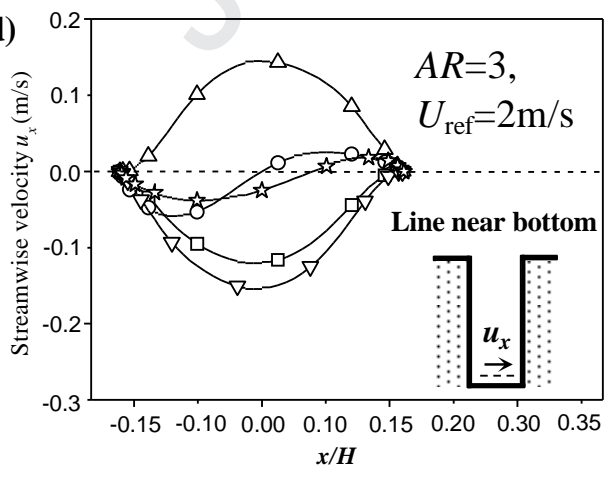

B [3, 2]
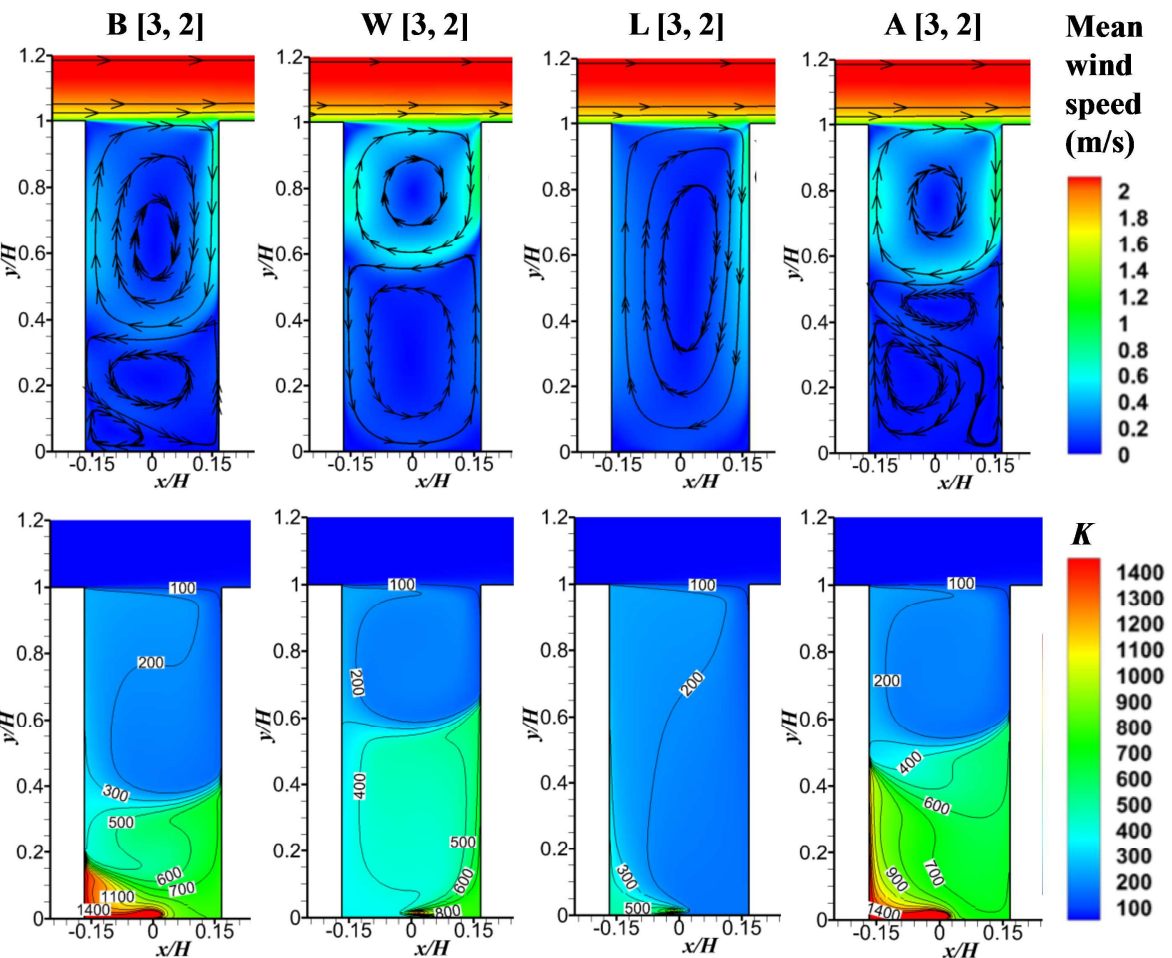

(c)

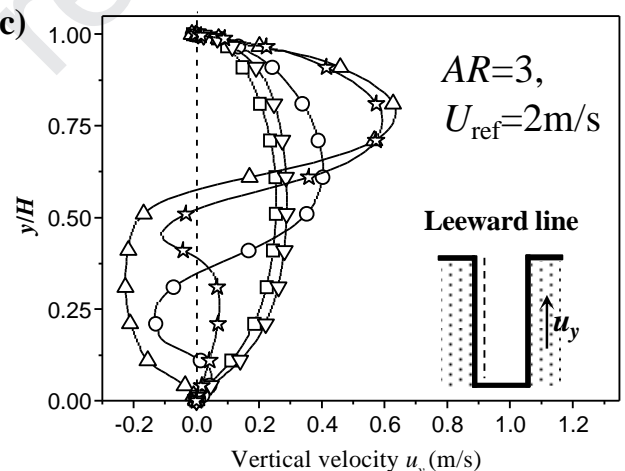

(e)

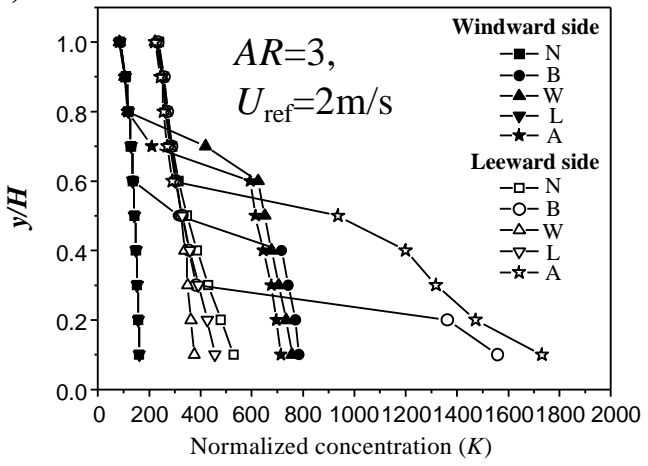

Figure 4. In cases where $A R=3, U_{\mathrm{ref}}=2.0 \mathrm{~m} \mathrm{~s}^{-1}$ : (a) Contour of the mean wind speed (m $\mathrm{s}^{-1}$ ) and normalized concentration $K$, Vertical velocity $\boldsymbol{u}_{\boldsymbol{y}}$ along (b) the windward line and (c) the leeward line, (d) streamwise velocity $\boldsymbol{u}_{\boldsymbol{x}}$ along the bottom line. (e) Spatial average $\langle K\rangle$ along windward wall and leeward wall. 
(a) $\quad \mathrm{N}[2,2]$
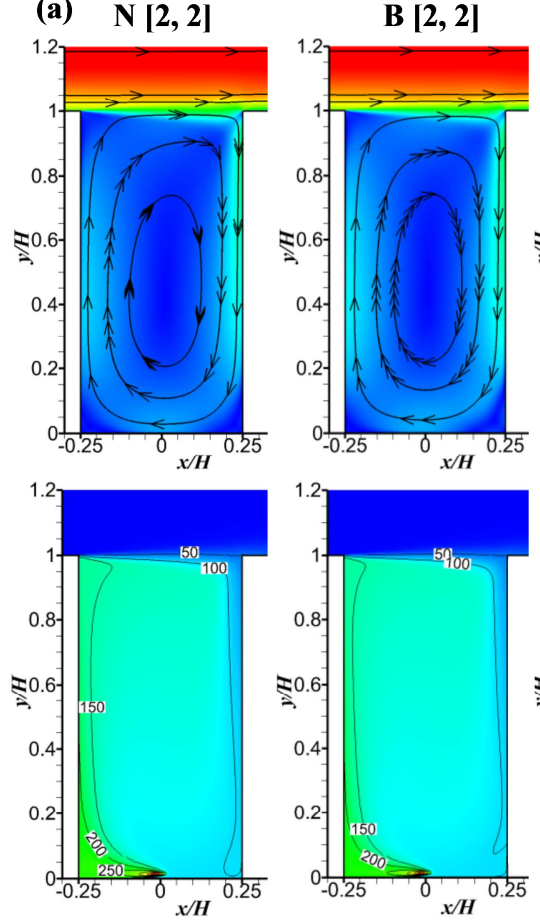

$\mathrm{W}[2,2]$
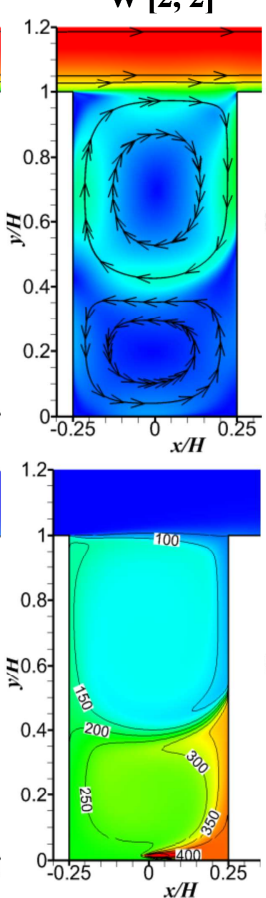

$\mathbf{L}[2,2]$
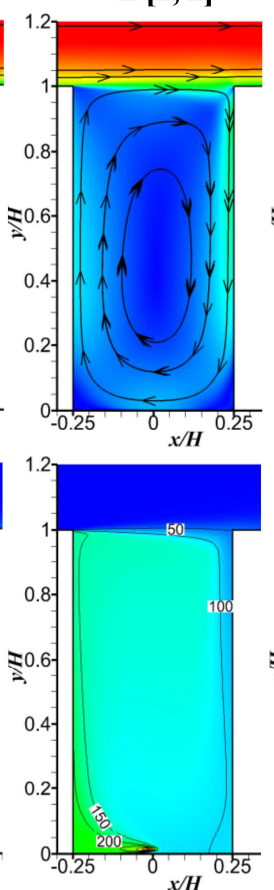

$\mathbf{A}[2,2]$
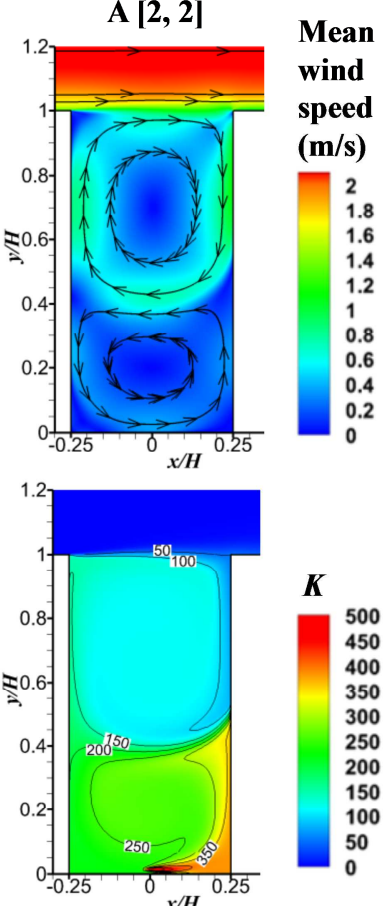
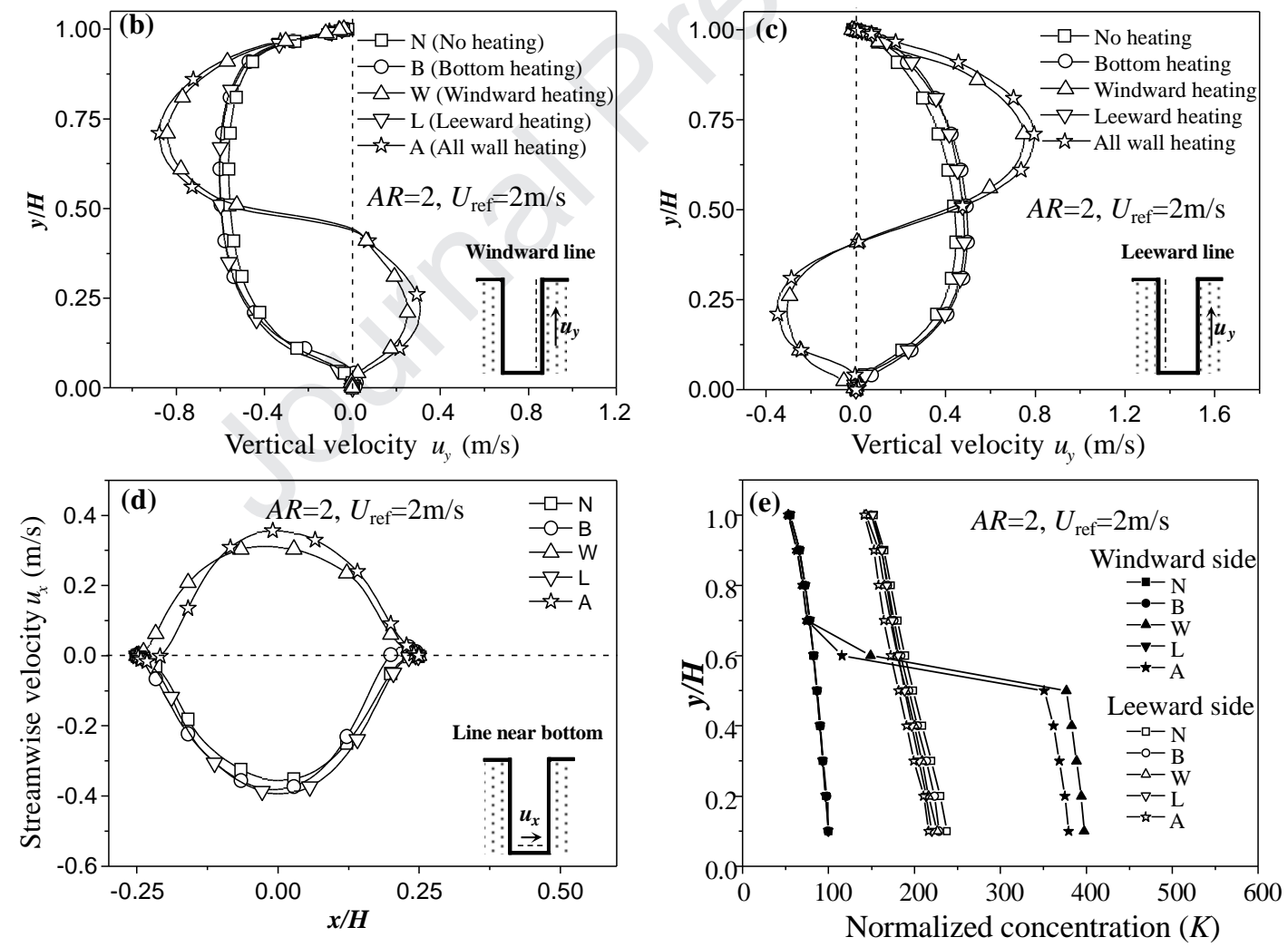

Figure 5. In cases where $A R=2, U_{\text {ref }}=2.0 \mathrm{~m} \mathrm{~s}^{-1}$ : (a) Contour of the mean wind speed ( $\mathrm{m}$ $\mathrm{s}^{-1}$ ) and $K ; u_{y}$ along (b) the windward line and (c) the leeward line; (d) $u_{x}$ along the bottom line; (e) $\langle K\rangle$ at the windward and leeward walls. 

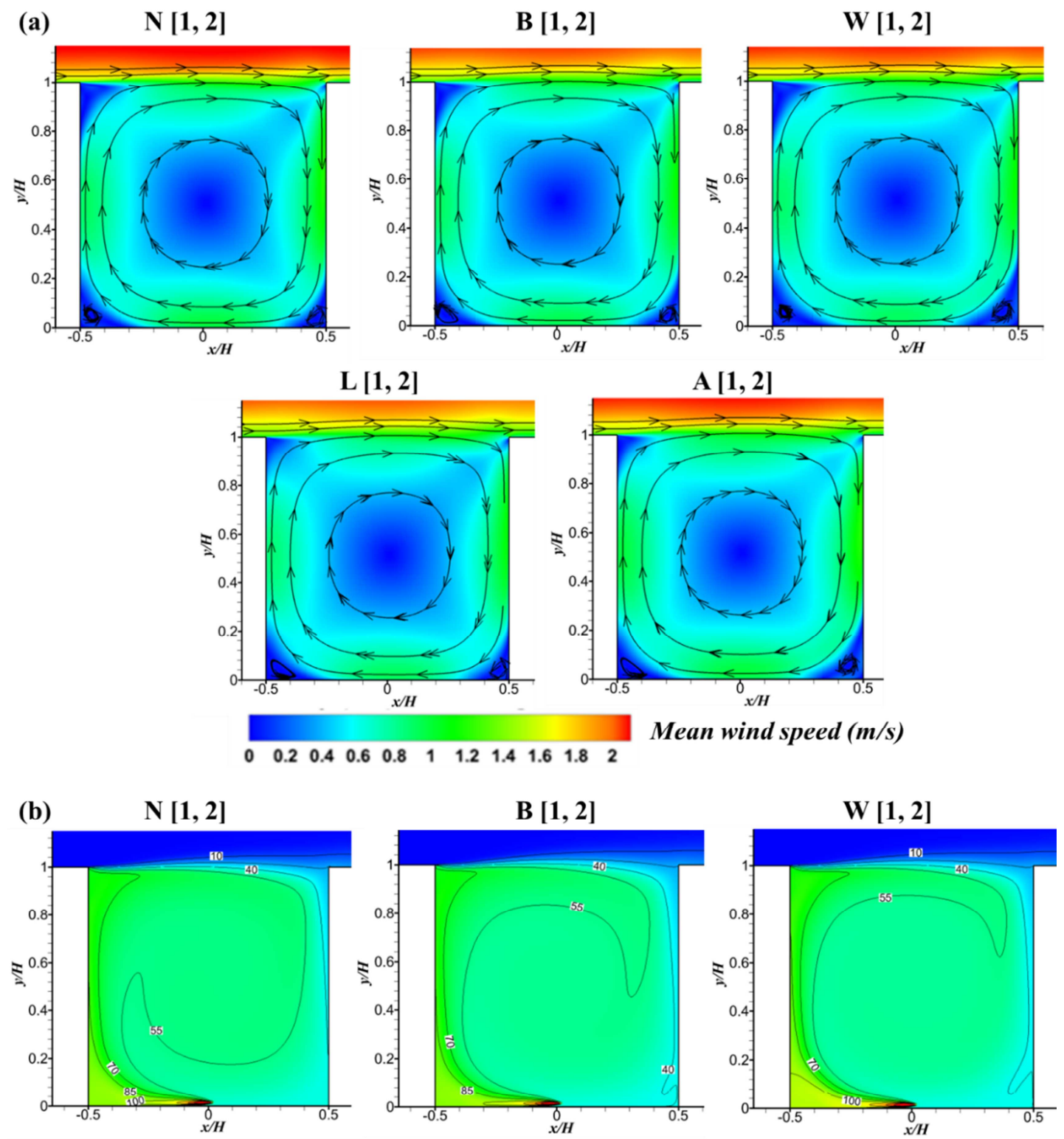

$L[1,2]$

A [1, 2]
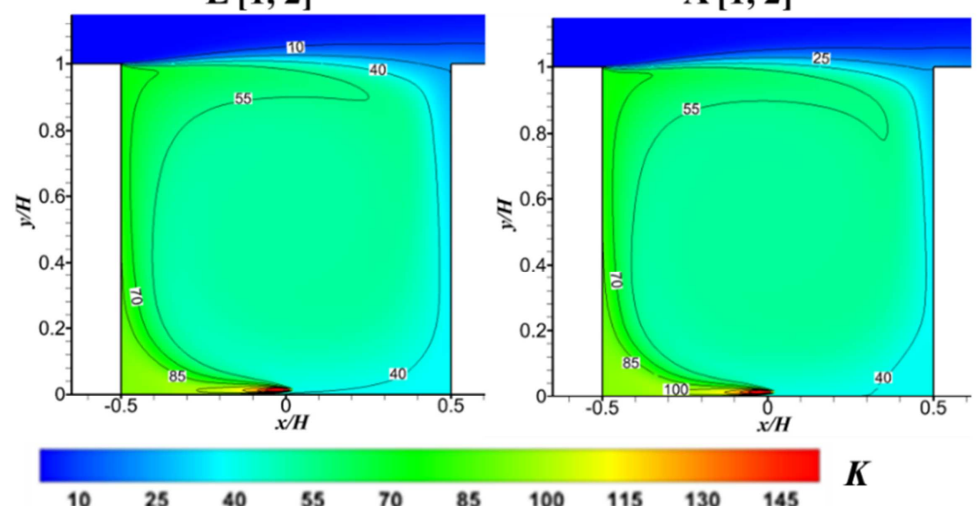

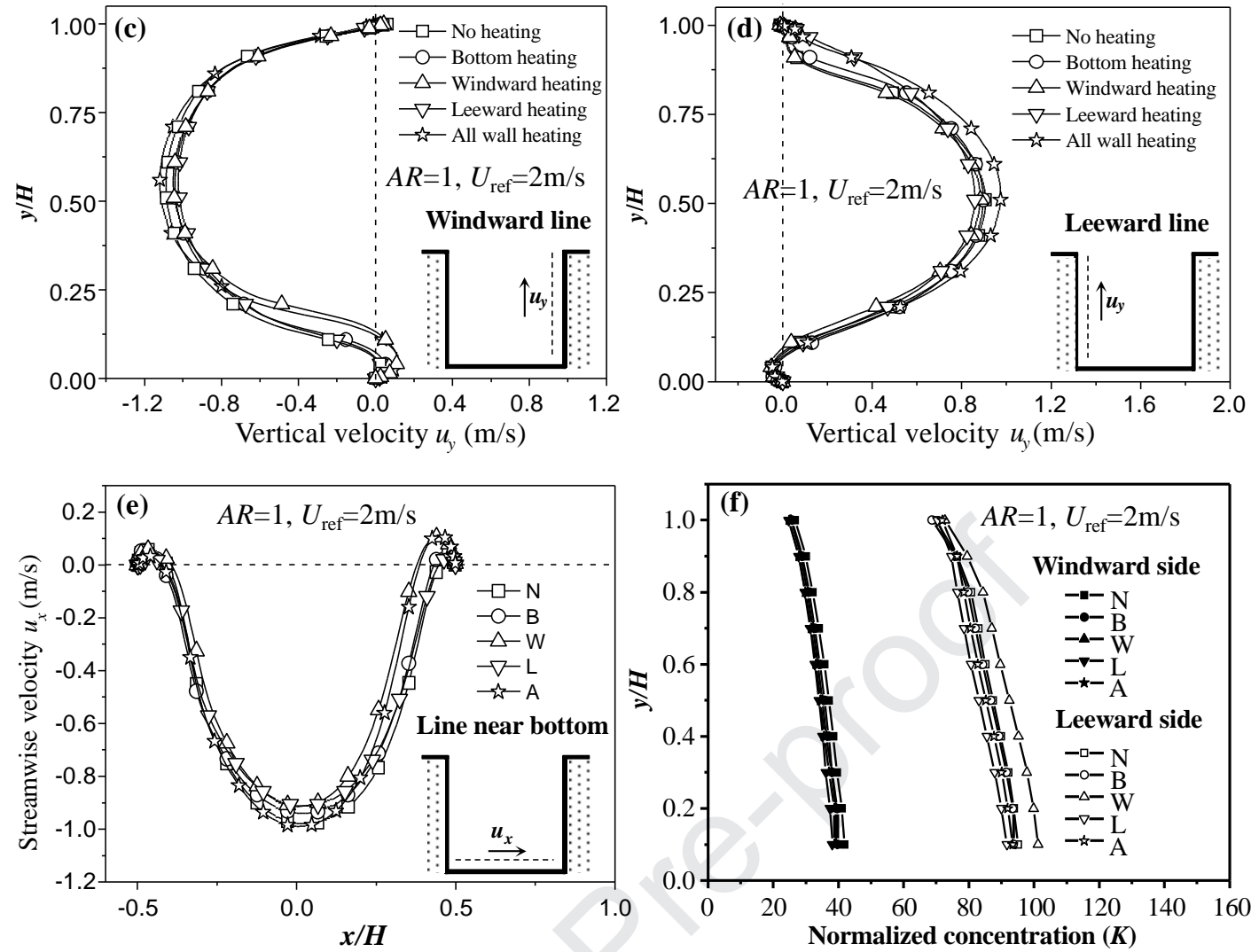

Figure 6. In cases where $A R=1$ and $U_{\text {ref }}=2 \mathrm{~m} \mathrm{~s}^{-1}$ : Contour of (a) the mean wind speed $\left(\mathrm{m} \mathrm{s}^{-1}\right)$ and $K . u_{y}$ along (c) the windward line and (d) the leeward line; (e) $u_{x}$ along the bottom line; (f) $\langle K\rangle$ at the windward and leeward walls. 


\section{(a) $\mathrm{N}[3,0.5]$}
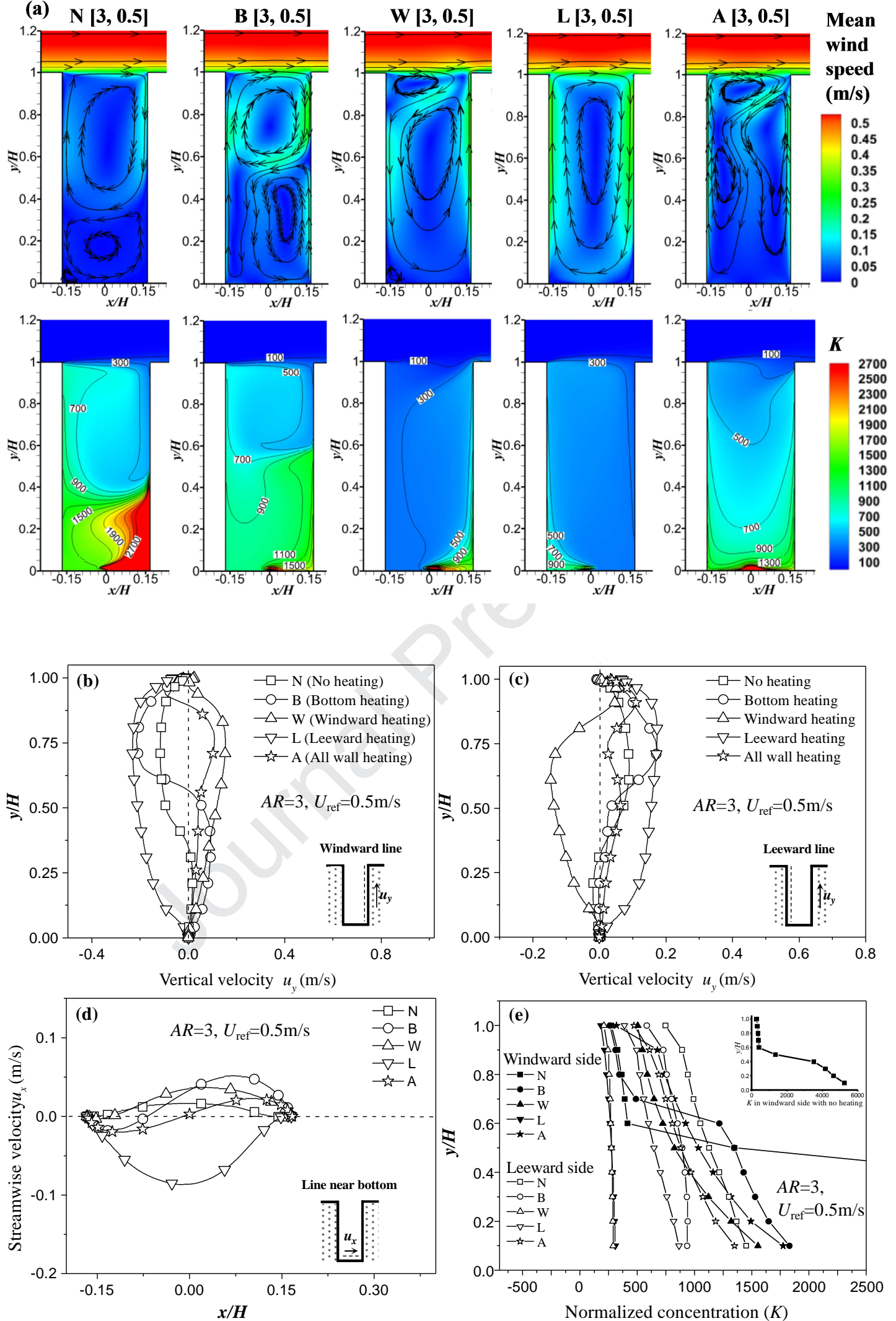

Figure 7. In cases where $A R=3$ and $U_{r e f}=0.5 \mathrm{~m} \mathrm{~s}^{-1}$ : (a) Contour of the mean wind speed $\left(\mathrm{m} \mathrm{s}^{-1}\right)$ and $K . u_{y}$ along (b) the windward line and (c) the leeward line; (d) $u_{x}$ along the bottom line; (e) $\langle K\rangle$ at the windward and leeward walls. 
(a) $\mathrm{N}[2,0.5]$
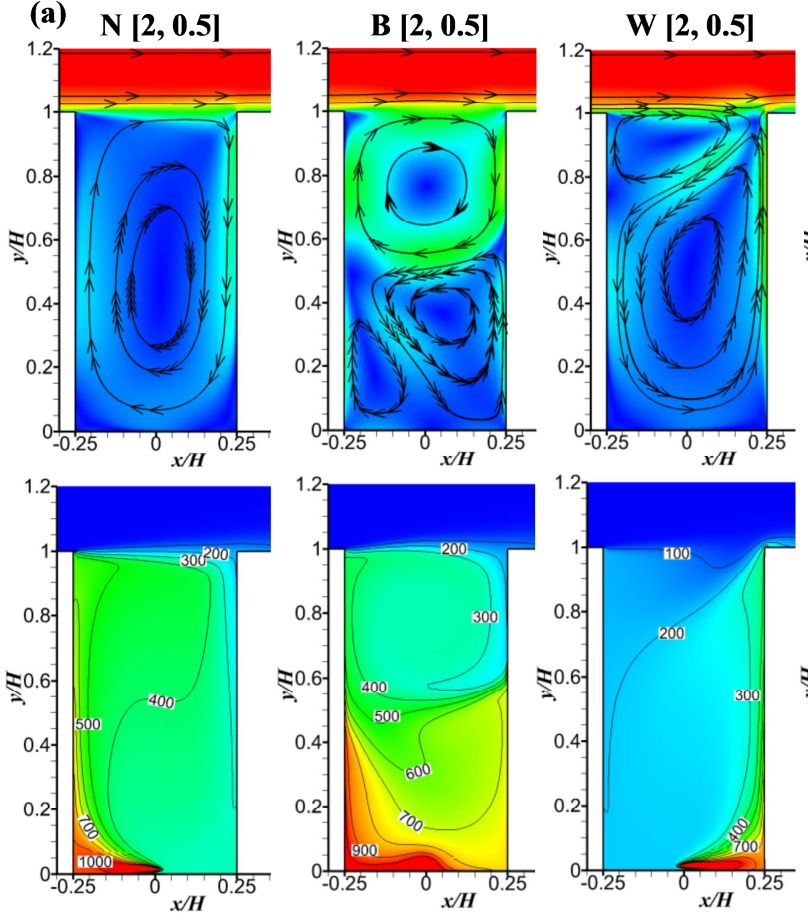

$\mathbf{L}[2, \mathbf{0 . 5}]$
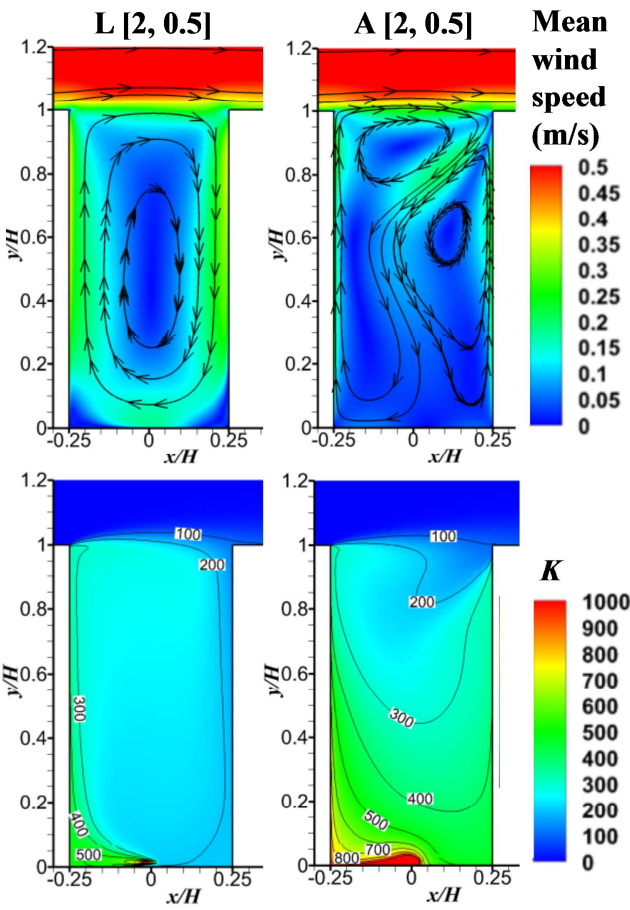
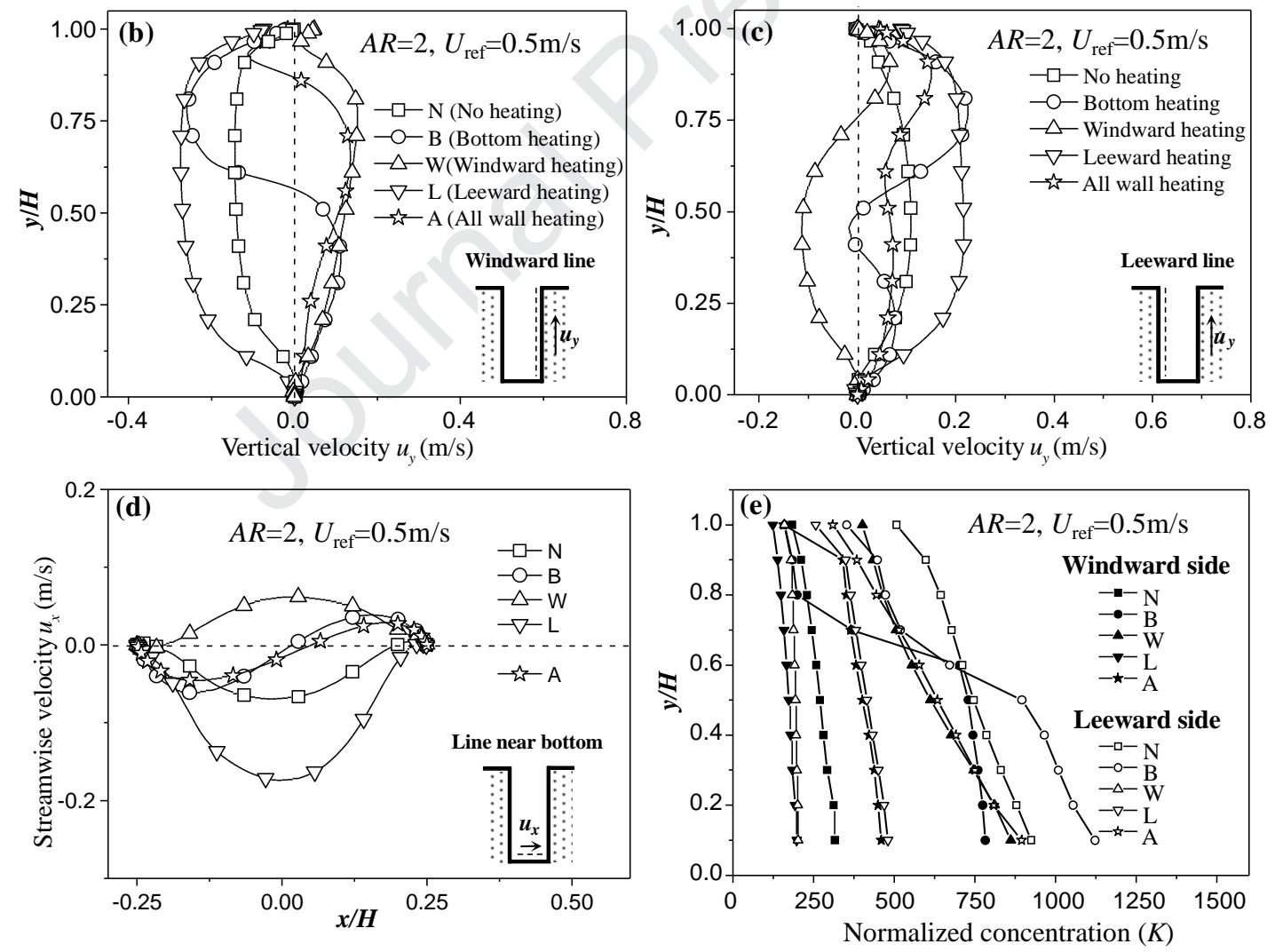

Figure 8. In cases where $A R=2$ and $U_{r e f}=0.5 \mathrm{~m} \mathrm{~s}^{-1}$ : (a) Contour maps of the mean wind speed $\left(\mathrm{m} \mathrm{s}^{-1}\right)$ and $K . u_{y}$ along (b) the windward line and (c) the leeward line; (d) $u_{x}$ along the bottom line; (e) $\langle K\rangle$ at the windward and leeward walls. 

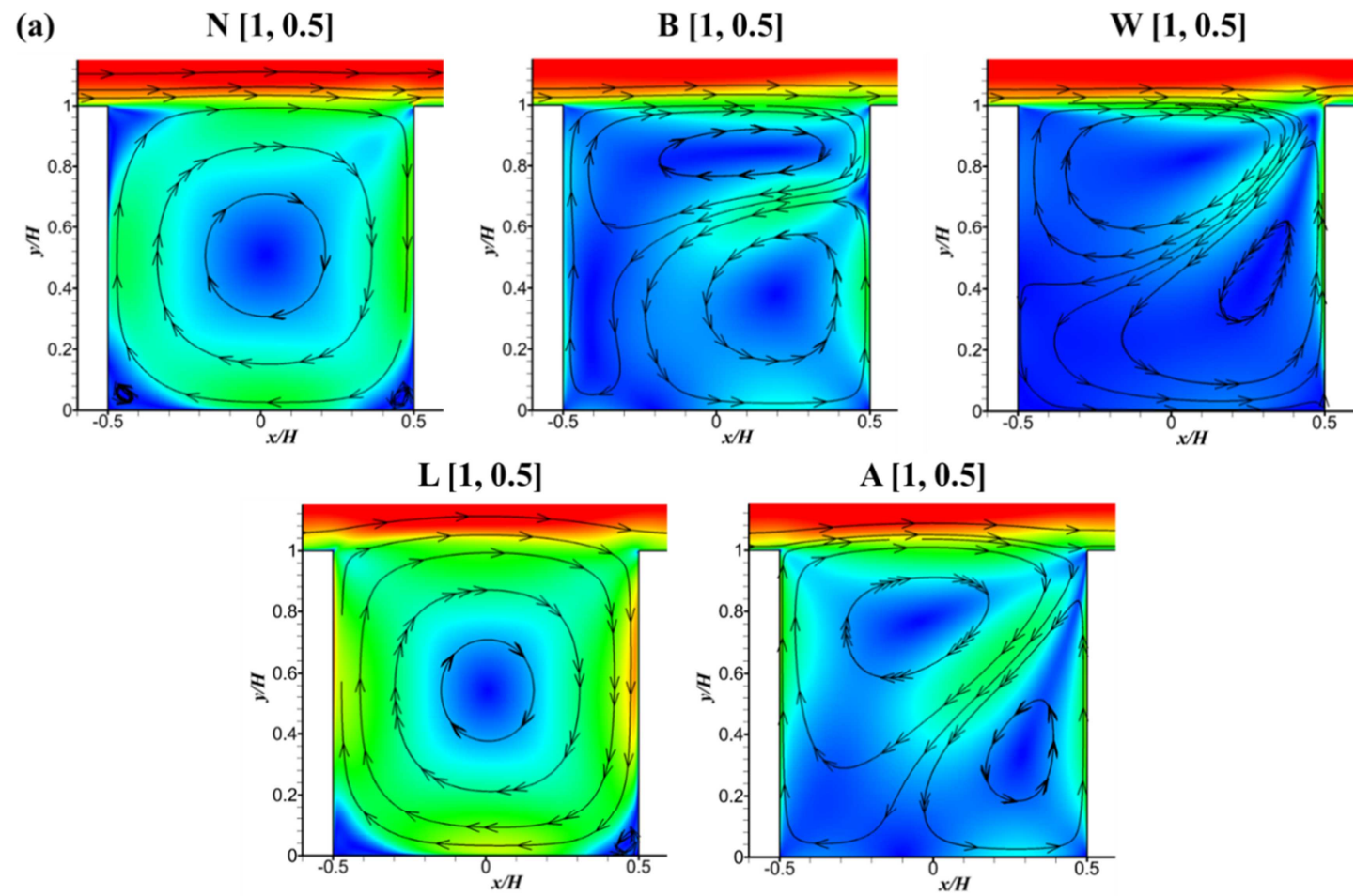

$\begin{array}{lllllllllll}0 & 0.05 & 0.1 & 0.15 & 0.2 & 0.25 & 0.3 & 0.35 & 0.4 & 0.45 & 0.5\end{array}$

Mean wind speed $(\mathrm{m} / \mathrm{s})$

(b) $\quad \mathrm{N}[1,0.5]$

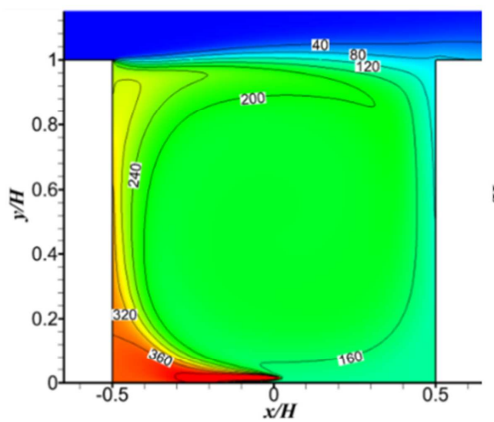

$L[1,0.5]$
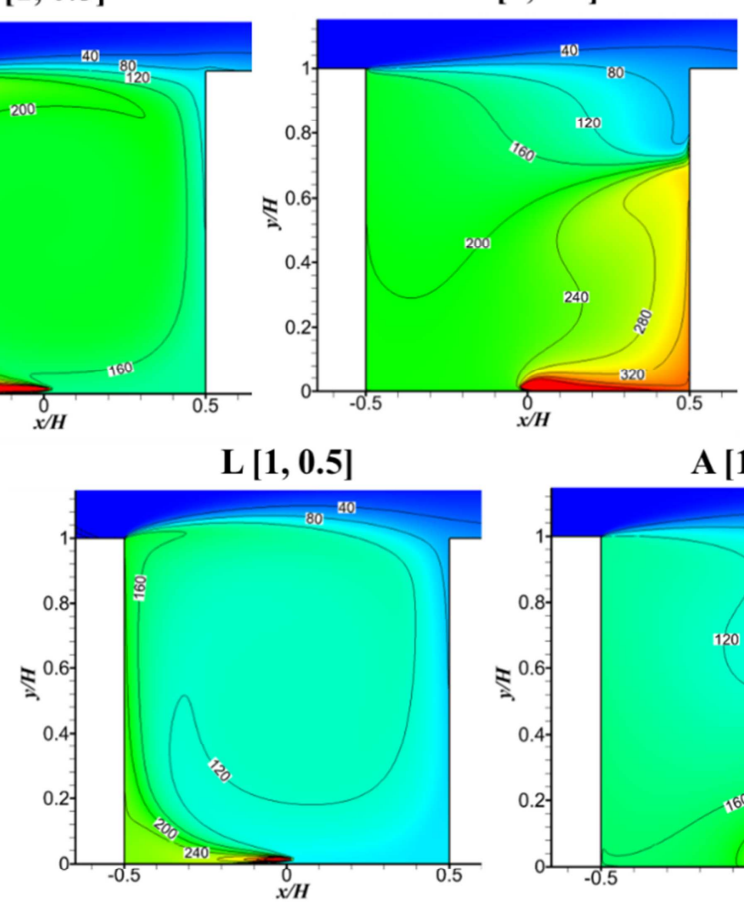

$A[\mathbf{1 , 0 . 5}]$
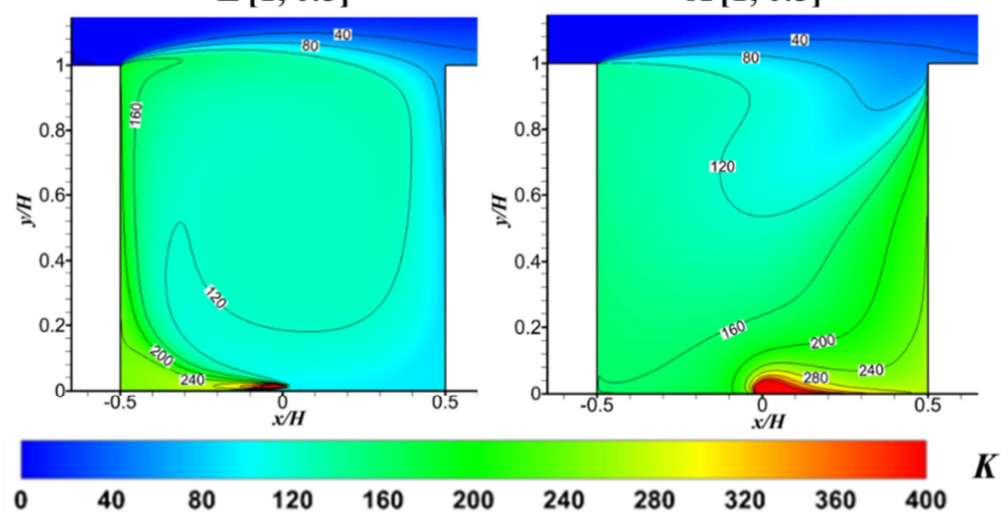

$\mathrm{W}[1,0.5]$

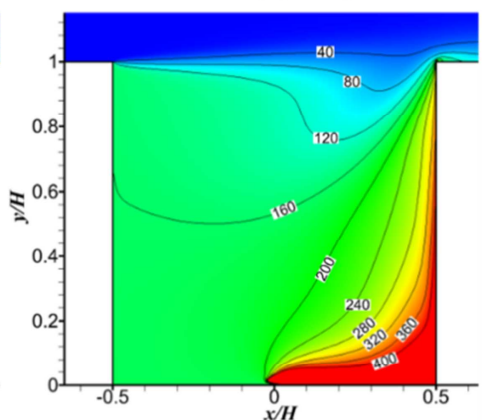



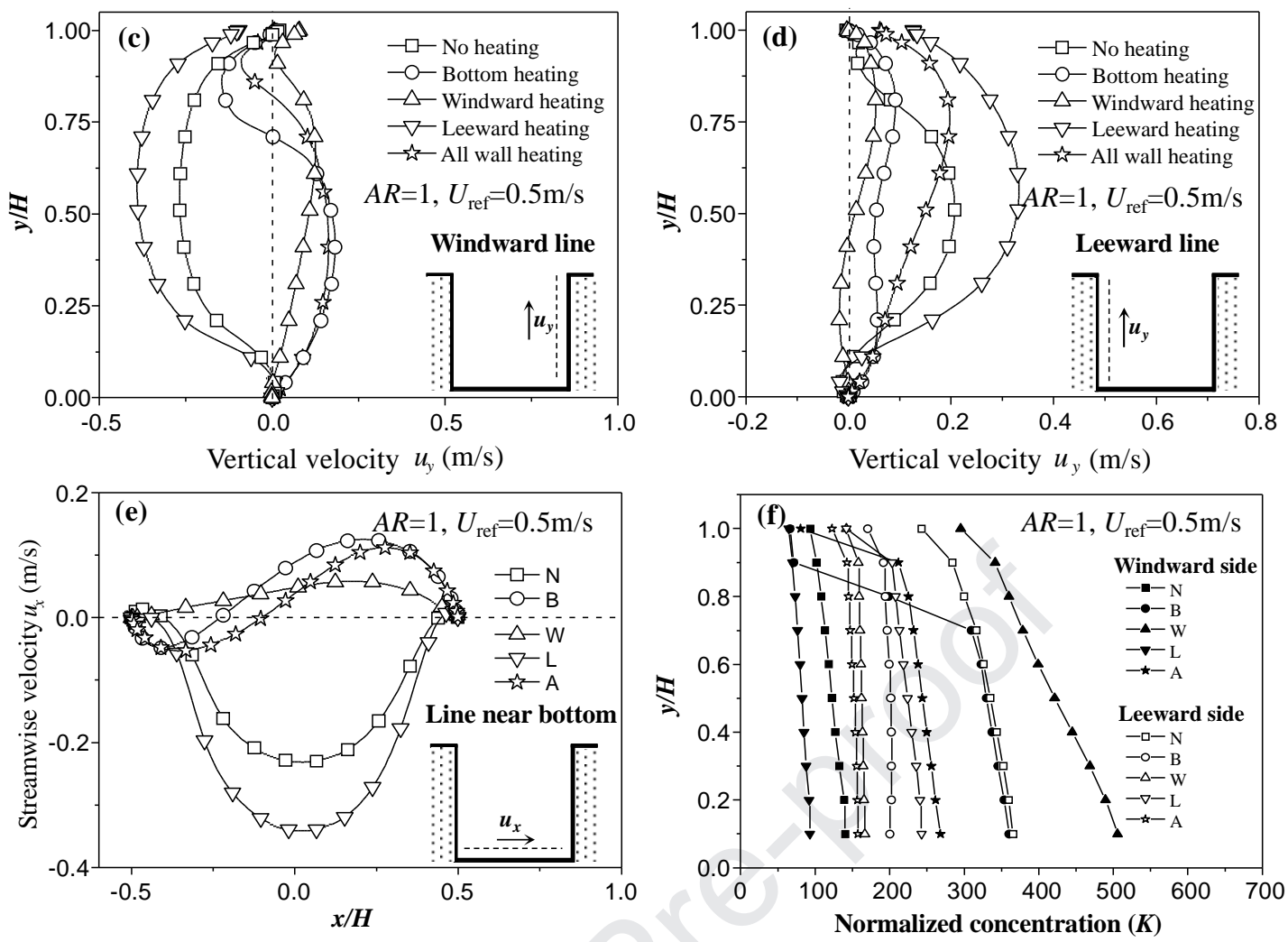

Figure 9. In cases where $A R=1$ an $U_{\text {ref }}=0.5 \mathrm{~m} \mathrm{~s}^{-1}$ : Contour of (a) the mean wind speed $\left(\mathrm{m} \mathrm{s}^{-1}\right)$ and (b) $K . u_{y}$ along (c) the windward line and (d) the leeward line; (e) $u_{x}$ along the bottom line; (f) $\langle K\rangle$ at the windward and leeward walls. 
(a)

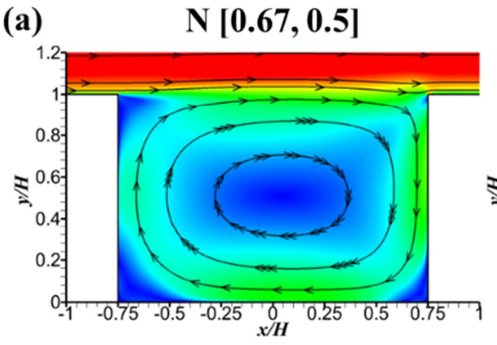

L $[0.67,0.5]$

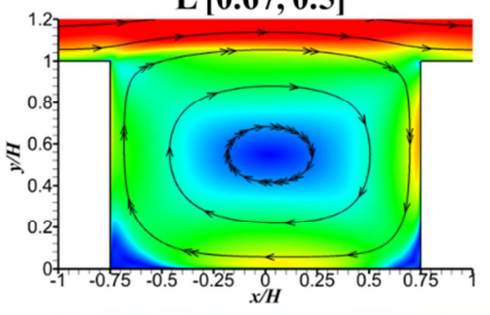

$\begin{array}{lllllllllll}0 & 0.05 & 0.1 & 0.15 & 0.2 & 0.25 & 0.3 & 0.35 & 0.4 & 0.45 & 0.5\end{array}$
B $[0.67,0.5]$

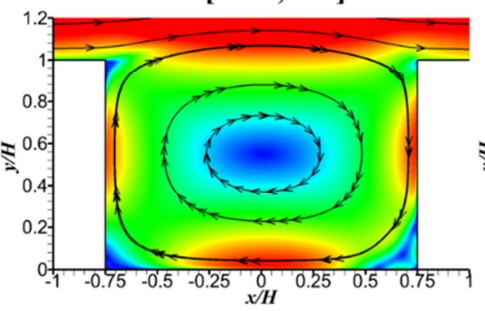

$\mathrm{W}[0.67,0.5]$

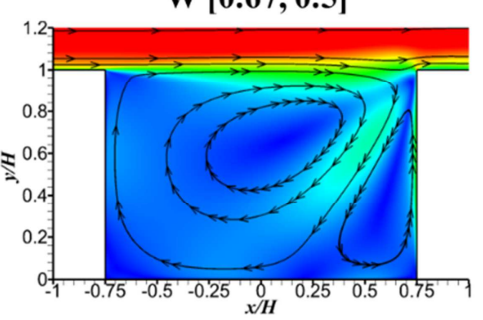

$\mathrm{A}[0.67,0.5]$

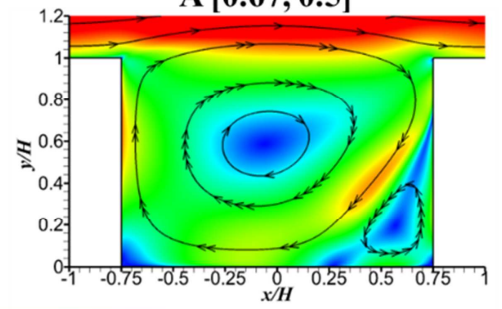

Mean wind speed $(\mathrm{m} / \mathrm{s})$
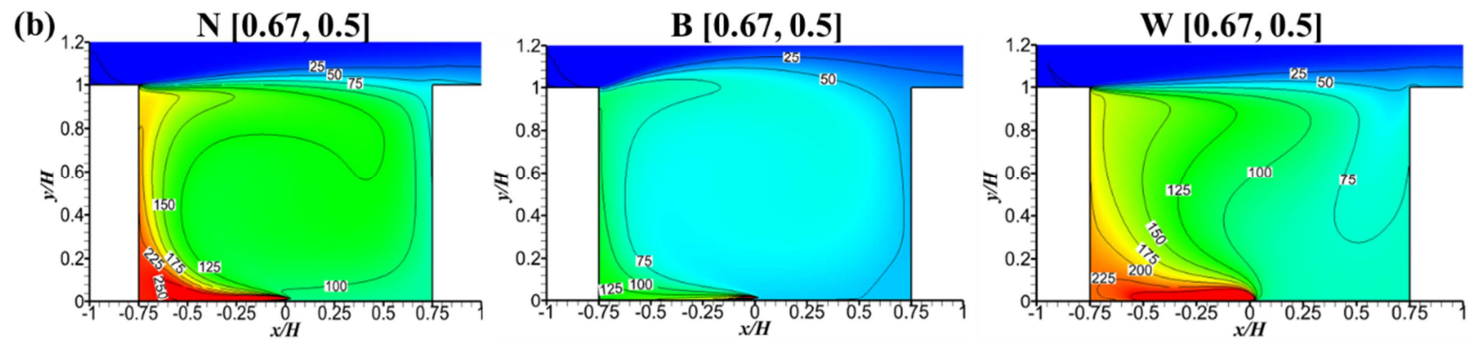

L $[0.67,0.5]$
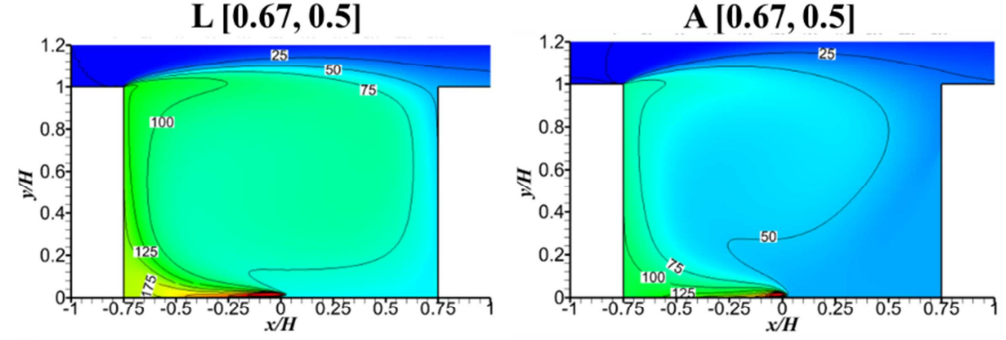

$\begin{array}{lllllllllll}0 & 25 & 50 & 75 & 100 & 125 & 150 & 175 & 200 & 225 & 250\end{array}$ 

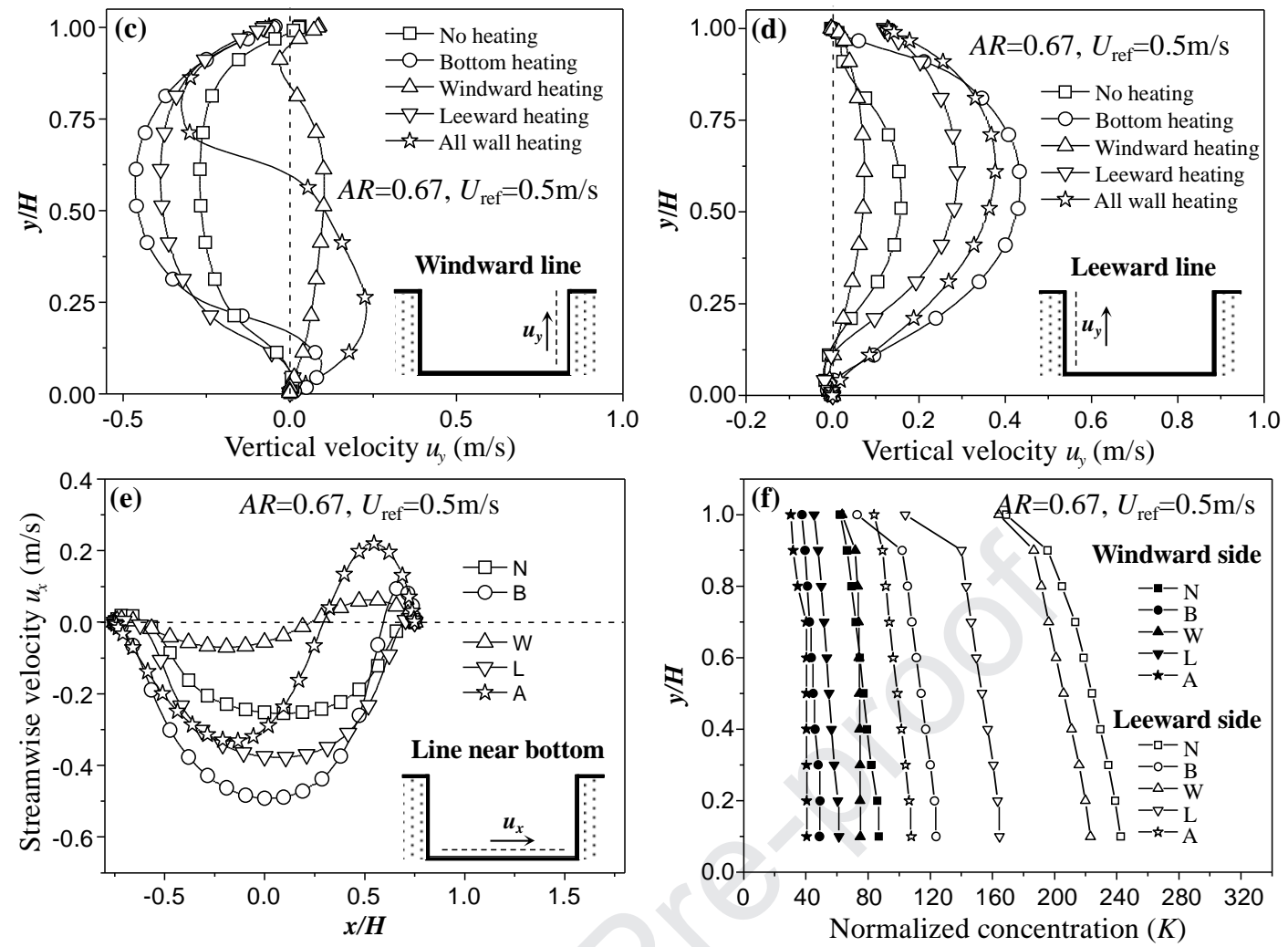

Figure 10. In cases where $A R=0.67$ and $U_{r e f}=0.5 \mathrm{~m} \mathrm{~s}^{-1}$ : Contour of (a) the mean wind speed $\left(\mathrm{m} \mathrm{s}^{-1}\right)$ and (b) $K . u_{y}$ along (c) the windward line and (d) the leeward line; (e) $u_{x}$ along the bottom line; (f) $\langle K\rangle$ at the windward and leeward walls. 

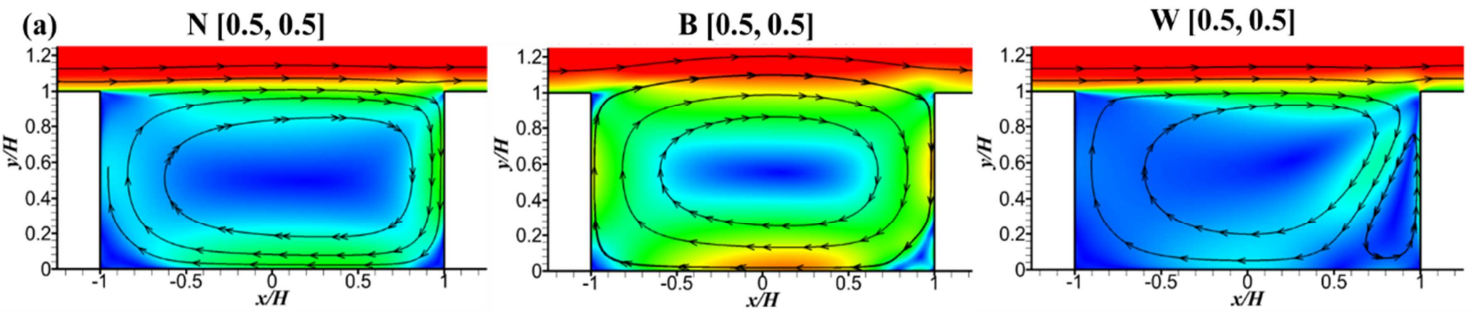

$\mathbf{L}[0.5,0.5]$

$\mathrm{A}[0.5,0.5]$
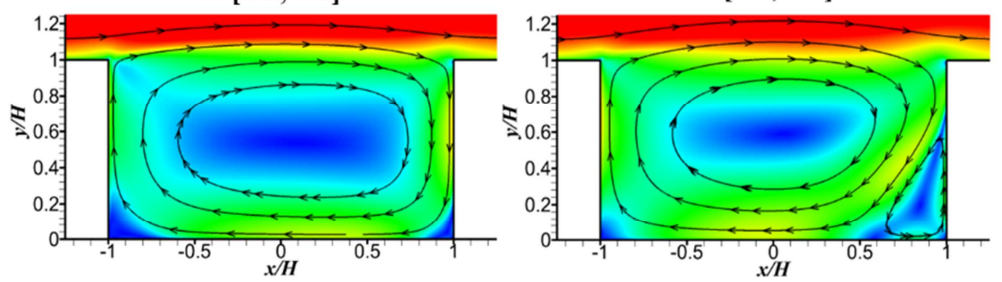

$\begin{array}{lllllllllll}0 & 0.05 & 0.1 & 0.15 & 0.2 & 0.25 & 0.3 & 0.35 & 0.4 & 0.45 & 0.5\end{array}$
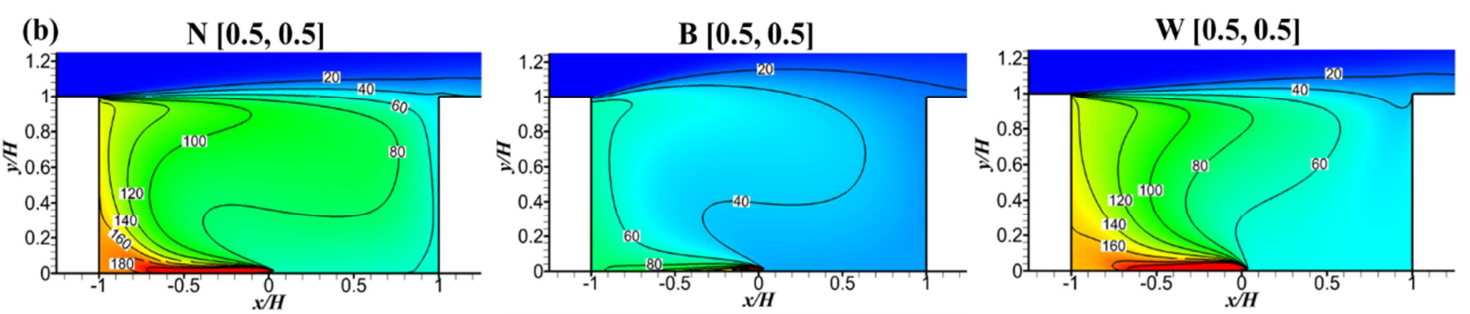

$\mathbf{L}[0.5,0.5]$

$\mathrm{A}[0.5,0.5]$
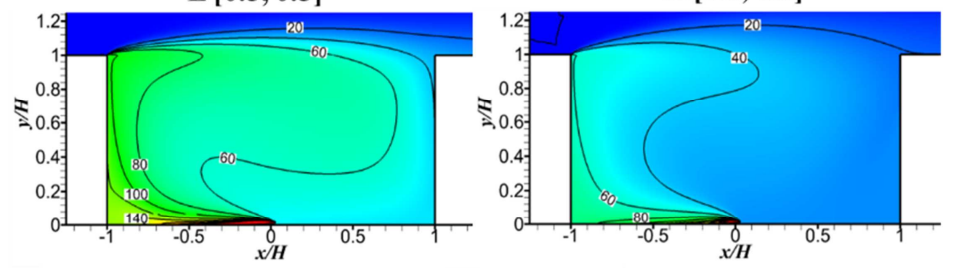

$\begin{array}{llllllllllll}0 & 20 & 40 & 60 & 80 & 100 & 120 & 140 & 160 & 180 & 200 & \end{array}$ 

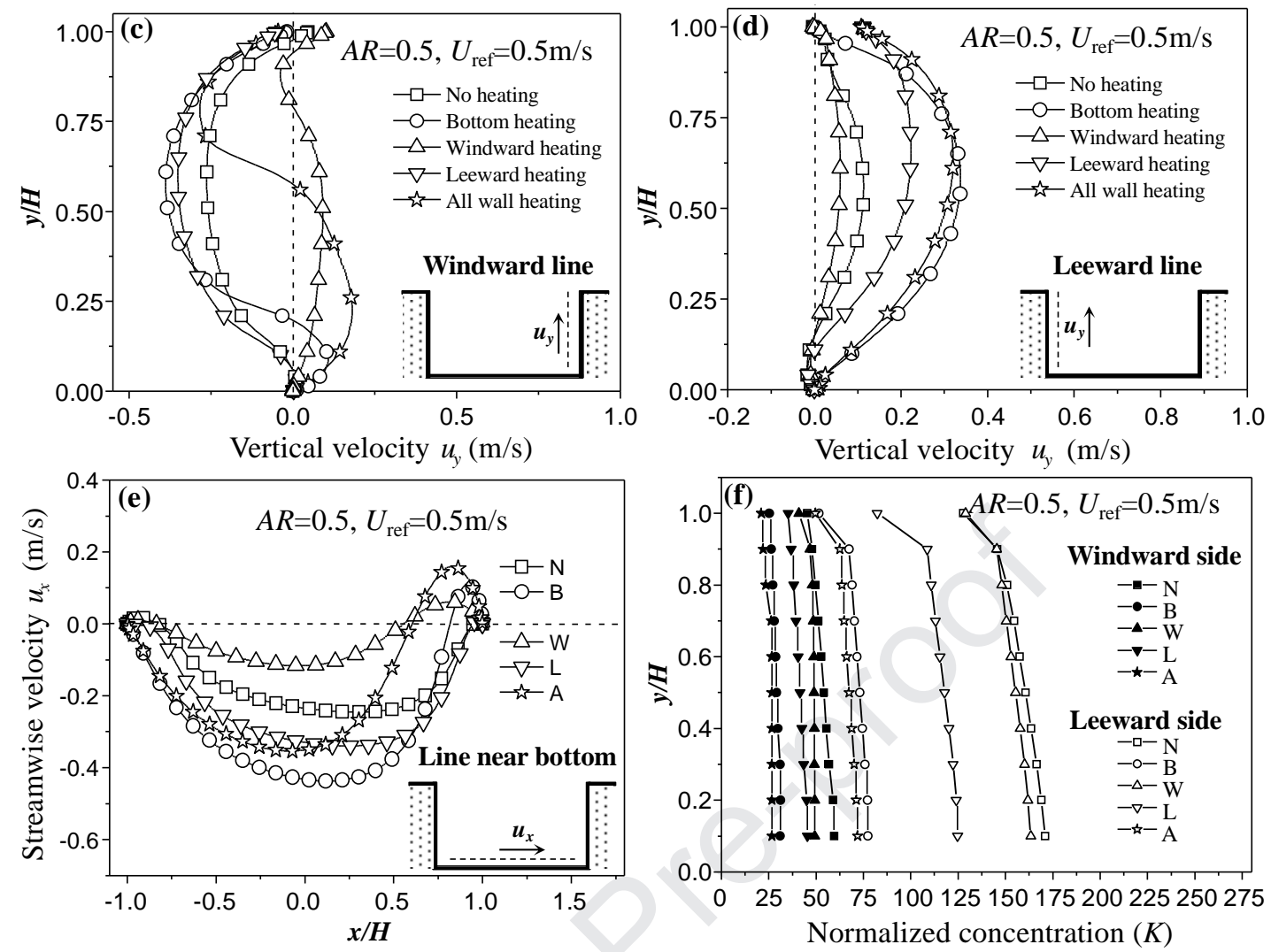

Figure 11. In cases where $A R=0.5$ and $U_{r e f}=0.5 \mathrm{~m} \mathrm{~s}^{-1}$. Contour maps of (a) the mean wind speed $\left(\mathrm{m} \mathrm{s}^{-1}\right)$ and (b) $K . u_{y}$ along (c) the windward line and (d) the leeward line; (e) $u_{x}$ along the bottom line; (f) $\langle K\rangle$ at the windward wall and leeward wall. 

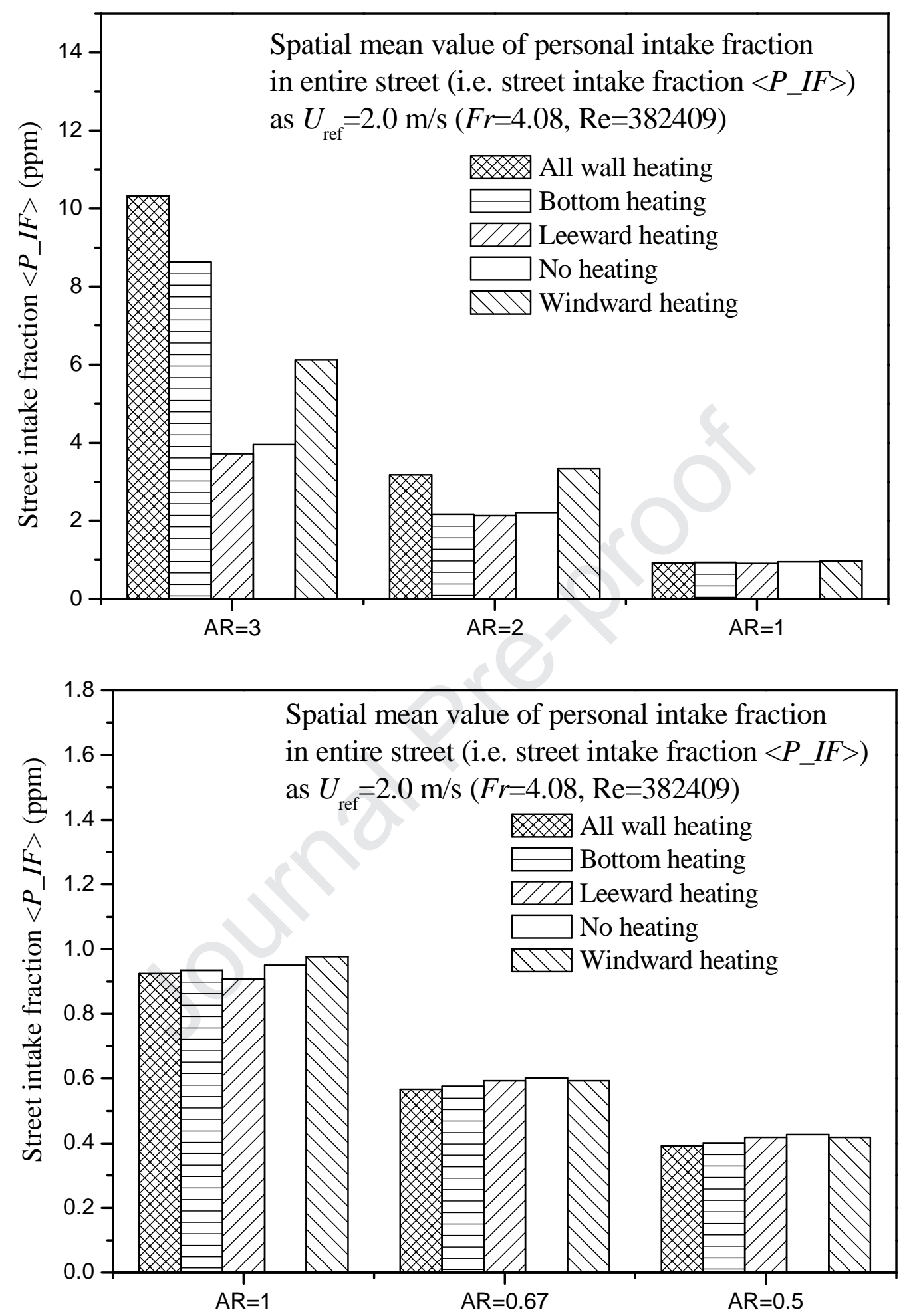

(a) 

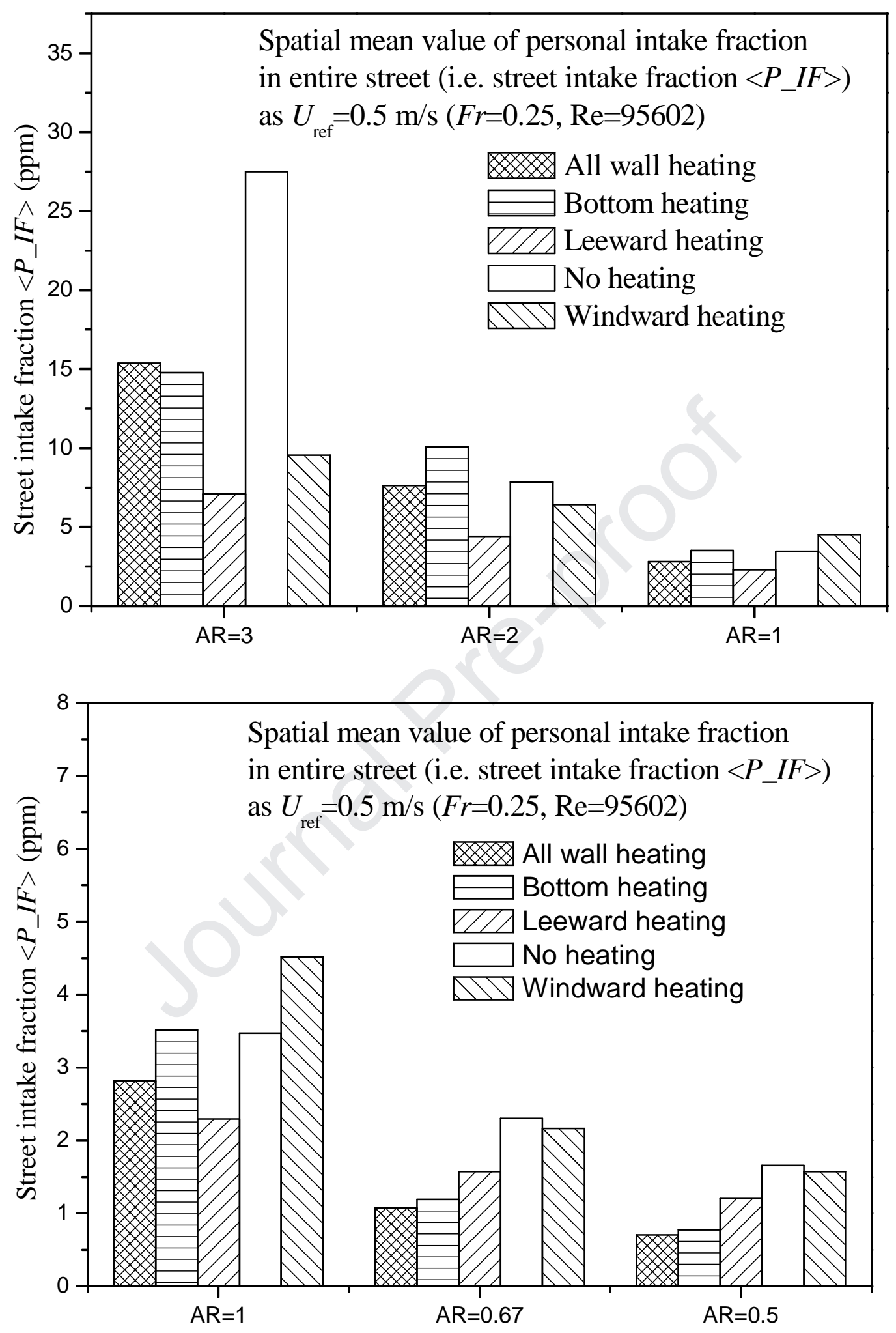

(b)

Figure 12. Spatial mean value of the personal intake fraction of a local street with different heating conditions as $H / W=A R=0.5-3$ with (a) $U_{\text {ref }}=2.0 \mathrm{~m} \mathrm{~s}^{-1}$, and (b) $U_{\text {ref }}=0.5 \mathrm{~m} \mathrm{~s}^{-1}$. 
Table 1 Breathing rate and time patterns for indoor at home for each age group [58,64-65]

$\begin{array}{llc}\text { Age groups } \quad \text { Population ratio } & \begin{array}{c}\text { Breathing rate } \\ B r\left(\mathrm{~m}^{3} / \mathrm{day}\right)\end{array} \quad \text { Time patterns }\end{array}$

\begin{tabular}{cccc}
\hline Children $(<18)$ & $21.2 \%$ & 12.5 & $61.7 \%$ \\
Adults $(18-60)$ & $63.3 \%$ & 13.8 & $59.5 \%$ \\
Elderly $(>60)$ & $15.5 \%$ & 13.1 & $71.6 \%$ \\
\hline
\end{tabular}

Table 2. Model descriptions of the simulated test cases.

\begin{tabular}{|c|c|c|c|}
\hline \multicolumn{4}{|c|}{ Case Name: Heating type $\left[A R, U_{\mathrm{ref}}\right]$} \\
\hline $\begin{array}{l}\text { Aspect ratio: } H / W \\
\qquad(H=3 \mathrm{~m})\end{array}$ & $\triangle T(K)$ & $\begin{array}{l}\text { The reference mean wind } \\
\text { speed }\left(U_{r e f}\right)\end{array}$ & Heating type \\
\hline$A R=3$ & \multirow{5}{*}{10} & \multirow{5}{*}{$\begin{array}{c}0.5 \mathrm{~m} / \mathrm{s} \\
\text { or } \\
2.0 \mathrm{~m} / \mathrm{s}\end{array}$} & $\mathrm{N}$ (no heating) \\
\hline$A R=2$ & & & B (bottom heating) \\
\hline$A R=1$ & & & L (leeward heating) \\
\hline$A R=0.67$ & & & W (windward heating) \\
\hline$A R=0.5$ & & & A (all wall heating) \\
\hline
\end{tabular}

Table 3. Reynolds and Froude numbers investigated in all test cases with wall heating $\left(T_{\text {wall }}-T_{\text {air }}=10 \mathrm{~K}, H=3 \mathrm{~m}\right)$

\begin{tabular}{|l|c|c|c|}
\hline \multirow{2}{*}{$\begin{array}{c}\text { Aspect ratio } \\
A R=H / W\end{array}$} & $\begin{array}{c}\text { Velocity in upstream } \\
\text { free flow } U_{r e f}\end{array}$ & $\begin{array}{c}\text { Reynolds number } \\
\left(\operatorname{Re}=U_{\text {ref }} H / v\right)\end{array}$ & $F_{r}=\frac{U_{r e f}^{2}}{g H\left(\Delta T / T_{r e f}\right)}$ \\
\hline $3,2,1$, & $2.0 \mathrm{~m} / \mathrm{s}$ & 382409 & 4.08 \\
\cline { 2 - 4 } $0.67,0.5$ & $0.5 \mathrm{~m} / \mathrm{s}$ & 95602 & 0.25 \\
\hline
\end{tabular}


Journal Pre-proof

Table 4. Boundary conditions and solver settings for the CFD simulations

\begin{tabular}{|c|c|c|}
\hline Location & Type & Profiles/conditions \\
\hline Inlet & $\begin{array}{l}\text { Velocity } \\
\text { inlet }\end{array}$ & $\begin{array}{l}U_{\text {in }}(y)=U_{\text {ref }}\left(\frac{y-y_{\text {ref }}}{y_{\text {ref }}}\right)^{\alpha}, \quad V_{\text {in }}(y)=0 \\
k_{\text {in }}(y)=\left(U_{\text {in }}(y) \times I_{\text {in }}\right)^{2}, \quad \varepsilon_{\text {in }}(y)=\frac{C_{\mu}^{3 / 4} k_{i}^{3 / 2}}{\kappa y} \\
\text { Here } \alpha=0.22, C=0.09, I_{\text {in }}=0.1, \kappa=0.41, y_{\text {ref }}=H=3 \mathrm{~m}\end{array}$ \\
\hline Outlet & Outflow & Zero normal gradients of all flow variables \\
\hline Top & Symmetry & Zero normal gradients of all flow variables \\
\hline $\begin{array}{l}\text { Street canyon } \\
\text { wall }\end{array}$ & No slip & $v=0 \frac{\partial}{\partial y}(u, v, k, \varepsilon)=0$ \\
\hline \multicolumn{3}{|r|}{ Solver settings } \\
\hline \multicolumn{2}{|c|}{ Pressure-velocity coupling } & SIMPLE algorithm \\
\hline \multicolumn{2}{|c|}{ Discretization scheme } & Second-order upwind scheme, implicit solver \\
\hline
\end{tabular}




\section{Declaration of interests}

$\bigotimes$ The authors declare that they have no known competing financial interests or personal relationships that could have appeared to influence the work reported in this paper.

$\square$ The authors declare the following financial interests/personal relationships which may be considered as potential competing interests:

Jian Hang, Xieyuan Chen, Guanwen Chen, Taihan Chen, Yuanyuan Lin, Zhiwen Luo, Xuelin Zhang, Qun Wang 
1. As $F r=4.08$, wind-driven force dominates the urban airflow as $A R=0.5-1$.

2. As $F r=0.25$, most heating conditions would lead to a lower $\left\langle P \_I F\right\rangle$

3. Formation of single main vortex is the most efficient way to decrease the $\left\langle P \_I F\right\rangle$.

4. Leeward heating condition always decreases the $\left\langle P \_I F\right\rangle$ as $F r=0.25$ and 4.08. 